\title{
Glyphosate, pathways to modern diseases IV: cancer and related pathologies
}

\author{
Anthony Samsel ${ }^{1, ~}{ }^{*}$ and Stephanie Seneff ${ }^{2, * *}$ \\ ${ }^{1}$ Research Scientist, Deerfield, NH 03037, USA \\ ${ }^{2}$ Computer Science and Artificial Intelligence Laboratory, MIT, Cambridge, MA 02139, USA
}

\begin{abstract}
Glyphosate is the active ingredient in the pervasive herbicide, Roundup, and its usage, particularly in the United States, has increased dramatically in the last two decades, in step with the widespread adoption of Roundup ${ }^{\circledR}$-Ready core crops. The World Health Organization recently labelled glyphosate as "probably carcinogenic." In this paper, we review the research literature, with the goal of evaluating the carcinogenic potential of glyphosate. Glyphosate has a large number of tumorigenic effects on biological systems, including direct damage to DNA in sensitive cells, disruption of glycine homeostasis, succinate dehydrogenase inhibition, chelation of manganese, modification to more carcinogenic molecules such as $\mathrm{N}$-nitrosoglyphosate and glyoxylate, disruption of fructose metabolism, etc. Epidemiological evidence supports strong temporal correlations between glyphosate usage on crops and a multitude of cancers that are reaching epidemic proportions, including breast cancer, pancreatic cancer, kidney cancer, thyroid cancer, liver cancer, bladder cancer and myeloid leukaemia. Here, we support these correlations through an examination of Monsanto's early studies on glyphosate, and explain how the biological effects of glyphosate could induce each of these cancers. We believe that the available evidence warrants a reconsideration of the risk/benefit trade-off with respect to glyphosate usage to control weeds, and we advocate much stricter regulation of glyphosate.
\end{abstract}

Keywords: cataracts, CYP 450 enzymes, glyphosate, gut microbiome, interstitial disease, kidney cancer, non-Hodgkin's lymphoma, pancreatic cancer

\section{INTRODUCTION}

Glyphosate is the active ingredient in the pervasive herbicide, Roundup. Its usage on crops to control weeds in the United States and elsewhere has increased dramatically in the past two decades, driven by the increase over the same time period in the use of genetically modified $(\mathrm{GM})^{1}$ crops, the widespread emergence of glyphosate-resistant weeds among the GM crops (necessitating ever-higher doses to achieve the same herbicidal effect), as well as the increased adoption of glyphosate as a desiccating agent just before harvest. GM crops include corn, soy, canola (rapeseed) and sugar beet [1]. Crop desiccation by glyphosate includes application to non-GM crops such as dried peas, beans and lentils. It should be noted that the use of glyphosate for pre-harvest staging for perennial weed control is now a major crop management strategy. The increase in glyphosate usage in the United States is extremely well correlated with the concurrent increase in the incidence and/or death rate of multiple diseases, including several cancers [1]. These include thyroid cancer, liver cancer, bladder cancer, pancreatic cancer, kidney cancer and myeloid leukaemia, as shown in Table 1, reproduced from [1]. The World
Health Organization (WHO) revised its assessment of glyphosate's carcinogenic potential in March 2015, relabelling it as a "probable carcinogen" $[2,3]$.

Table 1. Pearson's coefficients between time trends in various cancers and glyphosate applications to corn and soy crops, over the interval from 1990-2010, along with corresponding $P$-values, as determined from hospital discharge data and death data maintained by the US Centers for Disease Control (CDC). Table adapted from Swanson et al. 2014 [1].

\begin{tabular}{lcc}
\hline Disease & $R$ & $P$ \\
\hline Thyroid cancer (incidence) & 0.988 & $\leq 7.6 \times 10^{-9}$ \\
Liver cancer (incidence) & 0.960 & $\leq 4.6 \times 10^{-8}$ \\
Bladder cancer (deaths) & 0.981 & $\leq 4.7 \times 10^{-9}$ \\
Pancreatic cancer (incidence) & 0.918 & $\leq 4.6 \times 10^{-7}$ \\
Kidney cancer (incidence) & 0.973 & $\leq 2.0 \times 10^{-8}$ \\
Myeloid leukaemia (deaths) & 0.878 & $\leq 1.5 \times 10^{-6}$ \\
\hline
\end{tabular}

Sri Lanka's newly elected president, Maithripala Sirisena, banned glyphosate imports as one of his first acts following election. This action was based on studies by Jayasumana et al. that provided compelling evidence that glyphosate was a key factor in the chronic kidney disease that was affecting an alarming number of young

\footnotetext{
* E-mail: anthonysamsel@acoustictracks.net

${ }^{* *}$ Corresponding author. E-mail: seneff@csail.mit.edu

${ }^{1}$ Usually called genetically engineered (GE) in the USA.
} 
agricultural workers in the northern region $[4,5]$, and was probably further motivated by the WHO reevaluation of its carcinogenic potential. Kidney disease is a risk factor for multiple cancers, with kidney dialysis being associated with increased risk of Kaposi's sarcoma by more than 50-fold, with 3- to 10-fold increased risk of kidney cancer, and 2- to 9-fold increased risk of thyroid cancer. Many other cancers also show more modest risk increases [6].

A study of rats fed GM maize and/or Roundup in their water over their entire lifespan revealed significantly increased risk of massive mammary tumours in the females, along with kidney and liver damage in the males [7]. Most of the tumours were benign, but there were three metastases (in female animals) and two Wilm's tumours found in the kidneys of males, which had to be euthanized early due to the excessive tumours, which grew to more than $25 \%$ of their body size. The exposed animals also had a shortened life span compared to the controls.

The hormone oestrogen was declared to be a human carcinogen by the National Toxicology Program in 2003 [8]. Glyphosate has been demonstrated to have oestrogenic effects at minute dosages, in in vitro experiments on mammary tumour cells [9]. Glyphosate was able to induce proliferation in these cells in concentrations of parts per trillion, ${ }^{2}$ and it did so through binding affinity to the oestrogen receptor and inducing activation of the oestrogen response element (ERE). The fact that an oestrogen antagonist, ICI 182780, could inhibit glyphosate's action demonstrated rather conclusively that it was mediated through oestrogen mimicry.

Traditional concepts in toxicology are centred on Paracelsus' dictum that "the dose makes the poison", meaning that one should expect an increasing risk of toxicity as the level of exposure is increased. However, the generality of this concept has been challenged due to the realization that endocrine-disrupting chemicals (EDCs) often show a greater potential to cause cancer at very low doses than at higher doses; i.e., the relationship between dose and response is nonmonotonic, with higher doses producing a lower toxic effect than lower doses. In fact, levels of exposure well below the lowest level used in standard toxicology studies can be carcinogenic, as discussed by Vandenberg et al. [10]. These authors concluded their abstract as follows: "We illustrate that nonmonotonic responses and low-dose effects are remarkably common in studies of natural hormones and EDCs. Whether low doses of EDCs influence certain human disorders is no longer conjecture, because epidemiological studies show that environmental exposures to EDCs are associated with human diseases and disabilities. We conclude that when nonmonotonic dose-response curves occur, the effects of low doses cannot be predicted by the effects observed at high doses. Thus, fundamental changes in chemical testing and safety determination are needed to protect human health."

Glyphosate is toxic to many microbes as well as to most plants, and one likely effect of chronic low-dose oral exposure to glyphosate is a disruption of the balance among gut microbes towards an over-representation of pathogens [11]. This leads to a chronic inflammatory state in the gut, as well as an impaired gut barrier and many other sequelae. It has become increasingly apparent that chronic inflammation increases cancer risk and, in fact, many inflammatory conditions, such as Crohn's disease, hepatitis, schistosomiasis, thyroiditis, prostatitis and inflammatory bowel disease are known cancer risk factors [12].

In this paper, we review the research literature on glyphosate, with particular emphasis on evidence of carcinogenic potential, which includes glyphosate's induction of metabolic disorders, oxidative stress and DNA damage, known precursors to cancer development. We begin with a section that summarizes our own findings following perusal of large numbers of documents that were provided to one of us (Samsel) by the US Environmental Protection Agency (EPA), according to the Freedom of Information Act, which provided detailed information on Monsanto's own early experimental animal studies on glyphosate.

This section motivates and inspires subsequent sections where we seek to explain the likely mechanisms by which glyphosate might cause the tumours observed in Monsanto's studies as well as explaining the strong statistical correlations with human cancers. Following a section that provides direct evidence of DNA damage, the next four sections discuss metabolic disorders linked to glyphosate that are known to increase cancer risk, including succinate dehydrogenase inhibition, glycation damage, N-nitrosylation, and disrupted glycine homeostasis. The subsequent eight sections successively address cancer of the colon, liver, pancreas and kidney, melanoma, thyroid cancer, breast cancer, and lymphoma. In each section we provide evidence of a link to glyphosate from the research literature and propose plausible explanations for a causal link. We finally conclude with a summary of our findings.

\footnotetext{
${ }^{2}$ U.S. trillion, i.e. $10^{12}$.
} 


\section{MONSANTO'S EARLY STUDIES}

One of us (Samsel) petitioned the EPA for copies of documents originating from Monsanto, dating from the 1970s through the 1980s, which described experiments conducted by Monsanto to evaluate whether glyphosate is safe for human consumption. In this section, we provide a summary of our findings related to those documents, especially with respect to indications of kidney damage, tumorigenicity, bioaccumulation, and glyphosate metabolites.

\subsection{Kidney damage}

Classification of types of kidney damage, which are indicative of kidney disease, are noted below, based on information contained in Monsanto's glyphosate studies on rats and mice [13-18]. In [13], changes in the kidneys associated with chronic progressive neuropathy were noted mostly in males, but also in some female animals of both control and treated groups. There was also mineralization and mineralized debris found in the pelvic epithelium of the kidney, most often in females.

Following submission of the study, the EPA subsequently asked Monsanto for a histological reexamination of the low- and mid-dose male animals, which resulted in establishing a no observable effect level (NOEL). In response, Monsanto submitted an addendum [14] to the pathology report. The results of the addendum summarized the examination of the kidneys and found minimal tubular dilatation accompanied by interstitial fibrosis in all test groups. Statistically significant increases in tubular dilatation of the kidney were noted. A $50 \%$ increase in changes to the kidney of the low-dose group and, in the high-dose group, a fourfold increase in incidence was found compared to the control.

Interstitial renal fibrosis begins with an accumulation of extracellular matrix proteins, which is the result of inflammation and injury to the cells, which is found in every type of chronic kidney disease (CKD). Interstitial fibrosis is a progressive pathogenesis leading to end-stage renal failure [19].

The results of the 1981 study [17] further found:

1. Focal tubular hyperplasia, a hyperplasia of the tubular epithelium of the kidney caused by repeated tubular damage. It is characterized by an abnormal increase in the number of cells, which causes enlargement. Tubular epithelial hyperplasia precedes the pathogenesis of tubular dilatation in acute tubular necrosis [20].

2. Focal tubular dilation, a swelling or flattening of the renal tubule, seen as a result of an ischaemic or toxic event as in pharmaceutical, antibiotic or chemical poisoning. This leads to acute tubular necrosis, a cause of acute kidney injury and kidney failure.
3. Focal tubular nephrosis, a degenerative disease of the renal tubules of the kidney. This nephrosis is a noninflammatory nephropathy that features damage of the renal tubules [21].

4. Interstitial mononuclear cell infiltrate characteristic of inflammatory lesions, which consist of white blood cells that clear debris from an injury site.

Mineral deposits can be indicative of kidney stones, which may be calcium oxalate deposits inside the kidney, as we shall discuss more fully later in this paper.

A 1983 chronic feeding study in mice [16] found a carcinogenic response to glyphosate in both male and female mice. There was also an increased incidence of chronic interstitial nephritis in male animals. The study, lasting 18 months, involved feeding glyphosate by diet using concentrations of 1000, 5000 and $30000 \mathrm{ppm}$. The incidence of kidney tumours in the control animals was $0 / 49$, as was also noted in the lowest dose group. However, the mid-dose and high-dose groups produced incidences of neoplasms at $1 / 50$ and $3 / 50$ respectively, which caused the EPA Oncogenicity Peer Review Committee to temporarily classify glyphosate as a Class $\mathrm{C}$ carcinogen.

Monsanto, dissatisfied with the action, consulted another pathologist who, upon further examination, found a small tumour in the control. This was followed by the EPA using a number of pathologists to re-examine additional kidney sections from the mice to check the validity of the findings. However, their re-examination did not find any additional tumours nor confirm the tumour in the control animal. There were no tumours present in any additional sections. EPA asked for the decision to be externally refereed by the Federal Insecticide, Fungicide, and Rodenticide Act (FIFRA) Scientific Advisory Panel, who found the results were statistically significant even after comparing the data to historical controls. However, the committee agreed to downgrade glyphosate to a Class D compound, arguing inadequate evidence of oncogenicity, and further sealed the study as a trade secret of Monsanto.

Non-neoplastic changes included:

1. Renal tubular neoplasms (in male mice; none found in females);

2. Chronic interstitial nephritis (in males);

3. Renal tubular epithelial basophilia and hyperplasias (decreased in males, but a dose-related increase found in females);

4. Proximal tubule epithelial cell basophilia and hypertrophy (females).

\subsection{Tumorigenicity}

A 26-month long-term study in rats conducted by Bio/ dynamics revealed multitudes of tumours in glands and organs [13]. They occurred (from highest to lowest 
incidence) in the following organs: pituitary, thyroid, thymus, mammary glands, testes, kidney, pancreas, liver and lungs. Pituitary, thyroid and thymus glands control body and immune function, and disruption can induce disease, including cancer. These glands produce many necessary hormones that control numerous biological processes. Tumorigenic growth also disrupts functionality of the glands and organs where the growth occurs. A Monsanto trade secret document [13] revealed that there were statistically significant lymphocytic hyperplasias of the thymus as well as significant C-cell thyroid tumours. Thymus lymphoid hyperplasia occurs in Graves disease and thymus hyperplasia is commonly observed with computed tomography (CT) scans of thyroid cancer patients [22], and is also associated with autoimmune disorders such as myasthenia gravis, lupus erythematosis, scleroderma and rheumatoid arthritis [23].

It should be noted that significant incidence of tumours was found during these investigations. However, to create doubt and obscure the statistical significance of inconvenient findings, which may have prevented product registration, Monsanto used experimental noise from 3, 5, 7 and even 11 unrelated study controls to effectively eliminate results, as needed. In some instances the experiments' own control showed $0 \%$ incidence of tumours, while the results for the glyphosate-treated groups were statistically significant. However, through the dishonest magic of comparing the findings to data from unrelated historical controls, they were explained away as a mystery and deemed not to be related to administration of the glyphosate.
Using these deviations effectively neutralized the inconvenient results and thus allowed the product to be brought to market. Had they not engaged in this deception, glyphosate may never have been registered for use. EPA documents show that unanimity of opinion for product registration was not reached. Not all members of the EPA glyphosate review committee approved the registration of glyphosate. There were those who dissented and signed "DO NOT CONCUR.",

The EC GLP document [24] notes: "Misdosing and/ or cross-contamination of the test item is always a risk in animal studies. These problems are usually detected by the presence of the test item and /or its metabolites in plasma or other biological samples from control animals. It is recognized that dietary and topical studies might lead to a higher level and incidence of contamination of test item in control animals. However, contamination of biological samples from control animals has been observed also in studies using other routes of administration, e.g. gavage, intravenous, intraperitoneal, subcutaneous or inhalation. Exposure of the control animals to the test item may compromise or invalidate the study from a scientific point of view."

Thus, these unrelated historical controls were most likely corrupted studies, whether by technician error, contaminated water and /or feed, or other mistakes. This explains Monsanto's collusion with the EPA and the subsequent hiding of the data from purview.

Data tables are presented in Tables 2 through 7 , without the use of experimental noise from historical controls. Only the data results of the experiment are shown.

Table 2. 1981 Bio/dynamics 26-month glyphosate feeding study [17]: interstitial cell tumours of the testes in Sprague Dawley rats.

\begin{tabular}{lcccc}
\hline Glyphosate dose $/ \mathrm{mg} \mathrm{kg}^{-1} \mathrm{day}^{-1}$ & 0 & 3 & 10 & 30 \\
\hline Terminal sacrifice & $0 / 15(0 \%)$ & $2 / 26(7.69 \%)$ & $1 / 16(6.25 \%)$ & $4 / 26(15.38 \%)$ \\
All animals & $0 / 50(0 \%)$ & $3 / 50(6 \%)$ & $1 / 50(2 \%)$ & $6 / 50(12 \%)$ \\
\hline
\end{tabular}

Table 3. 1981 Bio/dynamics 26-month glyphosate feeding study [17]. Incidence of kidney focal tubular dilatation (FTD) and focal tubuler nephrosis (FTN) in Sprague Dawley rats.

\begin{tabular}{lrrrr}
\hline Glyphosate dose $/ \mathrm{mg} \mathrm{kg}^{-1} \mathrm{day}^{-1}$ & 0 & 3 & 10 & 30 \\
\hline FTD unilateral & $2 / 10(20 \%)$ & $3 / 10(30 \%)$ & $2 / 9(22 \%)$ & $7 / 10(70 \%)$ \\
FTD bilateral & $0 / 10(0 \%)$ & $2 / 10(20 \%)$ & $1 / 9(11 \%)$ & $1 / 10(10 \%)$ \\
FTN unilateral & $1 / 10(10 \%)$ & $2 / 10(20 \%)$ & $1 / 9(11 \%)$ & $0 / 10(0 \%)$ \\
FTN bilateral & $0 / 10(0 \%)$ & $0 / 10(0 \%)$ & $0 / 10(0 \%)$ & $1 / 10(10 \%)$ \\
\hline
\end{tabular}

\footnotetext{
${ }^{3}$ The practice of introducing "experimental noise" by using data from unrelated historical controls is still in use today, but is obviously really bad laboratory practice. The European Union Good Laboratory Practice (GLP) Working Group approved a guidance document for GLP inspectors and test facilities in 2005; it is available at the European Commission (EC) GLP internet site [24]. The document discusses the responsibilities of the study director and the principles of identifying misdosing as well as corrective measures.
} 
Table 4. 1981 Bio/dynamics 26-month glyphosate feeding study [17]: incidence of pancreatic islet cell tumours in male Sprague Dawley rats.

\begin{tabular}{lcccc}
\hline Glyphosate dose $/ \mathrm{mg} \mathrm{kg}^{-1}$ day $^{-1}$ & 0 & 3 & 10 & 30 \\
\hline Adenomas & $0 / 50(0 \%)$ & $5 / 49(10 \%)$ & $2 / 50(4 \%)$ & $2 / 50(4 \%)$ \\
Carcinomas & $0 / 50(0 \%)$ & $0 / 49(0 \%)$ & $0 / 50(0 \%)$ & $1 / 50(2 \%)$ \\
Adenomas and carcinomas & $0 / 50(0 \%)$ & $5 / 49(10 \%)$ & $2 / 50(4 \%)$ & $3 / 50(6 \%)$ \\
Hyperplasias & $3 / 50(6 \%)$ & $2 / 49(4 \%)$ & $1 / 50(2 \%)$ & $0 / 50(0 \%)$ \\
\hline
\end{tabular}

Table 5. 1990 Stout \& Rueker 24 month glyphosate feeding study [15]: incidence of pancreatic islet cell tumours in male Sprague Dawley rats.

\begin{tabular}{lcccc}
\hline Glyphosate dose $(\mathrm{ppm})$ & 0 & 2000 & 8000 & 20000 \\
\hline Adenomas & $1 / 43(2 \%)$ & $8 / 45(18 \%)$ & $5 / 49(10 \%)$ & $7 / 48(15 \%)$ \\
$P$ & 0.170 & 0.018 & 0.135 & 0.042 \\
Carcinomas & $1 / 43(2 \%)$ & $0 / 45(0 \%)$ & $0 / 49(0 \%)$ & $0 / 48(0 \%)$ \\
$P$ & 0.159 & 0.409 & 0.467 & 0.472 \\
Adenomas and carcinomas & $2 / 43(5 \%)$ & $8 / 45(18 \%)$ & $5 / 49(10 \%)$ & $7 / 48(15 \%)$ \\
$P$ & 0.241 & 0.052 & 0.275 & 0.108 \\
Hyperplasia & $2 / 43(5 \%)$ & $0 / 45(0 \%)$ & $3 / 49(6 \%)$ & $2 / 48(4 \%)$ \\
$P$ & 0.323 & 0.236 & 0.526 & 0.649 \\
\hline
\end{tabular}

Table 6. 1990 Stout \& Rueker 24 month glyphosate feeding study [15]: incidence of thyroid C-cell tumours in male Sprague Dawley rats.

\begin{tabular}{lcccc}
\hline Glyphosate dose $(\mathrm{ppm})$ & 0 & 2000 & 8000 & 20000 \\
\hline Adenomas & $2 / 54(4 \%)$ & $4 / 55(7 \%)$ & $8 / 58(14 \%)$ & $7 / 58(12 \%)$ \\
$P$ & 0.069 & 0.348 & 0.060 & 0.099 \\
Carcinomas & $0 / 54(0 \%)$ & $2 / 55(4 \%)$ & $0 / 58(0 \%)$ & $1 / 58(2 \%)$ \\
$P$ & 0.452 & 0.252 & 1.000 & 0.518 \\
Adenomas and carcinomas & $2 / 54(4 \%)$ & $6 / 55(11 \%)$ & $8 / 58(14 \%)$ & $8 / 58(14 \%)$ \\
$P$ & 0.077 & 0.141 & 0.060 & 0.060 \\
Hyperplasia & $4 / 54(7 \%)$ & $1 / 55(2 \%)$ & $5 / 58(9 \%)$ & $4 / 58(7 \%)$ \\
$P$ & 0.312 & 0.176 & 0.546 & 0.601 \\
\hline
\end{tabular}

Table 7. 1990 Stout and Rueker 24 month glyphosate feeding study [15]: incidence of thyroid C-cell tumours in female Sprague Dawley rats.

\begin{tabular}{lcccc}
\hline Glyphosa te dose $(\mathrm{ppm})$ & 0 & 2000 & 8000 & 20000 \\
\hline Adenomas & $2 / 57(4 \%)$ & $2 / 60(3 \%)$ & $6 / 59(10 \%)$ & $6 / 55(11 \%)$ \\
$P$ & 0.031 & 0.671 & 0.147 & 0.124 \\
Carcinomas & $0 / 57(0 \%)$ & $0 / 60(0 \%)$ & $1 / 59(2 \%)$ & $0 / 55(0 \%)$ \\
$P$ & 0.445 & 1.000 & 0.509 & 1.000 \\
Adenomas and carcinomas & $2 / 57(4 \%)$ & $2 / 60(3 \%)$ & $7 / 59(12 \%)$ & $6 / 55(11 \%)$ \\
$P$ & 0.033 & 0.671 & 0.090 & 0.124 \\
Hyperplasia & $10 / 57(18 \%)$ & $5 / 60(8 \%)$ & $7 / 59(12 \%)$ & $4 / 55(7 \%)$ \\
$P$ & 0.113 & 0.112 & 0.274 & 0.086 \\
\hline
\end{tabular}

In a long-term study conducted by Monsanto between 1987 and 1989 [15], glyphosate was found to induce a statistically significant $(P<0.05)$ cataractous lens formation, highest in male rats. Considerably higher doses of glyphosate, i.e., 2000, 8000 and 20000 ppm, were administered to low-, mid- and high-dose animals respectively, as compared to long-term studies conducted on mice and rats in the early 1980s. Over the course of the study, cataract lens changes were seen in low-, mid- and high-dosed groups of both male and female rats. A second pathology 
examination also found statistically significant changes (see Table 8). The pathologist concluded that there was a glyphosate-treatment related response for lens changes to the eyes. Monsanto documents also revealed an increased incidence of basophilic degeneration of the posterior subcapsular lens (fibroses) in highly dosed males.

Table 8. Incidence and occurrence of ophthalmic degenerative lens changes by glyphosate [15].

\begin{tabular}{lcccc}
\hline & Control & Low-dose & Mid-dose & High-dose \\
\hline Male rats & $2 / 14(14 \%)$ & $3 / 19(16 \%)$ & $3 / 17(18 \%)$ & $5 / 17(29 \%)$ \\
All Animals & $4 / 60(7 \%)$ & $6 / 60(10 \%)$ & $5 / 60(8 \%)$ & $8 / 60(13 \%)$ \\
\hline
\end{tabular}

At the conclusion and termination of the experiment, further incidence of degenerative lens changes was revealed, as shown in Table 8. The ophthalmic examination yielded no noticeable changes to the control animals $(0 / 15$ or $0.0 \%$ ); however, highly dosed males were significantly impacted as 5/20 (25\%), as shown in Table 9. The study again noted that "the occurrence of degenerative lens changes in high dose male rats appears to have been exacerbated by (glyphosate) treatment" [15]. Unrelated historical controls were used to negate all findings.

Table 9. Data on unilateral and bilateral cataracts (all types) and Y-suture opacities, excluding "prominent Y suture", following glyphosate exposure to rats. From Stout \& Rueker (1990) [15].

\begin{tabular}{lcccc}
\hline Sex & Group & No. Examined & No. Affected & \% Affected \\
\hline Male & $\mathrm{N}$ & 15 & 0 & 0 \\
& 1 & 22 & 1 & 5 \\
& 2 & 18 & 3 & 17 \\
Female & 3 & 20 & 5 & 25 \\
& $\mathrm{~N}$ & 23 & 0 & 0 \\
& 1 & 24 & 0 & 0 \\
& 2 & 17 & 1 & 6 \\
& 3 & 19 & 2 & 11 \\
\hline
\end{tabular}

Stout \& Ruecker [15] noted in a two year study with chronic feeding of glyphosate in rats: "Histopathological examination revealed an increase in the number of mid-dose females displaying inflammation of the stomach squamous mucosa. This was the only statistically significant occurrence of non-neoplastic lesions." Incidence of lesions of the squamous mucosa are shown in Table 10. Again, Monsanto used unrelated historical controls to negate these findings.

Table 10. Lesions of the stomach squamous mucosa in rats chronically exposed to glyphosate at three different levels (adapted from Stout and Ruecker [15].

\begin{tabular}{lcccc}
\hline & Controls & Low & Mid & High \\
\hline Glyphosate $(\mathrm{ppm})$ & 0 & 2000 & 8000 & 20000 \\
Males & $2 / 58(3.44 \%)$ & $3 / 58(5.17 \%)$ & $5 / 59(8.47 \%)$ & $7 / 59(11.86 \%)$ \\
Females & $0 / 58(0.00 \%)$ & $3 / 60(5.00 \%)$ & $9 / 60(15.00 \%)$ & $6 / 59(10.16 \%)$ \\
\hline
\end{tabular}

\subsection{Bioaccumulation}

Ridley and Mirly [25] found bioaccumulation of ${ }^{14} \mathrm{C}$ radiolabelled glyphosate in Sprague Dawley rat tissues. Residues were present in bone, marrow, blood and glands including the thyroid, testes and ovaries, as well as major organs, including the heart, liver, lungs, kidneys, spleen and stomach. Further details are shown in Table 11. A low-dose, oral absorption ( $10 \mathrm{mg} / \mathrm{kg}$ body weight) of the radiolabelled xenohormone indicated highest bioaccumula- tions. The 1988 Monsanto study disclosed: "A significantly greater percentage of the dose remained in the organs and tissues and residual carcasses for the males than for the females. Overall recoveries for group 5 animals were $92.8 \%$ and $94.2 \%$ for males and females respectively."

The study examined seven test groups of 3 to 5 animals per sex/group that were administered a single radiolabelled dose of glyphosate. Blood, expired air, faeces and urine were collected and analysed by liquid scintillation counting 
(LSC), and glyphosate with its metabolites analysed by two methods of high pressure liquid chromatography (HPLC). Three animals were used in groups sacrificed at the end of 24 hours, and 5 animals were used for all other groups, which were sacrificed at the end of the seven day study. Groups 3 and 7 received a $10 \mathrm{mg} / \mathrm{kg}$ intravenous dose, while group $4 \mathrm{a}$ high oral dose $(1 \mathrm{~g} / \mathrm{kg})$. Groups 1, 2, 5 and 6 each received a single oral $10 \mathrm{mg} / \mathrm{kg}$ radiolabelled dose. Group 6 animals received multiple low doses of $10 \mathrm{mg} / \mathrm{kg}$ of nonradiolabelled glyphosate for 14 days prior to administration of a single $10 \mathrm{mg} / \mathrm{kg}$ radiolabelled dose.

Oral absorption of glyphosate was $30 \%$ and $35 \%$, with a radiological $\beta$ half-life of 7.5 and 14 days in male and female animals, respectively. Bioaccumulation of glyphosate found in bone was $0.748 \mathrm{ppm}$ for males and $0.462 \mathrm{ppm}$ for females for group 6 animals. Group 5 animals retained $0.552 \mathrm{ppm}$ and $0.313 \mathrm{ppm}$ for males and females, respectively. Males also had higher levels of glyphosate in their blood. Approximately $0.27 \%$ of the orally administered dose was found in expired $\mathrm{CO}_{2}$ of the group 1 rats sacrificed after 24 hours. Table 11 shows the mean average and percentage distribution of radioactivity in ppm that were found in tissues and organs of groups 4,5 and 6 of the orally dosed animals.

Table 11. Distribution and bioaccumulation of ${ }^{14} \mathrm{C}$ radiolabelled glyphosate in blood, bone, glands, organs and other tissue of Sprague Dawley rats. Data obtained from Ridley \& Mirly, 1988 [25] (see text for details).

\begin{tabular}{|c|c|c|c|}
\hline Glyphosate mean (ppm) & $\begin{array}{c}\text { Group } 4 \\
\text { Male / Female }\end{array}$ & $\begin{array}{c}\text { Group 5 } \\
\text { Male / Female }\end{array}$ & $\begin{array}{c}\text { Group } 6 \\
\text { Male / Female }\end{array}$ \\
\hline \multicolumn{4}{|c|}{ BLOOD } \\
\hline Blood plasma & $0.129 / 0.127$ & $0.00158 / 0.00114$ & $0.00178 / 0.00152$ \\
\hline Red blood cells & $0.517 / 0.275$ & $0.00845 / 0.00424$ & $0.00763 / 0.00474$ \\
\hline Whole blood & $0.328 / 0.166$ & $0.00454 / 0.00269$ & $0.00476 / 0.00288$ \\
\hline Bone & $30.6 / 19.7$ & $0.552 / 0.313$ & $0.748 / 0.462$ \\
\hline Bone marow & $4.10 / 12.50$ & $0.0290 / 0.00639$ & $0.0245 / 0.0231$ \\
\hline \multicolumn{4}{|c|}{ GLANDS } \\
\hline Thyroid & $1.50 / 1.24$ & $0.000795 / 0.000358$ & $0.00703 / 0.00955$ \\
\hline Testes/ovaries & $0.363 / 0.572$ & $0.00276 / 0.00326$ & $0.00529 / 0.00813$ \\
\hline \multicolumn{4}{|c|}{ ORGANS } \\
\hline Brain & $0.750 / 0.566$ & $0.00705 / 0.00551$ & $0.0144 / 0.0110$ \\
\hline Eye & $0.655 / 0.590$ & $0.00215 / 0.000298$ & $0.00405 / 0.00337$ \\
\hline Heart & $0.590 / 0.518$ & $0.00622 / 0.00398$ & $0.00804 / 0.00632$ \\
\hline Kidney & $1.94 / 1.35$ & $0.0216 / 0.0132$ & $0.0327 / 0.0196$ \\
\hline Liver & $1.91 / 1.37$ & $0.0298 / 0.0135$ & $0.0407 / 0.0257$ \\
\hline Lung & $1.54 / 1.13$ & $0.0148 / 0.0120$ & $0.0211 / 0.0167$ \\
\hline Spleen & $2.61 / 2.98$ & $0.0119 / 0.00727$ & $0.0155 / 0.0130$ \\
\hline Uterus & $-/ 0.618$ & $-/ 0.00517$ & $-/ 0.00185$ \\
\hline \multicolumn{4}{|c|}{ DIGESTIVE SYSTEM } \\
\hline Stomach & $2.38 / 2.36$ & $0.00795 / 0.00367$ & $0.0377 / 0.0239$ \\
\hline Small intestine & $1.90 / 1.55$ & $0.216 / 0.0183$ & $0.0441 / 0.0257$ \\
\hline Colon & $11.0 / 9.20$ & $0.0342 / 0.0159$ & $0.0429 / 0.0298$ \\
\hline \multicolumn{4}{|c|}{ FAT/MUSCLE } \\
\hline Abdominal fat & $0.418 / 0.457$ & $0.00364 / 0.00324$ & $0.00557 / 0.00576$ \\
\hline Testicular/ovarian fat & $0.442 / 0.037$ & $0.00495 / 0.00347$ & $0.00721 / 0.00563$ \\
\hline Abdominal muscle & $0.262 / 0.214$ & $0.00232 / 0.00160$ & $0.00278 / 0.00216$ \\
\hline Shoulder muscle & $0.419 / 0.423$ & $0.00388 / 0.00667$ & $0.00783 / 0.00590$ \\
\hline Nasal mucosa & $1.71 / 1.79$ & $0.00485 / 0.0226$ & $0.0316 / 0.0125$ \\
\hline Residual carcass & $8.78 / 7.74$ & $0.106 / 0.0870$ & $0.157 / 0.101$ \\
\hline
\end{tabular}




\subsection{Glyphosate metabolites}

Howe, Chott \& McClanahan [26] identified, characterized and quantified glyphosate and its metabolites after intravenous and oral administration of the radiolabelled compound. They employed several analytical tools, including LSC, strong anion exchange (SAX), cation exchange (CX) and ion pair chromatography (IPC). CX and IPC methods of HPLC were used primarily for the identification of glyphosate and its metabolites contained in urine and faeces. Metabolites of glyphosate found during analysis include the nonbasic compounds aminomethylphosphonic acid (AMPA), methylaminomethylphosphonic acid (MAMPA), N-formylglyphosate, $\mathrm{N}$-acetylglyphosate, $\mathrm{N}$ nitrosoglyphosate and an unknown compound tagged as "Compound \#11". Metabolites found in the dosing solutions administered to rats of these experiments would be expected in all glyphosate-based products. CX analysis was used to identify AMPA and MAMPA and IPC was used to identify all other nonbasic glyphosate metabolites. Results are presented in Table 12. Metabolites were also found in the urine and faeces of both male and female rats, as shown in Table 13 for orally dosed groups 4,5 and 6.

Table 12. Glyphosate and its metabolites: Analysis of dose solutions expressed as \% of total. Table adapted from Howe et al. [26].

\begin{tabular}{lccccccc}
\hline Dose group & Glyphosate & AMPA & MAMPA & $\begin{array}{c}\text { N-acetyl- } \\
\text { glyphosate }\end{array}$ & $\begin{array}{c}\text { N-formyl- } \\
\text { glyphosate }\end{array}$ & $\begin{array}{c}\text { N-nitroso- } \\
\text { glyphosate }\end{array}$ & $\begin{array}{c}\text { Compound } \\
\# 11\end{array}$ \\
\hline $\begin{array}{l}1: \text { Oral } \\
10 \mathrm{mg} / \mathrm{kg}\end{array}$ & 98.21 & 0.63 & 0.26 & $<0.04$ & 0.49 & $<0.05$ & $<0.06$ \\
$\begin{array}{l}3: \mathrm{Intravenous} \\
10 \mathrm{mg} / \mathrm{kg}\end{array}$ & 99.14 & 0.36 & 0.00 & $<0.02$ & 0.36 & $<0.01$ & 0.03 \\
$\begin{array}{l}4: \text { Oral } \\
\begin{array}{l}1000 \mathrm{mg} / \mathrm{kg} \\
5: \text { Oral }\end{array}\end{array}$ & 98.88 & 0.57 & 0.31 & $<0.03$ & 0.14 & $<0.02$ & 0.04 \\
$\begin{array}{l}10 \mathrm{mg} / \mathrm{kg} \\
\begin{array}{l}\text { 6: Preconditioned } \\
\text { Oral } 10 \mathrm{mg} / \mathrm{kg}\end{array}\end{array}$ & 99.41 & 0.17 & 0.00 & $<0.03$ & 0.18 & $<0.03$ & 0.03 \\
\hline
\end{tabular}

Table 13. Glyphosate and its metabolites: Analysis of faeces and urine from male and female rats expressed as $\%$ of total. Table adapted from Howe et al. [26].

\begin{tabular}{|c|c|c|c|c|c|c|c|}
\hline Dose group & Glyphosate & $\begin{array}{r}\text { AMPA } \\
(\mathrm{A})\end{array}$ & $\begin{array}{r}\text { MAMPA } \\
(\mathrm{M})\end{array}$ & $\begin{array}{l}\text { N-Acetyl- } \\
\text { glyphosate }\end{array}$ & $\begin{array}{l}\text { N-Formyl- } \\
\text { glyphosate }\end{array}$ & $\begin{array}{l}\text { N-Nitroso- } \\
\text { glyphosate }\end{array}$ & $\begin{array}{c}\text { Compound } \\
\# 11\end{array}$ \\
\hline \multicolumn{8}{|l|}{4} \\
\hline Dose solution & 98.88 & 0.57 & 0.31 & $<0.03$ & 0.14 & $<0.02$ & 0.04 \\
\hline Male urine & 97.76 & $1.25 \mathrm{~A}+\mathrm{M}$ & & 0.10 & 0.20 & 0.09 & 0.46 \\
\hline Male faeces & 98.64 & $0.82 \mathrm{~A}+\mathrm{M}$ & & $<0.03$ & $<0.04$ & 0.13 & 0.16 \\
\hline Female urine & 97.71 & $1.39 \mathrm{~A}+\mathrm{M}$ & & $<0.05$ & 0.25 & 0.09 & 0.33 \\
\hline Female faeces & 98.68 & $0.88 \mathrm{~A}+\mathrm{M}$ & & $<0.04$ & $<0.04$ & 0.11 & 0.17 \\
\hline \multicolumn{8}{|l|}{5} \\
\hline Dose solution & 99.41 & 0.17 & 0.00 & $<0.03$ & 0.18 & $<0.03$ & 0.03 \\
\hline Male urine & 99.05 & $0.32 \mathrm{~A}+\mathrm{M}$ & & $<0.05$ & 0.12 & 0.11 & 0.31 \\
\hline Male faeces & 98.78 & $0.56 \mathrm{~A}+\mathrm{M}$ & & $<0.06$ & $<0.10$ & 0.21 & 0.16 \\
\hline Female urine & 98.65 & $0.30 \mathrm{~A}+\mathrm{M}$ & & $<0.06$ & 0.25 & 0.11 & 0.58 \\
\hline Female faeces & 98.23 & $0.64 \mathrm{~A}+\mathrm{M}$ & & $<0.05$ & $<0.09$ & 0.22 & 0.16 \\
\hline \multicolumn{8}{|l|}{6} \\
\hline Dose solution & 99.36 & 0.19 & 0.07 & $<0.03$ & 0.21 & $<0.02$ & $<0.02$ \\
\hline Male urine & 99.24 & $0.29 \mathrm{~A}+\mathrm{M}$ & & $<0.05$ & $<0.11$ & 0.08 & 0.18 \\
\hline Male faeces & 98.31 & $0.90 \mathrm{~A}+\mathrm{M}$ & & $<0.06$ & $<0.10$ & 0.24 & 0.17 \\
\hline Female urine & 98.84 & $0.26 \mathrm{~A}+\mathrm{M}$ & & $<0.04$ & 0.12 & 0.15 & 0.51 \\
\hline Female faeces & 98.27 & $0.93 \mathrm{~A}+\mathrm{M}$ & & $<0.05$ & $<0.10$ & 0.22 & 0.23 \\
\hline
\end{tabular}

In vivo metabolization of glyphosate to AMPA was found in the excreta in quantities $\leq 0.4 \%$. The bone was the site of highest bioaccumulation and it retained 0.02 to $0.05 \%$ of the oral dose and $1 \%$ of the intravenous dose. Repetitive dosing of group 6 animals did not significantly change the metabolization or excretion of glyphosate. Of all of the nonbasic compounds found during analysis of excreta, AMPA followed by N-nitrosoglyphosate were most prevalent. Total $\mathrm{N}$-nitrosoglyphosate levels found in the animals ranged between $0.06-0.20 \%$ of the given dose. Faecal samples contained $0.10-0.32 \%$ and urine $0.06-0.15 \%$ of N-nitrosoglyphosate. Stability studies 
revealed that the majority of the $\mathrm{N}$-nitrosoglyphosate found in the faeces was not completely due to presence of the compound as a contaminant of glyphosate, nor was it due to animal metabolism, but rather was due to the chemical reaction of glyphosate with nitrites contained in the excreta. Glyphosate readily reacts with oxides of nitrogen (e.g., $\mathrm{NO}_{2}$ ) to form the metabolite $\mathrm{N}$-nitrosoglyphosate. This engenders concern because $\mathrm{N}$-nitroso compounds are carcinogens. Nitrous acid occurring in sweat excreta of the skin could be problematic in the presence of glyphosate and may be responsible for the rise of some skin cancers. N-nitrosoglyphosate, the product of chemical reaction between glyphosate residues and nitrites in the colon, may in fact be a causal agent in the alarming increase in colorectal cancer. We discuss N-nitrosoglyphosate in $\S 8$.

Colvin, Moran \& Miller [27] evaluated the metabolism of ${ }^{14} \mathrm{C}$-AMPA in male Wistar rats. A $6.7 \mathrm{mg} / \mathrm{kg}$ dose of radiolabelled AMPA was administered orally, of which $20 \%$ was found unchanged in the urine of the animals and $74 \%$ in the faeces. Recovery from excreta totalled $94 \%$ of the dose. In another study, Sutherland [28] fed Sprague Dawley rats a single radiolabelled dose of $\mathrm{N}$-nitrosglyphosate and successfully quantified the metabolite in the urine and faeces. Male and female animals received $3.6 \mathrm{mg} / \mathrm{kg}$ and $4.7 \mathrm{mg} / \mathrm{kg}$, excreting $2.8 \%$ (faeces) $88.7 \%$ (urine) and $10.7 \%$ (faeces), $80.8 \%$ (urine) respectively. Both male and female rats retained $8.5 \%$ of the $\mathrm{N}$-nitrosoglyphosate dose, while $90.5 \%$ was eliminated in excreta.

\section{THE ISSUE OF CONTROL RATS' DIET}

"Historical control data" show that $13-71 \%$ of the lab animals used to conduct toxicity tests on various chemicals would spontaneously present with mammary tumours, and 26-93\% develop pituitary tumours. Their kidney function is also frequently impaired. A recent study by Mesnage et al. [29] sought to evaluate whether toxic chemicals present in the feed that is standard fare for these animals might be causative for this surprisingly high background rate of disease. Nine out of 13 samples of commonly used laboratory rat feeds tested positive for glyphosate. Thus, these "spontaneous" disease manifestations may well be due to the toxic chemicals in the feed in the control animals rather than to some underlying genetic defects, and this fact raises serious questions about the validity of any studies based on such exposed animals as a control group.

A 1995 paper by Dixon et al. describes a thorough analysis of the frequencies of various organ pathologies related to cancer and other diseases in "control" animals not subjected to any explicit administration of the toxic chemical under investigation [30]. The paper gave no information on the rats' feed or supplements, which would have been important as a possible confounding factor in the observed pathologies, one of which was acinar cell atrophy, present in the pancreas of $6.9 \%$ of the males and $5.0 \%$ of the female rats. The authors noted a decrease in size and number of acini and increased amounts of interstitial tissue, suggesting fibrosis, along with increased infiltration of lymphocytes and macrophages. Since this is quite similar to the pathology observed with glyphosate exposure to rats, a possibility is that glyphosate contamination in their feed or water supply contributed to the pathology, perhaps in part by chelating manganese; this transition metal is known to stimulate protein synthesis in acini isolated from both diabetic and normal rats and, in the case of diabetic rats, the effect was shown to be specific to manganese (cobalt, nickel, barium, strontium and magnesium failed to exert the effect) [31].

To test for the hypothesis of glyphosate contamination in rat feed, we used HPLC to test for glyphosate and AMPA levels in three distinct rat chow products, containing corn, soy and wheat middlings, and found significant levels of both chemicals in all products examined. We also tested for choline and folic acid. As shown in Table 14, our laboratory analysis of standard rodent diets found no detectable folic acid. Folic acid (folate) is supplied not only through diet but also, particularly, by commensal bacteria via the shikimate pathway [32]. Therefore, glyphosate evidently disrupts folic acid production both in exposed plant food sources and in the human gut, leading to deficiencies. Folate is a cofactor in many important biologic processes, including remethylation of methionine and single carbon unit donors during DNA biosynthesis. This impacts gene regulation, transcription and genomic repair. Folate deficiency enhances colorectal carcinogenesis, in part through impaired DNA methylation [33]. Folate deficiency has also been implicated in the development of several cancers, including cancer of the colorectum, breast, ovary, pancreas, brain, lung and cervix [34]. Folate deficiency during gestation is linked to neural tube defects such as anencephaly and spina bifida.

A synthetic form of choline, choline chloride, has been added to formulated lab chow diets for decades, as indicated from historical references available from manufacturers such as Purina. A 2010 European patent application describes the addition of choline chloride to glyphosate formulations to act as a bioactivator and to enhance penetration of glyphosate into the cells of the target weed [35]. A study of 47,896 male health professionals in the US found that high choline intake was associated with an increased risk of lethal prostate cancer [36]. Our samples all tested positive for choline (see Table 14). 
Table 14. Evidence of glyphosate contamination, and levels of folate and choline, in Purina rat chow products as determined from authors' own analyses.

\begin{tabular}{lcccc}
\hline & Glyphosate $/ \mathrm{mg} \mathrm{kg}^{-1}$ & AMPA $/ \mathrm{mg} \mathrm{kg}^{-1}$ & Folate $/ \mathrm{mg} \mathrm{g}^{-1}$ & Choline $/ \mathrm{mg} \mathrm{g}^{-1}$ \\
\hline Purina Rat Chow 5002 & 0.65 & 0.35 & 0 & 4.827 \\
Purina Chow 5K75 & 0.57 & 0.27 & 0 & 5.328 \\
Purina Chow 5LG3 & 0.37 & 0.10 & 0 & 5.919 \\
\hline
\end{tabular}

The American Veterinary Medical Foundation notes that "Cancer is the leading cause of death in older pets, accounting for almost half of the deaths of pets over 10 years of age." According to the Morris Animal Foundation, established in 1948, one in four dogs will die of cancer and over 22000 cats will be diagnosed with aggressive sarcomas. Oral cancer squamous cell carcinomas are now found in cats and lead to the destruction of the jawbone. Mammary tumours, a common cancer found in dogs and cats, are also on the rise. We suspect that glyphosate may be a causal agent related to the rise of pet cancers, and used HPLC to analyse 9 popular brands of dog and cat food. We found significant levels of both glyphosate and AMPA in all pet foods tested (Table 15).

Table 15. Glyphosate and AMPA residues found in various dog food and cat food products, as measured from samples tested by the authors.

\begin{tabular}{lcc}
\hline & Glyphosate $/ \mathrm{mg} \mathrm{kg}^{-1}$ & $\mathrm{AMPA} / \mathrm{mg} \mathrm{kg}^{-1}$ \\
\hline Purina Cat Chow Complete & 0.102 & 0.12 \\
Purina Dog Chow Complete & 0.098 & 0.076 \\
Kibbles-n-Bits Chefs Choice Am Grill & 0.30 & 0.24 \\
Friskies Indoor Delights & 0.079 & 0.11 \\
9 Lives Indoor Complete & 0.14 & 0.12 \\
Rachael Ray Zero Grain & 0.022 & Trace $(<0.02)$ \\
Iams Proactive Health & 0.065 & Trace $(<0.02)$ \\
Rachael Ray Nutrish Super Premium & 0.14 & 0.14 \\
Purina Beyond Natural - Simply Nine & 0.047 & 0.031 \\
\hline
\end{tabular}

Clearly, it is imperative that future studies on the potential toxicity of any environmental chemical address the issue of the possible toxicity of chemicals contaminating the diet of the control animals, and/or the potential impact of nutritional imbalances. Feeding the control animals an unhealthy diet leads to an increased risk of cancer in the control group making it much harder to see a signal in the experimental group. Furthermore, since oestrogenic chemicals are often more toxic at extremely low doses than at mid-range doses, it is easy to see why the control group may manifest a significant incidence of cancer.

\section{EVIDENCE OF DNA DAMAGE FROM THE RESEARCH LITERATURE}

According to the IARC's report [2], while there exists only limited direct evidence of carcinogenicity of glyphosate in humans, strong evidence exists to show that glyphosate can operate through two key features of carcinogens: induction of chromosomal damage and induction of oxidative stress. In this section, we review the evidence that glyphosate can damage DNA, a crucial first step leading to cancer. We examine evidence based on sea urchins, children in Malaysia, in mouse models, both in vitro and in vivo, in human lymphocytes, and in fish. We conclude with a paragraph on folate deficiency, its probable link to glyphosate exposure, and folate's essential rôle in DNA maintenance.

Cell cycle disruption is a hallmark of tumour cells and human cancers. A study on sea urchins investigated several different glyphosate-based pesticide formulations, and found that all of them disrupted the cell cycle. The sprays used to disseminate pesticides can expose people in the vicinity to 500 to 4000 times higher doses than those needed to induce cell cycle disruption [37].

A study on children living near rice paddy farms in Malaysia revealed DNA strand breaks and chromosome breakage associated with reduced blood cholinesterase levels [38], which were attributed to exposure to organophosphate insecticides. The study did not specify exactly to which pesticides the children were exposed, but glyphosate is a general-purpose herbicide whose use in rice paddies in Sri Lanka led to widespread kidney 
failure among young agricultural workers there, ultimately resulting in a ban on glyphosate usage in Sri Lanka $[4,5]$. While glyphosate is technically an organophosphonate rather than an organophosphate, a study on the fish Prochilodus lineatus has demonstrated that it suppresses cholinesterase in both muscle and brain [39].

Bolognesi et al. [40] studied the genotoxic potential of both glyphosate in isolation and Roundup, in both mouse in vivo studies and in vitro studies of human lymphocytes. In the mouse studies they found evidence of DNA strand breaks and alkali-labile sites in liver but especially in kidney, as well as in bone marrow. Roundup was found to be more toxic than glyphosate, with damage occuring at lower concentrations. They also demonstrated dose-dependent sister chromatid exchanges in human lymphocytes exposed to glyphosate and to Roundup.

A recent study on a 96-hour Roundup exposure to the economically important tropical fish tambaqui found disturbed gill morphology, inhibited cholinesterase activity in the brain and DNA damage in erythrocytes [41]. They found a sixfold increase in a genetic damage indicator (GDI) in erythrocytes, using the "comet" assay method. Similarly, the comet assay applied to goldfish erythrocytes revealed DNA damage following exposure to glyphosate [42], and studies on exposure of eels to realistic concentrations of Roundup and the principal individual components, glyphosate and the surfactant polyethoxylated amine (POEA) in isolation, confirmed DNA damage in erythrocytes $[43,44]$.

Folate deficiency mimics radiation in damaging DNA through single- and double-strand breaks as well as oxidative lesions [45]. It is estimated that $10 \%$ of the US population is at risk from folate deficiency-induced DNA damage. Cancer of the colorectum in particular is linked to folate deficiency $[45,34]$, which causes reduced bioavailability of cytosine methylation capacity in DNA, inappropriately activating proto-oncogenes and inducing malignant transformation. Folate is also itself crucial for DNA synthesis and repair. Folate deficiency can also lead to uracil misincorporation into DNA and subsequent chromosome breaks [34]. Folate is an essential B vitamin, but it can be synthesized by gut microbes, particularly Lactobacillus and Bifidobacterium [46]. Glyphosate is a patented antimicrobial agent, and these two species are more vulnerable than others to growth inhibition by glyphosate [47]. Furthermore, folate is derived from chorismate, a product of the shikimate pathway that glyphosate disrupts [48].

\section{SUCCINATE DEHYDROGENASE INHIBITION}

A study on Escherichia coli revealed that glyphosate suppressed three different components of the succinate dehydrogenase (SDH) enzyme, cytochrome b556, the avoprotein subunit and the hydrophobic subunit, reducing their activity three- to fourfold [48]. Roundup cytotoxicity in human cells is mediated in part through inhibition of $\mathrm{SDH}$, a key enzyme in mitochondrial complex II [49-51]. A theoretical study of the mechanism of inhibition suggests that glyphosate binds at the succinate binding site with a higher binding energy than succinate, thus blocking substrate bioavailability [52]. Roundup has also been shown to depress complexes II and III [53].

Both SDH (complex II) and fumarate hydratase (FH) (complex III) are tumour suppressors. Their suppressive mechanism can be understood through the effects of enhanced glycolysis following their inhibition [54]. Mutations in SDH lead to the development of paraganglioma (tumours originating in the ganglia of the sympathetic nervous system), and phaeochromocytoma (neuroendocrine tumours of the adrenal glands), and mutations in FH cause renal cell carcinoma. Neuroblastoma is the most common extracranial solid tumour in infants and young children [55]. An increase in growth rate and invasiveness in neuroblastomas is linked to impaired succinate dehydrogenase function [56].

Succinate and fumarate will accumulate in mitochondria when SDH and/or FH are suppressed, and they leak out into the cytosol. Two newly recognized signalling pathways result in enhanced glycolysis in a "pseudohypoxic response", as well as resistance to apoptotic signals [54]. A characteristic feature of tumour cells is their increased use of glycolysis as a source of energy, even in the presence of available oxygen, a phenomenon referred to as the Warburg effect $[57,58]$. Malignant, rapidly growing tumour cells typically have glycolytic rates up to 200 times higher than those of their normal tissues of origin, even when oxygen is plentiful.

\section{GLYOXAL, METHYLGLYOXALAND GLYOXYLATE}

In this section, we discuss the potent toxicity of multiple metabolites of fructose that are plausibly present in foods derived from glyphosate-resistant crops, or as a contaminant in glyphosate-based products, or as a breakdown product generated endogenously following glyphosate exposure. These include glyoxylate, glyoxal and methylglyoxal. We show that these molecules are genotoxic and can induce cancer. We surmise that their toxicity is enhanced by glyphosate exposure diminishing bioavailability of vitamin E, an antioxidant.

Vitamin E, a tocopherol, is derived from the shikimate pathway, which glyphosate disrupts [59]. One of the best characterized functions of tocopherols is to protect biological membranes against oxidative stress. Superoxide dismutase (SOD) catalyses the conversion of superoxide anion 
$\left(\mathrm{O}_{2}^{-}\right)$, a reactive oxygen species (ROS), to hydrogen peroxide $\left(\mathrm{H}_{2} \mathrm{O}_{2}\right)$ and molecular oxygen $\left(\mathrm{O}_{2}\right)$. Nicotinamide adenine dinucleotide phosphate (NADPH) oxidase can also produce ROS, which leads to proteinuria and haematuria [60]. $\mathrm{H}_{2} \mathrm{O}_{2}$ induces haem degradation in red blood cells, particularly when glutathione is deficient [61]. ROS causes irreversible DNA impairment, damage to lipid membranes and promotes the toxic carbonyl, malondialdehyde $[62,63]$. Excessive lipid peroxidation induced with ingestion of glyphosate residues likely leads to an overload of maternal and foetal antioxidant defence systems following liver damage, as shown in rat studies by Beuret et al. [64].

Glyoxal and methylglyoxal are very potent glycating agents, considerably more reactive than either glucose or fructose $[65,66]$. They attack the amine groups in amino acids, peptides and proteins to form advanced glycation end products (AGEs), and they cause carbonyl stress in the presence of oxidizing agents such as $\mathrm{O}_{2}^{-}$and $\mathrm{H}_{2} \mathrm{O}_{2}$ [66]. A study linking AGEs to cancer showed that methylglyoxal-bovine serum albumin (methylglyoxalBSA) induced significant DNA damage [67]. Cancer incidence is increased in association with chronic renal failure, and this is likely due to the binding of AGEs to receptors for advanced glycation end products (RAGE), leading to increased intracellular formation of ROS [67].

Extremely high levels of methylglyoxal are found in commercial carbonated beverages sweetened with high fructose corn syrup (HFCS), but not in those that are sweetened with artificial sweeteners [68]. Since HFCS is derived from glyphosate-resistant corn, it is conceivable that the methylglyoxal was produced in the plant in response to glyphosate exposure. There is a plausible biological mechanism for this, caused by the accumulation of excessive amounts of phosphoenolpyruvate (PEP) as a consequence of the disruption of the enzyme, 5enolpyruvyl-shikimate-3-phosphate (EPSP) synthase, that uses PEP as substrate for the first step in the shikimate pathway [69]. PEP suppresses glycolysis by binding to the active site in the enzyme, triose phosphate isomerase (TPI) [70], outcompeting the natural substrates.

Furthermore, PEP reacts with fructose to initiate its conversion to triose phosphate, also known as glyceraldehyde 3-phosphate (glyceraldehyde 3-p), as illustrated in Fig. 1 [71]. Glyceraldehyde 3-p is highly unstable and it spontaneously breaks down to methylglyoxal [72]. Severe impairment of TPI due to genetic defects leads to sharp increases in methylglyoxal and protein glycation, as well as oxidation and nitrosation damage [73]. Inhibition of glycolysis will increase the residence time of glyceraldehyde 3-p and increase its chances to spontaneously degrade to methylglyoxal. It can be expected that similar problems will occur in gut microbes exposed to glyphosate, as well as human cells, and this may explain the increased levels of methylglyoxal observed in association with diabetes [74].

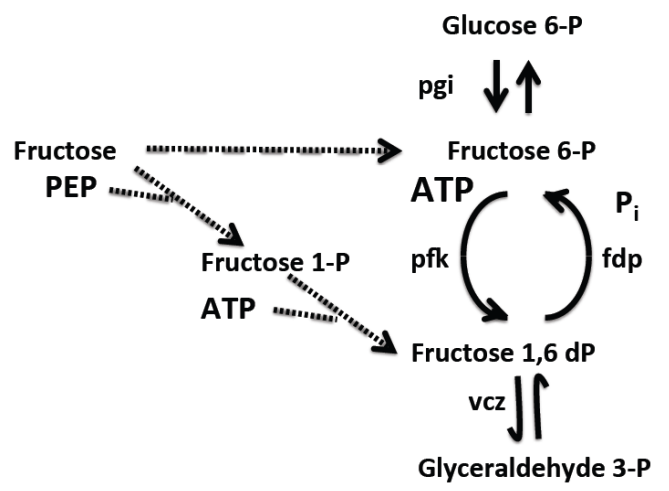

Figure 1. Possible pathways of fructose metabolism in E. coli. Genes are pgi, phosphoglucose isomerase; pc, fructose Bphosphate kinase; fdp, fructose diphosphatase; and fda, fructose diphosphate aldolase. PEP, phosphoenolpyruvate. Adapted from Fraenkel, 1968 [71].

A study comparing rats fed a high-fructose compared to a high-glucose diet revealed that those rats fed fructose experienced a significant increase in body weight, liver mass and fat mass compared to the glucosefed rats [75]. This was accompanied by a reduction in physical activity, although the total number of calories consumed remained equivalent. We suspect that this phenomenon may be largely due to the presence of glyphosate and methylglyoxal contamination in the fructose (which was likely derived from the GMO RoundupReady HFCS). A study exposing male Sprague Dawley rats to a high-fructose diet during an interval over a period of four months showed elevated serum levels of methylglyoxal, along with several indicators of diabetes and metabolic syndrome, including expression of RAGE, $\mathrm{NF}-\mathrm{kB}$, mediators of the renin angiotensin system and elevated blood pressure [76]. At physiological concentrations, methylglyoxal can modify plasmid DNA and cause mutations and abnormal gene expression [77].

Glyphosate formulations are trade secrets, but a 2006 Monsanto patent proposed using oxalic acid (oxalate) as an additive to increase the toxicity of glyphosate to weeds [78]. Oxalate inhibits pyruvate kinase and this leads to an elevation in PEP along with a reduction in production of lactate and pyruvate. The synthesis of PEP in rat livers exposed to $0.1 \mathrm{mM}$ oxalate more than doubled [79], which likely induces excess exposure to methylglyoxal as discussed above, causing liver stress. The effects of oxalate would be synergistic with the effects of glyphosate inhibition of the shikimate pathway in gut microbes, which can be expected to also increase PEP levels, since PEP is substrate for the enzyme that glyphosate disrupts. 
Several anaerobic bacteria, including Oxalobacter formigenes, Eubacterium lentum, Enterococcus faecalis and Lactobacillus acidophilus can metabolize oxalate in the gut [80]. However, both oxalate decarboxylase and oxalate oxidase, enzymes involved in oxalate metabolism, depend on manganese as a cofactor [81], and manganese is chelated by glyphosate, making it unavailable to gut microbes $[82,83]$.

Elevated serum glyoxylate has been found to be an early marker for diabetes risk [84]. The conversion of glyoxylate to oxalate by the enzyme lactate dehydrogenase is inhibited by oxalate $[85,86]$. Hence glyoxylate, derived from glyphosate breakdown, can be expected to accumulate in the presence of excess oxalate. Glyoxylate can be derived from glyoxal, and both glyoxal and glyoxylate have been proposed as key reactants in the production of glyphosate, as described in multiple patents from the mid-1980s $[87,88]$. Furthermore, glyphosate can itself be metabolized to AMPA and glyoxylate by microbial action along two distinct pathways, via glycine oxidase or via glyphosate oxidoreductase [89]. In vitro exposure of hepatocytes to glyoxal showed hepatotoxicity induced by lipid peroxidation, ROS, and collapsed mitochondrial membrane potential $[90,91]$.

$\mathrm{LDH}$ is also known to be involved in tumour metabolism. A Monsanto study conducted by Johnson on rabbits found that extremely high doses of glyphosate $(5000 \mathrm{mg} / \mathrm{kg}$ ) severely downregulated production of $\mathrm{LDH}$, reducing values in both male and female animals, whereas a fivefold lower dose $(1000 \mathrm{mg} / \mathrm{kg})$ upregulated LDH similarly in both males and females compared to the experimental control [92]. Glyphosate was administered by dermal absorption to three groups, each of 5 male and 5 female rabbits. Doses of 100, 1000 and $5000 \mathrm{mg} / \mathrm{kg}$ were held in place by occlusion for 6 hours/day, five days/week for 21 days. A control group of the same numbers of animals and sex did not receive the compound. Results for the control, low-, mid- and highdose groups were 250,169, 291 and 76 for male animals and $189,149,258$ and 28 for female animals, respectively. Not understanding glyphosate's nonmonotonic doseresponse relationship caused Johnson to dismiss this haematological finding. A similar pattern of LDH regulation was recorded by Stout \& Ruecker in 1990 in experiments with albino rats [15].

A Monsanto patent application from 1985 describes the invention as follows: "glyphosate and various glyphosate derivatives can be produced with very high selectivity by the reductive alkylation of aminomethylphosphonic acid, its salts or its esters, in an aqueous medium with a carbonyl compound, such as, for example, glyoxal, glyoxylic acid, a glyoxylate salt, or a glyoxylate polyacetal salt or ester"
[88]. An earlier US patent application disclosed a similar process whereby aminomethylphosphonic acid is reacted in an aqueous medium with glyoxal in the presence of sulfur dioxide to produce glyphosate. Methylglyoxal is cytotoxic, and it has been shown to arrest growth and react with nucleotides, increasing the incidence of sister chromatid exchanges, a step towards tumorigenesis [93].

Methylglyoxal also decreases protein thiols, especially glutathione, an essential antioxidant. In in vitro studies, glyphosate has also been shown to reduce glutathione levels in mammalian cells, possibly mediated through methylglyoxal [94]. Methylglyoxal induces DNA mutations mainly at G:C base pairs, and it severely inhibits DNA replication by inducing cross-links between DNA and DNA polymerase [95]. The mutagenicity of methylglyoxal is suppressed by sulfur-containing molecules, such as sulfite, cysteine and glutathione [96]. Glyphosate has been shown to deplete methionine levels by $50 \%$ to $65 \%$ in a glyphosate-sensitive carrot plant line [97]. Methionine is an essential sulfur-containing amino acid crucial for maintaining levels of cysteine, glutathione and sulfate. Most bacteria possess biosynthetic pathways for methionine [98], and it is possible that glyphosate disrupts their ability to supply this critical nutrient to the host.

Glyoxalase is a key enzyme in the pathway that detoxifies methylglyoxal. Mouse studies have demonstrated that its overexpression can reduce AGE production and oxidative damage associated with hyperglycaemia [99], thus demonstrating a direct link between methylglyoxal and these pathologies. Glyoxalase is upregulated in association with rapid cell proliferation [100] and also in association with some cancers, including gastric cancer [101] and prostate cancer [102] (gastric cancer is the second highest cause of cancer-related mortality worldwide [103]). Overexpression of glyoxalase I is associated with increased gastric wall invasion and lymph node metastasis [101]. Glyphosate exposure has been shown experimentally to induce increased expression of glyoxalase activity in Arachis hypogaea (groundnut), which was engineered to be glyphosate-tolerant [100]. In addition, the observed upregulation of redox-regulated kinases, phosphatases and transcription factors shows the importance of redox couples to reorganize growth and metabolic needs under stress conditions, such as exposure to glyphosate. Mitogen-activated protein kinase (MAPK) phosphatases (MKPs) play an important rôle in the development of cancer in humans [104].

\section{N-NITROSOGLYPHOSATE AND N-NITROSOSARCOSINE}

As was shown by Monsanto's own studies [26], glyphosate readily reacts with nitrogen oxides to form Nnitrosoglyphosate (NNG), which is of great concern due 
to its toxicity [105]. N-nitroso compounds (NOCs) can induce cancer in multiple organs in at least 40 different animal species, including higher primates [106-108]. In in vitro studies on human liver slices, the mechanism of action was shown to be nucleic acid alkylation [109]. Schmahl and Habs commented: "N-nitroso compounds can act carcinogenically in a large number of animal species; there is no rational reason why human beings should be an exception, all the less so since in vitro experiments have shown $\mathrm{N}$-nitroso compounds are metabolized in the same way by human livers as by the livers of experimental animals" [108, p. 240]. Several different nitrosylated compounds have been targeted as potential carcinogenic agents, although it is conceded that the long lag time between exposure and tumour development makes it difficult to recognize the links [110]. Dietary N-nitrosyl compounds especially are thought to increase the risk of colon cancer and rectal carcinoma $[111,112]$.

The Food and Agricultural Organization of the United Nations (FAO) has set a strict upper limit of 1 ppm NNG [113]. The accepted methodology for measuring contamination levels, proposed by Monsanto in 1986 [114], has complicated instrumentation and operation conditions and is relatively insensitive [105]. New advanced methodologies offer safer and more reliable testing methods $[115,105]$.

One of the pathways by which some bacteria break down glyphosate is by first using carbon-phosphorus lyase (C-P lyase) to produce sarcosine as an immediate breakdown product $[89,116]$. Nitrosylated sarcosine is well recognized as a carcinogenic agent. Injection of $225 \mathrm{mg} / \mathrm{kg}$ of nitrososarcosine into mice at days 1, 4 and 7 of life led to the development of metastasizing liver carcinomas in later life in 8 out of 14 exposed animals [117].

Elevated levels of sarcosine are also linked to prostate cancer, particularly metastatic prostate cancer [118]. An unbiased metabolomic survey of prostate cancer patients identified elevated levels of serum or urinary sarcosine as a marker of aggressive disease [119] (prostate cancer is the most commonly diagnosed cancer in men in the USA, and it afflicts one in nine men over the age of 65 [120]). In both in vitro and in vivo prostate cancer models, exposure to sarcosine, but not glycine or alanine, induced invasion and intravasation [119].

\section{IMPAIRED GLYCINE SYNTHESIS}

Perhaps surprisingly, a recent study has proposed that glyphosate might serve a useful rôle in cancer treatment due to its ability to inhibit glycine synthesis [121]. Glycine is essential for the synthesis of DNA and, therefore, for cell proliferation. In vitro studies on 8 different cancer cell lines (including prostate, ovarian, cervical and lung cancer) demonstrated that glyphosate at doses ranging from 15 to $50 \mathrm{mM}$ was cytotoxic to tumour cells, and that cytotoxicity to normal cell lines required higher doses (e.g., $100 \mathrm{mM}$ ). It was hypothesized that the mechanism of action involved impaired glycine synthesis due to glyphosate acting as a glycine mimetic.

In direct contradiction, however, glycine has been shown to prevent tumorigenesis [122] and it is a potent anti-angiogenic nutrient that suppresses tumour growth, possibly through activation of a glycine-gated chloride channel [123]. Impaired glycine synthesis likely has other adverse effects as well, such as the possibility that glyphosate interferes with glycine conjugation of benzenebased compounds. In particular, this is a mechanism used by gut microbes, particularly Bifidobacteria, to detoxify phenolic compounds, producing hippurate (benzoylglycine), a glycine conjugate of benzoic acid, as a mechanism for detoxification [124]. Glycine has been shown to be a limiting factor for hippurate production [125]. We stated earlier that glyphosate preferentially harms Bifidobacteria [46], and studies have shown reduced counts of Bifidobacteria in obese rats along with reduced excretion of hippurate [126]. Obese humans have also been shown to have reduced urinary hippurate [127]. Furthermore, lower urinary hippurate is linked to ulcerative colitis, particularly Crohn's disease [128]. A Swedish study of over 21000 Crohn's disease patients identified increased risk of a broad range of cancers, including liver, pancreatic, lung, prostate, testicular, kidney, squamous cell skin cancer, nonthyroid endocrine tumours and leukaemia [129]. Crohn's and inflammatory bowel disease have been increasing in incidence in the USA in step with the increase in glyphosate usage on corn and soy crops $(R=$ $\left.0.938, P \leq 7.1 \times 10^{-8}\right)[1]$.

\section{COLONAND LIVER CANCER}

As shown in Table 1, the incidence of liver cancer in the USA has increased substantially in the past two decades, pari passu with the increase in glyphosate usage on corn and soy crops $(P \leq 4.6) \times 10^{-8}$.

Nonalcoholic steatohepatitis (NASH) is a fatty liver disease that has been linked to excess dietary fructose [130]. We hypothesize that it is due primarily to the disruption in gut metabolism of fructose due to glyphosate blocking the shikimate pathway, as discussed previously. Fructose, which should have been processed in the gut leading to production of aromatic amino acids, instead is delivered to the liver, which converts it into fat for either local storage or distribution within low-density lipid particles (LDL). NASH affects a large proportion of the US population and is increasing in prevalence worldwide 
with adoption of a "Western diet" [131]. NASH causes cirrhosis and increases risk of liver cancer [131, 132]. Hepatocellular carcinoma (HCC) is the most common cause of obesity-related cancer deaths among middle-aged men in America. The consumption of refined carbohydrates in soft drinks has been postulated to be a key factor in the development of NASH [130]. As we have seen, soft drinks containing HFCS are very high in methylglyoxal.

A study from 1988 on children with severe chronic liver disease revealed that those children with low vitamin E levels were susceptible to $\mathrm{H}_{2} \mathrm{O}_{2}$-induced haemolytic anaemia [133]. We earlier discussed the rôle of glyphosate in depleting vitamin E. Haemolysis leads to haemochromatosis (release of free iron from haem). The endocrine glands, heart, liver, testes and pancreas are all affected by haemochromatosis. Damage to pancreatic islet $\beta$-cells from iron deposition can lead to cellular death and functional impairment associated with diabetes [134]. Other effects of haemochromatosis include bone and joint pain, arthritis, cardiomyopathy and testicular problems.

The liver synthesizes substantial amounts of haem, which is needed primarily for the cytochrome P450 (CYP) enzymes, which perform many important rôles, including bile acid synthesis, hormone activation and breakdown, and detoxifying many carcinogenic agents, including phenolic and other organic xenobiotics as well as drugs and bilirubin. Glyphosate likely contributes to the destruction of CYP enzymes both through $\mathrm{H}_{2} \mathrm{O}_{2}$ attack at their haem centre as well as through direct interference via nitrosylation at the active site by glyphosate [11]. CYP-mediated drug metabolism is impaired in patients with liver disease, particularly CYP1A, CYP2C19, and CYP3A [135], and this makes these individuals even more susceptible to liver damage.

Inflammation and metabolic disorders are intimately linked, and both are characteristic features of diabetes and obesity [136]. Diabetes and obesity are linked to dramatically higher risk of cancer, particularly of the liver and gastrointestinal tract [137]. This is directly linked to bile acid dysregulation and dysbiosis of the gut microbiome. Elevated levels of cytotoxic secondary bile acids and inflammation induced by an immune response to gut pathogens induce heightened oxidative DNA damage, increased cell proliferation and enterohepatic carcinogenesis [137]. Temporal patterns of glyphosate use on corn and soy crops strongly correlate with the increase in both diabetes and liver cancer observed over the same time interval [1].

Gut dysbiosis, due in part to glyphosate's antimicrobial effects, leads to gut inflammation and impairment of the gut barrier function. This means that pathogens will escape the gut and infiltrate the liver. Exposure to endotoxin produced by gut microbes, such as lipopolysaccharides (LPS) leads to inflammation in the liver along with hepatic fibrosis [138]. Several types of chronic liver disease are associated with increased levels of bacterial LPS in the portal and/or systemic circulation [139].

Acute hepatic porphyrias are disorders caused by enzyme defects in haem biosynthesis [140], and they are risk factors for liver cancer [141-143]. Glyphosate has been shown to disrupt haem synthesis, by suppressing the enzyme that activates the first step, combining glycine with succinyl coenzyme $A$ to form $\delta$-aminolevulinic acid [144]. An often-overlooked component of glyphosate's toxicity to plants is inhibition of chlorophyll synthesis [145], as $\delta$-aminolevulinic acid is also a precursor to chlorophyll as well as haem.

$\gamma$-glutamyl transferase (GGT) is a membrane-bound enzyme that decomposes glutathione into cysteinyl glycine and glutamate; it is highly expressed in the liver. Excess serum GGT has been linked to both oxidative stress [146] and increased cancer risk [147] as well as many other diseases [148]. In a study on 283438 people who were divided into five subgroups based on GGT level, a hazard ratio of 18.5 for risk of hepatic carcinoma was ascertained for the highest level compared to the lowest [149]. Another study based in Korea found an increased risk of multiple cancers in association with elevated GGT: most especially liver cancer, but also cancer of the esophagus, larynx, stomach, bile ducts, lungs and colon [150]. GGT induces generation of reactive oxygen species through interactions of cysteinyl glycine with free iron $[151,152]$.

Exposure to Roundup at low doses increased GGT expression in rat testis and Sertoli cells [94]. A comparison between goats fed GM Roundup-Ready solvent-extracted soybean $v s$ goats fed a conventional soy equivalent revealed that the male kids born to the goats fed the GM soy had elevated expression of GGT in both liver and kidney $(P<0.01)$ [153]. A study has shown that $70 \%$ of GM Roundup-ready soy samples had significant levels of glyphosate, whereas the conventional soy did not [154].

Exposure of Wistar rats to the herbicide GlyphosateBiocarb over a period of 75 days resulted in liver damage, including elevated serum alanine aminotransferase (ALT) and aspartate aminotransferase (AST), suggesting irreversible hepatocyte damage, as well as large deposition of reticulin fibres containing collagen type III [155], suggesting liver fibrosis [156], which is a major risk factor for hepatocarcinogenesis.

Excessive retinoic acid signalling in the liver is expected due to the interference of glyphosate with liver CYP enzymes [11, 157, 158], because the CYP2C gene 
family is needed to metabolize retinoic acid in the liver [159]. The action of retinoic acid is likely mediated through sonic hedgehog signalling [160]. Studies on mice have revealed that hedgehog signalling induces fibrosis and hepatocellular carcinoma [161]. Studies on tadpoles have demonstrated that glyphosate produces teratogenic effects characteristic of excessive retinoic acid signalling, and these effects were reversed by a retinoic acid antagonist [162].

\section{PANCREATIC CANCER}

Pancreatic cancer is one of the cancers whose incidence is going up in step with the increase in glyphosate usage on corn and soy crops $\left(R=0.918 ; P \leq 4.6 \times 10^{-7}\right.$. $)[1]$. As of 2002, pancreatic adenocarcinoma was the fourth leading cause of cancer death in the USA, with an overall 5 -year survival rate of less than 5\% [163]. We have already noted that excess methylglyoxal exposure can lead to diabetes. Direct evidence of this was obtained when methylglyoxal injection into Sprague Dawley rats caused pancreatic $\beta$-cell dysfunction [164]. We earlier discussed the rôle of excess iron deposition in the destruction of pancreatic $\beta$ cells [134].

Glyphosate's metal chelation effects led to severe manganese deficiency in cows [83]. Rats fed a diet deficient in manganese showed significantly lower concentrations of manganese in liver, kidney, heart and pancreas compared to controls [165]. Pancreatic insulin content was reduced by $63 \%$, and insulin output was correspondingly reduced, suggesting that manganese deficiency may play a direct rôle in insulin-deficient diabetes and islet cell stress.

Acinar cell carcinoma is the second most common type of pancreatic cancer, characterized histologically by zymogen-like granules as well as fibrillary internal structures in the tumour cells [166]. A comparison between mice fed GM soy and wild soy demonstrated alterations in pancreatic acinar cells including smaller zymogen granules and less zymogen content in one month-old mice, along with reduced production of $\alpha$ amylase [167]. The authors did not consider possible effects of glyphosate contamination, even though another study has shown significant glyphosate residues in GM soy as compared to conventional soy treated with glyphosate [154]. Pancreatic atrophy of the acinar cells along with degranulation and intracellular fibrillation is a fundamental aspect of the childhood wasting disease kwashiorkor [168], which is linked to disrupted gut microbes [169], and may also be in part attributable to glyphosate poisoning.
A two-year study of glyphosate toxicity to rats reported by the EPA in 1991 showed several signs of tumours, which were ultimately dismissed partly because of a lack of a dose-response relationship, and in part because it was argued that historical controls (but not the controls in the study) demonstrated tumours at comparable rates, but under very different and uncontrolled dietary and lifestyle practices [170]. The most frequently observed tumours were pancreatic islet cell adenomas in males, thyroid C-cell adenomas and/or carcinomas in males and females, and hepatocellular adenomas and carcinomas in males. Both low-dose and high-dose, but not mid-dose, males had a statistically significant increased incidence of pancreatic islet cell adenomas.

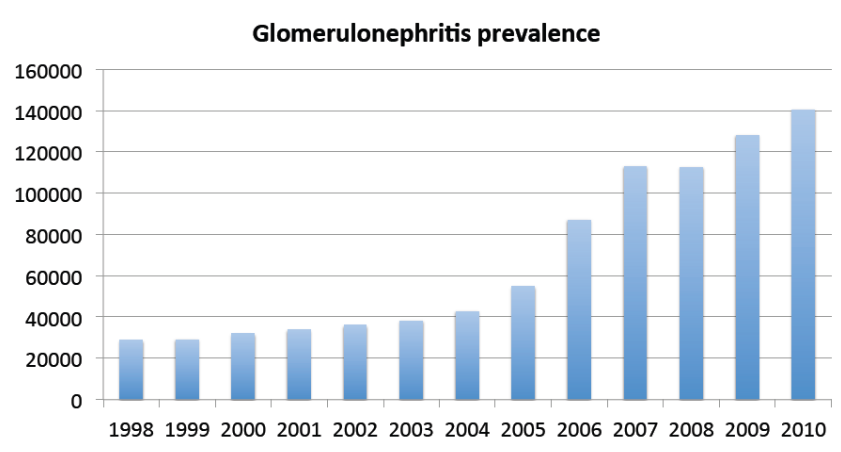

Figure 2. Incidence of nephritis and kidney failure reports in the US CDC's hospital discharge data from 1998 to 2010 normalized to counts per million population each year. This includes all reports of ICD-9 codes from 580 to 589.

\section{KIDNEY CANCER}

Chronic kidney disease (CKD) and cancer are closely linked in reciprocal fashion: cancer or its treatment can cause CKD and patients with CKD have increased risk of cancer. Dialysis patients have an increased risk ranging from $10 \%$ to $80 \%$; kidney transplant recipients have a 3- to 4-fold increased risk of cancer [6]. The number of patients with kidney failure treated by dialysis and transplantation increased dramatically in the USA from 209000 in 1991 to 472000 in 2004 [171]. There have been concurrent increases in earlier stages of chronic kidney disease such as albuminuria and impaired glomerular filtration [172]. Since 2004, this trend has worsened. Figure 2 shows the trend over time in the US Centers for Disease Control (CDC)'s hospital discharge data $^{4}$ for ICD-9 codes 580-589, including acute and chronic glomerulonephritis, nephritis and nephropathy, acute and chronic renal failure, renal sclerosis, and disorders resulting from impaired renal function. There has been an alarming rise in the frequency of these conditions, especially since 2006.

\footnotetext{
${ }^{4} \mathrm{ftp} / / / \mathrm{ftp} . c d c . g o v /$ pub/Health Statistics/NCHS/Datasets/NHDS
} 
Studies on rats show that CYP 2B1 plays a pivotal rôle as an important site for ROS production through cytotoxicity in the glomeruli [173]. The breakdown of the CYP haem protein through attack by $\mathrm{H}_{2} \mathrm{O}_{2}$ leads to the release of catalytic iron, which, in turn, generates more potent tissue-damaging oxidants such as the hydroxyl radical. Glyphosate's induction of excess $\mathrm{H}_{2} \mathrm{O}_{2}$ as discussed earlier would cause an increase in the bioavailability of catalytic free iron to work synergistically with $\mathrm{H}_{2} \mathrm{O}_{2}$ to cause toxicity.

Methylglyoxal and other glycating agents may be a significant factor in the development of kidney disease. Twelve weeks of administration through drinking water of methylglyoxal to Dahl salt-sensitive rats led to an increase in systolic blood pressure and significantly increased urinary albumin excretion, glomerular sclerosis, tubular injury, myocardial collagen content and cardiac perivascular fibrosis [174]. Renal markers of AGE production, oxidative stress and inflammation were all elevated.

Acquired cystic kidney disease (ACKD) can lead to renal tumours, and the tumours often accumulate calcium oxalate crystals [175]. These tumours are often associated with distinctive morphological features, where the tumour cells have ill-defined cell membranes, abundant granular eosinophilic cytoplasm, large nuclei and prominent nucleoli. In another study identifying intratumoral calcium oxalate crystal deposition in two cases of high-grade renal carcinomas, the authors suggested a relationship between tumour growth and oxalate crystal deposition [176]. This suggests a rôle for oxalic acid added to glyphosate-based formulations.

An in vitro study on rat testis and Sertoli cells demonstrated that Roundup triggers calcium-mediated cell death associated with reductions in levels of the antioxidant glutathione, along with thiobarbituric acid reactive species (TBARS) and protein carbonyls indicative of protein oxidation and glycation damage [94]. Administration of L-buthionine(S,R)-sulfoximine (BSO), a specific inhibitor of glutathione synthesis, to rats caused reduced glutathione levels in the kidneys and a marked increase in pathologies linked to polycystic kidney disease [177].

\section{CATARACTS AND MELANOMA}

As we showed previously, Monsanto's own studies revealed increased risk of cataracts following exposure to Roundup. Early-onset cataracts are associated with insufficient antioxidative activity and, therefore, are a potential risk of cancer, as verified in a recent nationwide study based in Taiwan [178].

Methylglyoxal is implicated in cataract development $[179,180]$. Methylglyoxal induces endoplasmic reticulum stress in human lens epithelial cells, and activates an unfolded protein response leading to overproduction of ROS. Overexpression of Keap1 protein causes proteasomal degradation of Nrf2, thus suppressing Nrf2-dependent stress protection. As a consequence, the cellular redox balance is altered toward lens oxidation and cataract formation [179].

There is a link between cholestasis and cataracts via poor absorption of nutrients that protect the lens from UV damage. Studies on short-term exposure of catfish to sublethal levels of Roundup revealed toxicity to the gills, liver and kidneys [181]. The observed elevated levels of unconjugated bilirubin and alanine aminotransferase (ALT) are indicative of cholestasis, likely in part a consequence of impaired CYP enzyme function. Cholestasis impairs the absorption of fat-soluble vitamins and previtamins such as the carotenoids [182]. Lutein and zeaxanthin are carotenoids that play an important rôle in the lens and macular region of the retina to protect from oxidative damage due to sunlight exposure [183, 184]. They are highly lipophilic and, therefore, like the fat-soluble vitamins, depend on adequate bile flow for gastrointestinal absorption. Cholestatic patients have greatly reduced serum levels of these nutrients [182].

Tryptophan is a product of the shikimate pathway that glyphosate suppresses. A tryptophan-free diet induces cataracts in young Wistar rats, along with a significant decrease in lens weight and water-soluble lens protein [185]. Kynurenine is a breakdown product of tryptophan, and it has been suggested that kynurenine and its glycoside derivatives in the ocular lens protect the retina from UV light by absorbing UV radiation [186]. Kynurenine is present in excessive concentrations in cataracts [186].

Melanoma is one of the types of cancer that have been linked to glyphosate exposure in agriculture. An age-adjusted analysis revealed an $80 \%$ increased risk of melanoma associated with glyphosate use in a study on pesticide applicators in Iowa and North Carolina [187]. It is possible that impaired supply of the aromatic amino acids, tryptophan and tyrosine due to disruption of the shikimate pathway in gut microbes plays a rôle in increased risk to melanoma.

In vitro, exposure to $0.1 \mathrm{mM}$ glyphosate induced hyperproliferation in human skin keratinocytes $(\mathrm{HaCaT})$ cells, suggesting carcinogenic potential [188]. The mechanism involves increased ROS expression and the emptying of intracellular calcium stores, which facilitates basal cell or squamous cell carcinomas. Cells accumulated in S-phase of the cell cycle, while mitochondrial apoptotic signalling pathways were downregulated.

Melanin plays an important protective rôle in the skin against UV exposure, and dark-skinned races have 
significantly reduced risk of skin melanoma because of their naturally higher levels of melanin [189]. Melanosomes are tissue-specific organelles in pigment cells that resemble lysosomes, in which melanin is synthesized and stored [190]. L-tyrosine is the precursor to melanin synthesis, and the pathway involves the intermediary, L-dopa. Both L-tyrosine and L-dopa, when supplied to cells with melanogenic potential, increase not only the synthesis of melanin but also the formation of melanosomes within the cells [191].

While blacks have protection against skin cancer due to the high concentration of melanin in their skin, dark skin also appears to be a risk factor for autism. A study based in Los Angeles showed that children born to black foreign-born women had a substantially increased risk for low-functioning autism [192]. A similar observation has been made in Sweden [193] and the UK [194]. One possibility is that increased demand for melanin in the skin depletes the supply of tyrosine for dopamine synthesis. Genetic mutations in dopamine transport proteins have been linked to autism $[195,196]$. The defect features a persistent reverse transport of dopamine (substrate efflux from the synapse), which reduces the amount of time extracellular dopamine is available for signalling effects [195]. Other genes of the dopaminergic network are also linked to autism, including syntaxin [197] and enzymes involved in dopamine metabolism [198]. Hence, we hypothesize that reduced bioavailability of tyrosine (due to disruption of the shikimate pathway in gut microbes) for either dopamine synthesis or melanin synthesis leads to different outcomes (autism vs melanoma) depending on race-related skin colour.

Tryptophan is an essential amino acid for lymphocyte activation and proliferation, which promotes surveillance and elimination of tumour cells [199, 200]. Tryptophan is also produced by gut microbes via the shikimate pathway that glyphosate disrupts, suggesting that glyphosate exposure to gut microbes could impair tryptophan bioavailability to the human host. The enzyme indoleamine 2,3-dioxygenase (IDO) catalyses the degradation of tryptophan to kynurenines. Tumours of the lung [201], colon [202], liver [203], breast [204] and uvea [205], as well as skin melanoma [206], overexpress IDO, and it is believed that this leads to an ability to evade immune surveillance by Tcells via depletion of tryptophan bioavailability in the surrounding milieu [205]. It is interesting that IDO offers significant protection from UV damage by producing tryptophan-based filters that protect the cornea, lens and retina from UV-induced photo-oxidation [207, 208]. It may well be that tumours exploit IDO for this purpose as well. Clearly, decreased bioavailability of tryptophan due to glyphosate's effects on gut microbes would enhance the tumour's ability to deplete tryptophan and avoid immune surveillance, but might also lead to accelerated DNA damage within the tumour and increased risk of metastasis [209].

\section{THYROID CANCER}

The incidence of thyroid cancer in the United States has increased dramatically in the past two decades, in step with the increase in glyphosate usage on corn and soy crops $\left(R=0.988, P \leq 7.6 \times 10^{-9}\right)[1]$. It is not clear how glyphosate might increase risk of thyroid cancer beyond the general factors already described previously in this paper, but it is possible that impaired selenium incorporation into selenoproteins plays a rôle.

Selenium is an important trace element involved in the protection of cells from oxidative stress, and it is particularly important for the thyroid. Low serum levels of selenium are associated with increased risk of thyroid cancer, and probably play a rôle in carcinogenesis. All three of the deiodinases that convert thyroxine (T4) into triiodothyronine (T3) contain selenocysteine, as do glutathione peroxidase and thioredoxin reductase, which are important antioxidant enzymes essential for protecting thyrocytes from oxidative damage [210].

The microbiome plays an important rôle in incorporating free selenium into selenoproteins, especially selenocysteine. Lactobacillus reuteri is a popular species in probiotics, shown to be effective against diarrhoea in children [211], and to inhibit the prooxidant cytokine TNF- $\alpha$ in humans [212]. This species has been found to be especially effective in its ability to produce selenocysteine, and has been proposed to have therapeutic benefit in cases of selenium deficiency [213]. Lactobacillus is especially vulnerable to glyphosate due to its crucial and unusual need for manganese as an antioxidant [214, 215], so it is plausible that diminished Lactobacillus representation in the gut could lead to an impaired supply of selenocysteine for the thyroid.

\section{BREAST CANCER}

Breast cancer accounts for one third of cancer diagnoses and $15 \%$ of cancer deaths in women in the United States. As mentioned previously, an in vitro study has confirmed that glyphosate stimulates proliferation of human breast cancer cells when present in concentrations of parts per trillion [9]. ${ }^{1}$ This effect is specific to hormone-dependent cell lines, and is mediated by the ability of glyphosate to act as an oestrogenic agent.

One can obtain an estimate of the time trends in breast cancer by looking at the CDC's hospital discharge data. The results show a steady decrease in breast cancer 
diagnoses up to 2006, followed by an increase from 2006 to 2010 (the last year for which data are available). The decrease can logically be explained by a growing awareness of the increased risk of breast cancer associated with hormone replacement therapy (HRT). A Women's Health Initiative (WHI) study, published in 2003 , showed a $24 \%$ increase in invasive breast cancer risk associated with oestrogen/progestin therapy [216]. In direct response to this alarming report, HRT prescriptions in the United States decreased by $38 \%$ in 2003. A large study on 1642824 women published in 2013, based on the Breast Cancer Surveillance Consortium, revealed that HRT (commonly used to treat symptoms of menopause) increased the risk of breast cancer by $20 \%$ in whites, Asians and hispanics, but not in blacks [217].

By forming separate records from the hospital discharge data for black and white women, it can be confirmed that the breast cancer rates among blacks remained flat up to 2006, supporting the observation that black women are not subject to increased risk from HRT. This suggests that one can build a model to correct for the influence of reduced use of HRT among white women in order to arrive at a time trend that might more closely capture any effects of glyphosate. A simple decaying exponential model matches well for the Caucasian data from 1998 to 2006, and this model can be extended into the time interval from 2006 to 2010, and then subtracted from the original plot, to yield a plot of the residual trends for breast cancer. The resulting plot is shown in Fig. 3 alongside rates of glyphosate usage on corn and soy crops. The correlation coefficient is 0.9375 ( $P$-value $\leq 0.0001132)$.

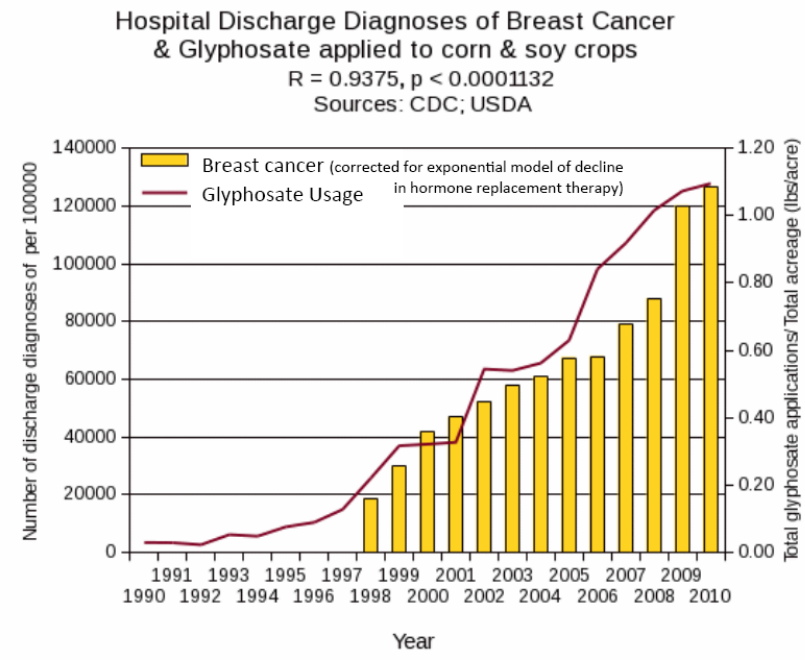

Figure 3. Incidence of breast cancer in US hospital discharge data from 1998 to 2010 normalized to counts per 1,000,000 population each year, after subtraction of an exponential model accounting for the decline in the years up to 2006 in the Caucasian subpopulation [see text]. This includes all reports of ICD-9 codes 174 and 175. The red line shows trends in glyphosate usage on corn and soy crops over the same time period.
A study on rats conducted by Séralini et al. [7] divided the rats into four groups: (1) control, (2) GM maize without Roundup, (3) GM maize with Roundup, and (4) Roundup alone. The major tumours detected in the female rats were mammary fibroadenomas and adenocarcinomas. These authors summaraized their findings as: "The Roundup treatment groups showed the greatest rates of tumour incidence, with $80 \%$ of animals affected with up to 3 tumours for one female, in each group." For the group that received Roundup in their drinking water, all but one of the females presented with mammary hypertrophies and hyperplasias. The one exception suffered from a metastatic ovarian carcinoma.

Glyphosate may also indirectly increase risk of breast cancer by impairing metabolism of toxic phenolic compounds such as nonylphenols, diethylstilbestrol (DES), and Bisphenol A (BPA), all widely recognized to possess oestrogenic activity. Nonylphenols, also known as alkylphenols, are a family of organic compounds used extensively as additives in laundry detergents, lubricating oils, paints, pesticides, personal care products and plastics, which are known to be xenoestrogenic [218]. DES is an oestrogenic compound linked to vaginal tumours in women exposed in utero to this compound when it was mistakenly believed to be of therapeutic benefit. BPA, commonly used in plastics production, is now widely recognized as an endocrine disruptor. PCBs were widely used as coolants and insulating fluids for transformers and capacitors until their ban in 1979 by the US government due to recognition of their toxicity due to oestrogenic activity. However, they degrade very slowly, and therefore are still environmental pollutants today.

Liver CYP enzymes play an important rôle in metabolizing all of these xenoestrogenic compounds. CYP1A1 is upregulated in response to PCB exposure, and therefore it likely metabolizes these toxic phenols [219]. High serum levels of PCBs in conjunction with at least one (defective) exon 7 variant allele of CYP1A1 increased breast cancer risk [219]. CYP enzymes are also involved with the metabolism of nonylphenols [220]. Similarly, BPA is mainly metabolized by the CYP2C subfamily in the liver [221]. Thus, impaired CYP function due to glyphosate exposure $[11,157,158]$ can be expected to interfere with metabolism of PCBs and therefore increase their oestrogenic potential, leading indirectly to increased risk of breast cancer.

High dietary iron enhances the incidence of carcinogeninduced mammary cancer in rats and oestrogen-induced kidney tumours in hamsters [222]. Oestrogen facilitates iron uptake by cells in culture. Elevated body iron storage increases the risk of several cancers, including breast cancer in humans. Although it might be argued that 
glyphosate's chelating effects may protect from iron overload, glyphosate could increase the bioavailability of free iron due to its damaging effects on red blood cells $[42,223]$ working synergistically with its interference in haem synthesis [144], and by acting as an oestrogen mimetic to enhance iron uptake. Haem degradation by reactive oxygen species [224] will lead to the release of free iron, and we have previously discussed how glyphosate would induce oxidative stress. In fact, recent evidence strongly suggests that GGT induces lipid peroxidation of red blood cell membranes leading to haemolysis and the release of free iron from chelating agents [225]. This also results in impaired deformability which impedes their passage through narrow capillaries. GGT was found to be enhanced up to 5.4-fold in the liver in Séralini et al.'s long-term study of rats exposed to GMO's plus Roundup [7].

\section{NON-HODGKIN'S LYMPHOMA}

Striking increases in the incidence of non-Hodgkin lymphoma (NHL) cancer have occurred over the past three decades, both in Europe [226] and America [227]. Agricultural workers have a higher risk of NHL than the general population, but it is difficult to tease out the effects of glyphosate compared to the myriad other toxic chaemicals they are exposed to, which also confer increased risk [228]. However, some studies have been able to directly link glyphosate to NHL. A threefold increased risk of NHL in association with glyphosate exposure was found in a 2002 study from Sweden [229]. A later Swedish study in 2008 of over 900 cancer cases also found a significant increased risk of NHL (OR 2.02) [230]. A Canadian study demonstrated a correlation between the number of days per year of glyphosate exposure and the risk of NHL [231].

Increased exposure to superoxide is implicated as a causal agent in oncogenesis [232], and manganese SOD (Mn-SOD) is an important antioxidant defence agent in mitochondria [233]. Mice engineered to be defective in Mn-SOD had increased DNA damage and higher cancer incidence [234]. We mentioned earlier that Mn-SOD is protective against pancreatic cancer. Mn-SOD expression was also found to be anomalously low in erythrocytes of patients suffering from NHL [235]. In vitro studies have shown that an Mn-SOD mimetic had an anti-proliferation effect on human NHL Raji cells [236]. Glyphosate's chelating effects on manganese can be expected to interfere with Mn-SOD function [82]. Increased Mn-SOD expression potentiates apoptosis of tumour cells exposed to dexamethasone [237]. Cationic manganese porphyrins, probably by acting as Mn-SOD mimetics, have also been found to play a protective rôle in treating NHL $[238,239]$.
Bone marrow involvement is common in NHL and, particularly for those of T-cell origin, it portends a poor prognosis [240]. An unpublished study by Monsanto in 1983 confirmed that glyphosate administered by intraperitoneal injection to rats reaches the bone marrow within 30 minutes [241]. In an experiment to assess potential toxicity to bone marrow cells [242], a single intraperitoneal dose of glyphosate at concentrations of 25 and $50 \mathrm{mg} / \mathrm{kg}$ was administered to Swiss albino mice. Chromosal aberrations and micronuclei, analysed 24, 48, and 72 hours later, were shown to be significantly increased compared to vehicle control $(P<0.05)$. Mitosis rates were also decreased, indicating cytotoxic effects.

Multiple myeloma is the second most common haematological malignancy in the USA after non-Hodgkin lymphoma; it constitutes $1 \%$ of all cancers [243]. In a prospective cohort study of 57311 licensed pesticide applicators in Iowa and North Carolina, a greater than twofold increased risk of multiple myeloma was associated with ever-use of glyphosate [187].

Coeliac disease, along with the more general condition, gluten intolerance, has recently reached epidemic levels in the United States, and it has been hypothesized that this heightened wheat sensitivity is a direct consequence of glyphosate contamination of the wheat, due to the increasingly common practice of wheat desiccation with glyphosate just before harvest [158]. Coeliac disease patients are at increased risk of cancer, particularly non-Hodgkin lymphoma, and they have statistically a shortened lifespan mainly due to this increased cancer risk.

For coeliac disease patients, serum prolactin (PRL) levels are high in association with an unrestricted glutencontaining diet, and PRL has been proposed as a useful marker for coeliac disease [244]. PRL is an important regulatory hormone released by the pituitary gland, which is best known for inducing lactation. Bisphenol A, a wellestablished oestrogenic agent, has been shown to lead to hyperprolactinaemia and growth of prolactin-producing pituitary cells [245]. Prolonged exposure to Bisphenol A during childhood may contribute to the growth of a prolactinoma, the most common form of cancer of the pituitary. Oestrogen treatment of ovariectomized rats induced a marked elevation of serum PRL levels [246], and this was found to be due to oestrogen's ability to reduce the capacity of PRL cells to incorporate dopamine into their secretory granules. Since glyphosate has been confirmed to be oestrogenic, it is plausible that glyphosate contamination in wheat is the true source of the observed elevation of PRL in association with gluten ingestion among coeliac patients. 


\section{CONCLUSION}

In this paper, we have reviewed the research literature on glyphosate and on the biological processes associated with cancer, and we have provided strong evidence that glyphosate is likely contributing to the increased prevalence of multiple types of cancer in humans. Monsanto's own early studies revealed some trends in animal models that should not have been ignored. Forty years of glyphosate exposure have provided a living laboratory where humans are the guinea pigs and the outcomes are alarmingly apparent.

We have shown that glyphosate transforms exposed cells into a tumour-provoking state by suppressing crucial enzymes in the electron transport chain, such as succinate dehydrogenase and fumarate hydratase. Glyphosate chelates manganese, reducing its bioavailability, and manganese is an important catalyst for Mn-SOD, which protects mitochondria from oxidative damage, which can cause mutations in DNA. Glyphosate also causes impaired metabolism of fructose, due to the accumulation of PEP following blockage of the shikimate pathway. This leads to the synthesis of multiple short-chain sugars that are known to be highly potent glycating agents, such as methylglyoxal and glyoxalate. Glyphosate is readily nitrosylated, and nitrosyl glyphosate is known to be extremely toxic and carcinogenic. Microbial pathways convert glyphosate into sarcosine, a known marker for prostate cancer, likely due to its nitrosylated form.

An often overlooked aspect of glyphosate's toxicity is its interference with enzymes that have glycine as substrate, due to mimicry. Phenolic compounds are detoxified by gut microbes through glycine conjugation to produce products such as hippurate. Bifidobacteria are important for the rôle they play in protecting from these xenobiotics through such conjugation. Reduced hippurate is linked to Crohn's diseases and inflammatory bowel disease, which show epidemiological trends that match the increased use of glyphosate on core crops, and which are linked to increased risk of a broad range of cancers, most especially non-Hodgkin lymphoma. Lymphoma has also been linked to glyphosate through studies of environmental exposure in agricultural settings.

Multiple studies, both in vitro and in vivo, have shown that glyphosate damages DNA, a direct step towards tumorigenicity. These studies have been conducted on sea urchins, fish, mice and various human cell types in vitro. Children in Malaysia living near rice paddies have evidence of DNA damage.

Epidemiological studies strongly support links between glyphosate and multiple cancers, with extremely well matched upward trends in multiple forms of cancer in step with the increased use of glyphosate on corn and soy crops. While these strong correlations cannot prove causality, the biological evidence is strong to support mechanisms that are likely in play, which can explain the observed correlations through plausible scientific arguments.

Glyphosate's links to specific cancer types can often be explained through specific pathologies. For example, succinate dehydrogenase deficiency is linked to adrenal cancer [17]. Selenoprotein deficiency is likely contributory towards thyroid cancer. Glyphosate's action as an oestrogen mimetic explains increased breast cancer risk. Prostate cancer is linked to sarcosine, a by-product of glyphosate breakdown by gut microbes. Impaired fructose metabolism links to fatty liver disease, which is a risk factor for hepatic tumorigenesis. Impaired melanin synthesis by melanocytes due to deficiencies in the precursor, tyrosine, a product of the shikimate pathway, can explain increased incidence of skin melanoma. This is compounded by tryptophan deficiency, as tryptophan is also protective against UV exposure.

Manganese deficiency stresses the pancreas and impairs insulin synthesis, and this could explain the recent epidemic in pancreatic cancer. Increased oxalate, due in part to the proprietary formulations, stresses the kidney and contributes to risk of renal tumours. Glyphosate's accumulation in bone marrow can be expected to disrupt the maturation process of lymphocytes from stem cell precursors. Glycine forms conjugates with organic benzenederived carcinogenic agents, and glyphosate likely interferes with this process. Glyphosate's interference with CYP enzyme function impairs detoxification of multiple other carcinogenic agents, increasing their carcinogenic potential. Overall, the evidence of the carcinogenicity of glyphosate is compelling and multifactorial.

\section{APPENDIX: NEOPLASTIC INCIDENCE DATA FROM MONSANTO}

\section{Two-Year Animal Studies}

In this section we present selected tables tabulating tumours and malignancies, separately for male and female rats, in the long-term study conducted by Lankas \& Hogan and reported on in an unpublished document in 1981 [17]. The rats were exposed to three different doses of glyphosate added to their feed $\left(3,10\right.$, and $30 \mathrm{mg} \mathrm{kg}^{-1}$ day $\left.^{-1}\right)$ and compared with unexposed controls.

Similarly, we present tables tabulating all of the tumours and malignancies that were found, separately for male and female mice, in the long-term study conducted by Knezevich \& Hogan and reported on in an unpublished document in 1983 [18]. The mice were exposed to three different doses of glyphosate added to their feed (1000, 5000 and $30000 \mathrm{ppm})$ and compared with unexposed controls. 
Table A1. Incidence of neoplastic findings in male rats with glyphosate administered by diet. Part I. Data extracted from Lankas \& Hogan (1981) [17].

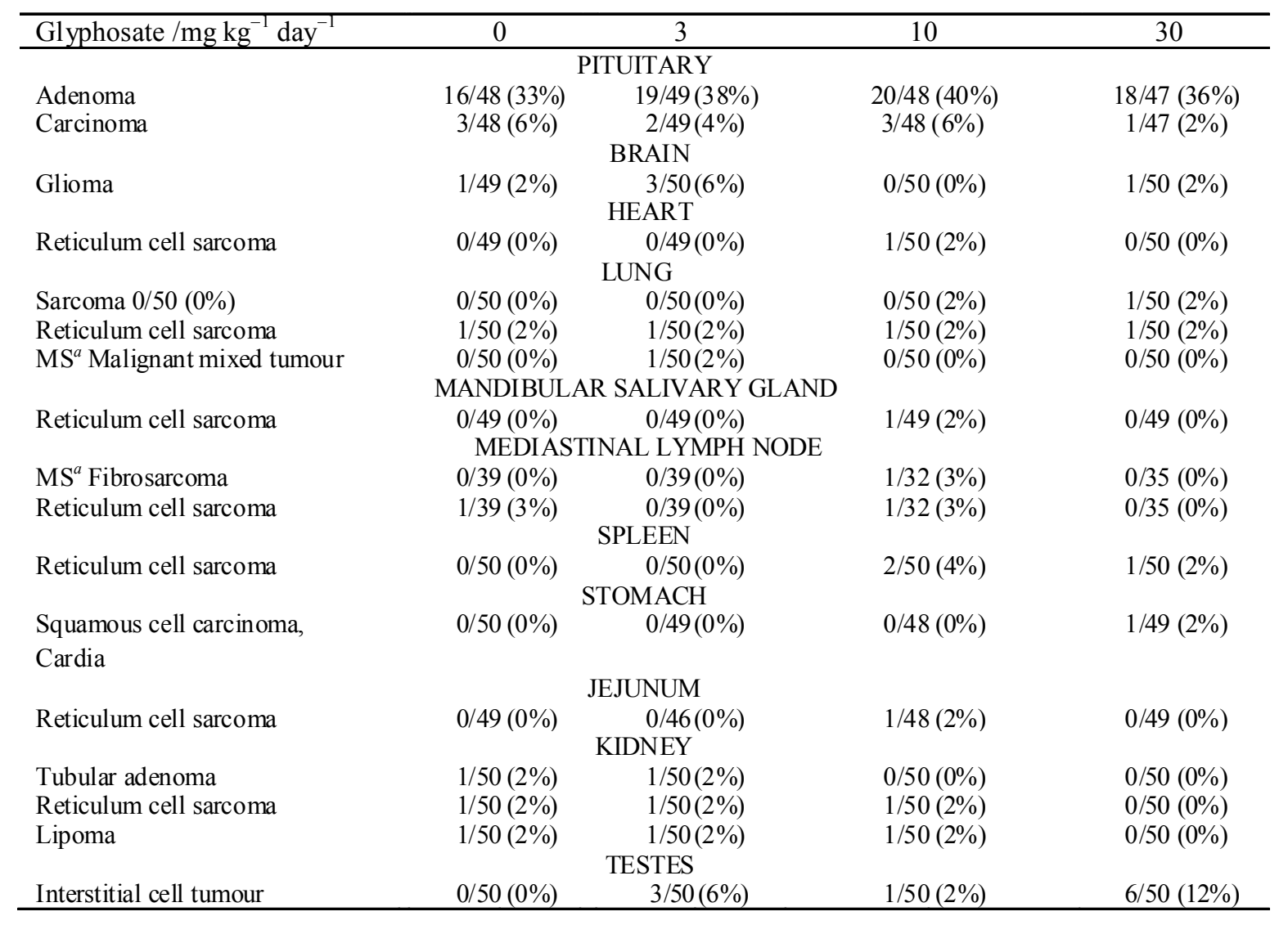

${ }^{a} \mathrm{MS}=$ metastatic. 
Table A2. Incidence of neoplastic findings in male rats with glyphosate administered by diet. Part II. Data extracted from Lankas \& Hogan (1981) [17].

\begin{tabular}{|c|c|c|c|c|}
\hline Glyphosate $/ \mathrm{mg} \mathrm{kg}^{-1}$ day $^{-1}$ & 0 & 3 & 10 & 30 \\
\hline \multicolumn{5}{|c|}{ PROSTATE } \\
\hline Reticulum cell sarcoma & $0 / 50(0 \%)$ & $0 / 47(0 \%)$ & $1 / 49(2 \%)$ & $0 / 49(0 \%)$ \\
\hline \multicolumn{5}{|c|}{ URINARY BLADDER } \\
\hline Papilloma & $0 / 46(0 \%)$ & $1 / 45(2 \%)$ & $0 / 43(0 \%)$ & $0 / 46(0 \%)$ \\
\hline \multicolumn{5}{|c|}{ THYROID } \\
\hline C-cell carcinoma & $0 / 47(0 \%)$ & $0 / 49(0 \%)$ & $1 / 49(2 \%)$ & $0 / 49(0 \%)$ \\
\hline Follicular adenoma & $1 / 47(2 \%)$ & $2 / 49(4 \%)$ & $4 / 49(8 \%)$ & $4 / 49(8 \%)$ \\
\hline \multicolumn{5}{|c|}{ PARATHYROID } \\
\hline Adenoma & $0 / 27(0 \%)$ & $2 / 30(4 \%)$ & $0 / 28(0 \%)$ & $0 / 27(0 \%)$ \\
\hline \multicolumn{5}{|c|}{ ADRENAL } \\
\hline Reticulum cell sarcoma & $0 / 50(0 \%)$ & $0 / 50(0 \%)$ & $1 / 50(2 \%)$ & $0 / 50(0 \%)$ \\
\hline Pheochromo-cytoma & $8 / 50(16 \%)$ & $8 / 50(16 \%)$ & $5 / 50(10 \%)$ & $11 / 50(22 \%)$ \\
\hline Cortical adenoma & $2 / 50(4 \%)$ & $4 / 50(8 \%)$ & $1 / 50(2 \%)$ & $1 / 50(2 \%)$ \\
\hline \multicolumn{5}{|c|}{ SKIN } \\
\hline Basosquamous cell tumour & $0 / 49(0 \%)$ & $0 / 48(0 \%)$ & $0 / 49(0 \%)$ & $1 / 49(2 \%)$ \\
\hline Sebaceous gland adenoma & $0 / 49(0 \%)$ & $0 / 48(0 \%)$ & $0 / 49(0 \%)$ & $1 / 49(2 \%)$ \\
\hline \multicolumn{5}{|c|}{ PERIOCULAR TISSUE } \\
\hline Squamous cell carcinoma & $0 / 0(0 \%)$ & $0 / 0(0 \%)$ & $1 / 1(100 \%)$ & $0 / 0(0 \%)$ \\
\hline \multicolumn{5}{|c|}{ SUBCUTANEOUS TISSUE } \\
\hline Fibrosarcoma & $2 / 10(20 \%)$ & $1 / 12(8 \%)$ & $2 / 10(20 \%)$ & $3 / 7(43 \%)$ \\
\hline Fibroma & $0 / 10(0 \%)$ & $3 / 12(24 \%)$ & $1 / 10(10 \%)$ & $2 / 7(29 \%)$ \\
\hline Neuro brosarcoma & $0 / 10(0 \%)$ & $0 / 12(0 \%)$ & $0 / 10(0 \%)$ & $1 / 7(14 \%)$ \\
\hline Lipoma & $1 / 10(10 \%)$ & $2 / 12(17 \%)$ & $0 / 10(0 \%)$ & $0 / 7(0 \%)$ \\
\hline Osteogenic sarcoma & $0 / 10(0 \%)$ & $0 / 12(0 \%)$ & $1 / 10(10 \%)$ & $0 / 7(0 \%)$ \\
\hline Malignant mixed tumour & $0 / 10(0 \%)$ & $1 / 12(8 \%)$ & $0 / 10(0 \%)$ & $0 / 7(0 \%)$ \\
\hline \multicolumn{5}{|c|}{ MEDIASTINAL TISSUE } \\
\hline Reticulum cell sarcoma & $0 / 7(0 \%)$ & $0 / 1(0 \%)$ & $0 / 4(0 \%)$ & $1 / 2(50 \%)$ \\
\hline \multicolumn{5}{|c|}{ ABDOMEN } \\
\hline Lipoma & $0 / 0(0 \%)$ & $0 / 0(0 \%)$ & $0 / 0(0 \%)$ & $1 / 1(100 \%)$ \\
\hline \multicolumn{5}{|c|}{ ABDOMINAL CAVITY } \\
\hline Reticulum cell sarcoma & $0 / 0(0 \%)$ & $0 / 0(0 \%)$ & $1 / 1(100 \%)$ & $0 / 0(0 \%)$ \\
\hline \multicolumn{5}{|c|}{ LUMBAR LYMPH NODE } \\
\hline $\mathrm{MS}^{a}$ Islet cell carcinoma & $0 / 0(0 \%)$ & $0 / 0(0 \%)$ & $0 / 0(0 \%)$ & $1 / 1(100 \%)$ \\
\hline \multicolumn{5}{|c|}{ SACRAL LYMPH NODE } \\
\hline Reticulum cell sarcoma & $0 / 1(0 \%)$ & $1 / 3(33 \%)$ & $0 / 3(0 \%)$ & $0 / 3(0 \%)$ \\
\hline
\end{tabular}

${ }^{a} \mathrm{MS}=$ metastatic. 
Table A3. Incidence of neoplastic findings in female rats with glyphosate administered by diet. Part I. Data extracted from Lankas \& Hogan (1981) [17].

\begin{tabular}{|c|c|c|c|c|}
\hline Glyphosate $/ \mathrm{mg} \mathrm{kg}^{-1}$ day $^{-1}$ & 0 & 3 & 10 & 30 \\
\hline \multicolumn{5}{|c|}{ PITUITARY } \\
\hline Carcinoma & $8 / 48(17 \%)$ & $7 / 48(15 \%)$ & $5 / 50(10 \%)$ & $12 / 49(24 \%)$ \\
\hline \multicolumn{5}{|c|}{ BRAIN } \\
\hline Invasive pituitary carcinoma & $0 / 50(0 \%)$ & $0 / 49(0 \%)$ & $1 / 50(2 \%)$ & $1 / 50(2 \%)$ \\
\hline Malignant lymphoma & $0 / 50(0 \%)$ & $0 / 49(0 \%)$ & $0 / 50(0 \%)$ & $1 / 50(2 \%)$ \\
\hline Glioma & $0 / 50(0 \%)$ & $0 / 49(0 \%)$ & $0 / 50(0 \%)$ & $1 / 50(2 \%)$ \\
\hline \multicolumn{5}{|c|}{ CERVICAL SPINAL CORD } \\
\hline Malignant lymphoma & $0 / 50(0 \%)$ & $0 / 50(0 \%)$ & $0 / 50(0 \%)$ & $1 / 50(2 \%)$ \\
\hline \multicolumn{5}{|c|}{ HEART } \\
\hline Malignant lymphoma & $0 / 50(0 \%)$ & $0 / 50(0 \%)$ & $0 / 50(0 \%)$ & $1 / 50(2 \%)$ \\
\hline \multicolumn{5}{|c|}{ LUNG } \\
\hline Reticulum cell sarcoma & $2 / 49(4 \%)$ & $2 / 50(4 \%)$ & $1 / 49(2 \%)$ & $3 / 50(6 \%)$ \\
\hline Malignant lymphoma & $0 / 49(0 \%)$ & $1 / 50(2 \%)$ & $0 / 49(0 \%)$ & $1 / 50(2 \%)$ \\
\hline Adenocarcinoma & $0 / 49(0 \%)$ & $0 / 50(0 \%)$ & $0 / 49(0 \%)$ & $1 / 50(2 \%)$ \\
\hline Carcinoma & $0 / 49(0 \%)$ & $0 / 50(0 \%)$ & $1 / 49(2 \%)$ & $0 / 50(0 \%)$ \\
\hline \multicolumn{5}{|c|}{ LIVER } \\
\hline Reticulum cell sarcoma & $2 / 50(4 \%)$ & $2 / 50(4 \%)$ & $1 / 50(2 \%)$ & $2 / 50(4 \%)$ \\
\hline Malignant lymphoma & $0 / 50(0 \%)$ & $0 / 50(0 \%)$ & $1 / 50(2 \%)$ & $2 / 50(4 \%)$ \\
\hline Hepatocellular carcinoma & $1 / 50(2 \%)$ & $0 / 50(0 \%)$ & $0 / 50(0 \%)$ & $2 / 50(4 \%)$ \\
\hline \multicolumn{5}{|c|}{ MESENTERIC LYMPH NODE } \\
\hline Malignant lymphoma & $0 / 42(0 \%)$ & $0 / 39(0 \%)$ & $0 / 48(0 \%)$ & $1 / 47(2 \%)$ \\
\hline Reticulum cell sarcoma & $0 / 42(0 \%)$ & $0 / 39(0 \%)$ & $0 / 48(0 \%)$ & $2 / 47(4 \%)$ \\
\hline \multicolumn{5}{|c|}{ PANCREAS } \\
\hline Islet cell carcinoma & $0 / 50(0 \%)$ & $1 / 50(2 \%)$ & $1 / 50(2 \%)$ & $1 / 49(2 \%)$ \\
\hline \multicolumn{5}{|c|}{ MANDIBULAR SALIVARY GLAND } \\
\hline Metastatic fibrosarcoma & $0 / 48(0 \%)$ & $0 / 50(0 \%)$ & $1 / 49(2 \%)$ & $0 / 49(0 \%)$ \\
\hline \multicolumn{5}{|c|}{ THYMUS } \\
\hline Malignant lymphoma & $0 / 25(0 \%)$ & $0 / 32(0 \%)$ & $1 / 37(3 \%)$ & $1 / 34(3 \%)$ \\
\hline Thymoma & $0 / 25(0 \%)$ & $0 / 32(0 \%)$ & $1 / 37(3 \%)$ & $0 / 34(0 \%)$ \\
\hline \multicolumn{5}{|c|}{ MEDIASTINAL LYMPH NODE } \\
\hline Reticulum cell sarcoma & $0 / 33(0 \%)$ & $1 / 29(3 \%)$ & $0 / 37(0 \%)$ & $0 / 30(0 \%)$ \\
\hline Malignant lymphoma & $0 / 33(0 \%)$ & $0 / 29(0 \%)$ & $1 / 37(3 \%)$ & $2 / 30(7 \%)$ \\
\hline \multicolumn{5}{|c|}{ SPLEEN } \\
\hline Malignant lymphoma & $0 / 50(0 \%)$ & $0 / 50(0 \%)$ & $1 / 50(2 \%)$ & $2 / 50(4 \%)$ \\
\hline Reticulum cell sarcoma & $2 / 50(4 \%)$ & $2 / 50(4 \%)$ & $1 / 50(2 \%)$ & $5 / 50(10 \%)$ \\
\hline \multicolumn{5}{|c|}{ STOMACH } \\
\hline Malignant lymphoma & $0 / 50(0 \%)$ & $0 / 50(0 \%)$ & $0 / 50(0 \%)$ & $1 / 50(2 \%)$ \\
\hline \multicolumn{5}{|c|}{ JEJUNUM } \\
\hline Leiomyosarcoma & $0 / 50(0 \%)$ & $1 / 48(2 \%)$ & $0 / 49(0 \%)$ & $0 / 49(0 \%)$ \\
\hline \multicolumn{5}{|c|}{ ILEUM } \\
\hline Reticulum cell sarcoma & $0 / 47(0 \%)$ & $0 / 49(0 \%)$ & $0 / 49(0 \%)$ & $1 / 48(2 \%)$ \\
\hline \multicolumn{5}{|c|}{ COLON } \\
\hline Reticulum cell sarcoma & $0 / 50(0 \%)$ & $0 / 50(0 \%)$ & $0 / 49(0 \%)$ & $1 / 48(2 \%)$ \\
\hline \multicolumn{5}{|c|}{ URINARY BLADDER } \\
\hline Transitional cell tumour & $0 / 50(0 \%)$ & $0 / 48(0 \%)$ & $0 / 48(0 \%)$ & $1 / 44(2 \%)$ \\
\hline
\end{tabular}


Table A4. Incidence of neoplastic findings in female rats with glyphosate administered by diet. Part II.

Data extracted from Lankas \& Hogan (1981) [17].

\begin{tabular}{|c|c|c|c|c|}
\hline Glyphosate $/ \mathrm{mg} \mathrm{kg}^{-1}$ day $^{-1}$ & 0 & 3 & 10 & 30 \\
\hline \multicolumn{5}{|c|}{ OVARY } \\
\hline Granulosa cell tumour & $8 / 49(16 \%)$ & $8 / 50(16 \%)$ & $6 / 48(13 \%)$ & $6 / 45(13 \%)$ \\
\hline Theca-granulosa cell tumour & $0 / 49(0 \%)$ & $0 / 50(0 \%)$ & $0 / 48(0 \%)$ & $1 / 45(2 \%)$ \\
\hline \multicolumn{5}{|c|}{ UTERUS } \\
\hline Squamous cell carcinoma & $0 / 50(0 \%)$ & $0 / 50 \quad(0 \%)$ & $0 / 49(0 \%)$ & $1 / 49(2 \%)$ \\
\hline Endometrial sarcoma & $0 / 50(0 \%)$ & $0 / 50 \quad(0 \%)$ & $0 / 49(0 \%)$ & $1 / 49(2 \%)$ \\
\hline Adenoma & $0 / 50(0 \%)$ & $0 / 50 \quad(0 \%)$ & $2 / 49(4 \%)$ & $1 / 49(2 \%)$ \\
\hline \multicolumn{5}{|c|}{ THYROID } \\
\hline C-cell adenoma & $5 / 47(10 \%)$ & $(6 \%)$ & $6 / 50(12 \%)$ & $3 / 47(6 \%)$ \\
\hline C-cell carcinoma & $1 / 47(2 \%)$ & $(0 \%)$ & $2 / 50(4 \%)$ & $6 / 47(12 \%)$ \\
\hline Metastatic fibrosarcoma & $0 / 47(0 \%)$ & $(0 \%)$ & $1 / 50(2 \%)$ & $0 / 47(0 \%)$ \\
\hline \multicolumn{5}{|c|}{ PARATHYROID } \\
\hline Adenoma & $0 / 23(0 \%)$ & $0 / 25 \quad(0 \%)$ & $0 / 25(0 \%)$ & $1 / 23(4 \%)$ \\
\hline \multicolumn{5}{|c|}{ ADRENAL } \\
\hline Reticulum cell sarcoma & $1 / 50(2 \%)$ & $1 / 50 \quad(2 \%)$ & $1 / 50(2 \%)$ & $3 / 49(6 \%)$ \\
\hline Pheochromo-cytoma & $1 / 50(2 \%)$ & $2 / 50 \quad(4 \%)$ & $2 / 50(4 \%)$ & $2 / 49(4 \%)$ \\
\hline Cortical adenoma & $5 / 50(10 \%)$ & $10 / 50 \quad(20 \%)$ & $6 / 50(12 \%)$ & $4 / 49(8 \%)$ \\
\hline Malignant lymphoma & $0 / 50(0 \%)$ & $0 / 50 \quad(0 \%)$ & $0 / 50(0 \%)$ & $1 / 49(2 \%)$ \\
\hline \multicolumn{5}{|c|}{ MAMMARY GLAND (L\&R) } \\
\hline Adenoma (L) & $4(47)(8 \%)$ & $7(46)(15 \%)$ & $10(48)(20 \%)$ & $5(44)(11 \%)$ \\
\hline Adenoma (R) & $4(47)(8 \%)$ & $7(46)(15 \%)$ & $8(48)(16 \%)$ & $5(44)(11 \%)$ \\
\hline Fibroadenoama (L) & $33 / 47)(66 \%)$ & $28(46)(61 \%)$ & $27(48)(56 \%)$ & $22(44)(50 \%)$ \\
\hline Fibroadenoama (R) & $24(47)(48 \%)$ & $16(46)(35 \%)$ & $20(48)(41 \%)$ & $16 / 44(36 \%)$ \\
\hline \multicolumn{5}{|c|}{ EYE } \\
\hline Periocular fibrosarcoma & $0 / 49(0 \%)$ & $0 / 48 \quad(0 \%)$ & $1 / 50(2 \%)$ & $0 / 47(0 \%)$ \\
\hline \multicolumn{5}{|c|}{ HARDERIAN GLAND } \\
\hline Malignant lymphoma & $0 / 47(0 \%)$ & $0 / 45 \quad(0 \%)$ & $0 / 47(0 \%)$ & $1 / 44(2 \%)$ \\
\hline Invasive fibrosarcoma & $0 / 47(0 \%)$ & $0 / 45$ & $1 / 47(2 \%)$ & $0 / 44(0 \%$ \\
\hline \multicolumn{5}{|c|}{ BONE MARROW } \\
\hline Malignant lymphoma & $0 / 46(0 \%)$ & $0 / 44$ & $1 / 46(2 \%)$ & $1 / 45(2 \%)$ \\
\hline Reticulum cell sarcoma & $1 / 46(2 \%)$ & $0 / 44 \quad(0 \%)$ & $1 / 46(2 \%)$ & $3 / 45(6 \%)$ \\
\hline \multicolumn{5}{|c|}{ SUBCUTANEOUS TISSUE } \\
\hline Lipoma & $0 / 4(0 \%)$ & $0 / 6(0 \%)$ & $0 / 1(0 \%)$ & $2 / 2(100 \%)$ \\
\hline Reticulum cell sarcoma & $0 / 4(0 \%)$ & $2 / 6(33 \%)$ & $0 / 1(0 \%)$ & $0 / 2(0 \%)$ \\
\hline \multicolumn{5}{|c|}{ MEDIASTINAL TISSUE } \\
\hline Reticulum cell sarcoma & $0 / 2(0 \%)$ & $1 / 1(100 \%)$ & $0 / 2(0 \%)$ & $0 / 2(0 \%)$ \\
\hline \multicolumn{5}{|c|}{ MESENTERY } \\
\hline Reticulum cell sarcoma & $0 / 5 \quad(0 \%)$ & $0 / 5(0 \%)$ & $0 / 2(0 \%)$ & $2 / 7(29 \%)$ \\
\hline & MANDIBUL & YMPH NODE & & \\
\hline Malignant lymphoma & $0 / 2(0 \%)$ & $0 / 3(0 \%)$ & $0 / 6(0 \%)$ & $1 / 6(17 \%)$ \\
\hline \multicolumn{5}{|c|}{ URETER } \\
\hline Transitional cell carcinoma & $0 / 0(0 \%)$ & $0 / 0(0 \%)$ & $1 / 1(100 \%)$ & $1 / 1(100 \%)$ \\
\hline
\end{tabular}


Table A5. Incidence of neoplastic findings in male mice with glyphosate administered by diet. Part I. From Knezevich \& Hogan, 1983 [18]. BN = Benign, $\mathrm{MG}=$ Malignant, $\mathrm{MS}=$ Metastatic.

\begin{tabular}{|c|c|c|c|c|}
\hline Glyphosate (ppm) & 0 & Low (1000) & Mid (5000) & High (30000) \\
\hline \multicolumn{5}{|c|}{ BRAIN } \\
\hline $\begin{array}{l}\text { MS Lymphoblastic lymphosarcoma } \\
\text { with leukaemic manifestations }\end{array}$ & $0 / 49(0 \%)$ & $0 / 50(0 \%)$ & $1 / 50(2 \%)$ & $0 / 50(0 \%)$ \\
\hline \multicolumn{5}{|c|}{ HEART } \\
\hline $\begin{array}{l}\text { MS Lymphoblastic lymphosarcoma } \\
\text { with leukaemic manifestations }\end{array}$ & $0 / 47(0 \%)$ & $1 / 49(2 \%)$ & $2 / 49(4 \%)$ & $1 / 50(2 \%)$ \\
\hline \multicolumn{5}{|c|}{ LUNGS } \\
\hline BN Bronchiolar-alveolar adenoma & $5 / 48(10 \%)$ & $9 / 50(18 \%)$ & $9 / 50(18 \%)$ & $9 / 50(18 \%)$ \\
\hline $\begin{array}{l}\text { MG Bronchiolar-alveolar } \\
\text { adeno-carcinoma }\end{array}$ & $4 / 48(8 \%)$ & $3 / 50(6 \%)$ & $2 / 50(4 \%)$ & $1 / 50(2 \%)$ \\
\hline $\begin{array}{l}\text { MS Lymphoblastic lymphosarcoma } \\
\text { with leukaemic manifestations }\end{array}$ & $1 / 48(2 \%)$ & $4 / 50(8 \%)$ & $3 / 50(6 \%)$ & $1 / 50(2 \%)$ \\
\hline MS Lymphoblastic lymphosarcoma & $0 / 48(0 \%)$ & $1 / 50(2 \%)$ & $0 / 50(0 \%)$ & $0 / 50(0 \%)$ \\
\hline \multicolumn{5}{|c|}{ LIVER } \\
\hline MG Hepatocellular adenocarcinoma & $5 / 49(10 \%)$ & $6 / 50(12 \%)$ & $6 / 50(12 \%)$ & $4 / 50(8 \%)$ \\
\hline BN Hepatocellular adenoma & $0 / 49(0 \%)$ & $0 / 50(0 \%)$ & $1 / 50(2 \%)$ & $0 / 50(0 \%)$ \\
\hline MG Hepatocellular carcinoma & $0 / 49(0 \%)$ & $0 / 50(0 \%)$ & $0 / 50(0 \%)$ & $2 / 50(4 \%)$ \\
\hline MS Histiocytic sarcoma & $0 / 49(0 \%)$ & $1 / 50(2 \%)$ & $0 / 50(0 \%)$ & $0 / 50(0 \%)$ \\
\hline MS Liposarcoma & $0 / 49(0 \%)$ & $0 / 50(0 \%)$ & $1 / 50(2 \%)$ & $1 / 50(2 \%)$ \\
\hline MS Lymphoblastic lymphosarcoma & $1 / 49(2 \%)$ & $4 / 50(8 \%)$ & $2 / 50(4 \%)$ & $2 / 50(4 \%)$ \\
\hline \multicolumn{5}{|c|}{ MESENTERIC LYMPH NODES } \\
\hline $\begin{array}{l}\text { MG Histiocytic Sarcoma } \\
\text { with leukaemic manifestations }\end{array}$ & $0 / 40(0 \%)$ & $1 / 50(2 \%)$ & $0 / 46(0 \%)$ & $0 / 49(0 \%)$ \\
\hline $\begin{array}{l}\text { MG Lymphoblastic lymphosarcoma } \\
\text { with leukaemic manifestations }\end{array}$ & $1 / 40(2 \%)$ & $2 / 50(4 \%)$ & $1 / 46(2 \%)$ & $0 / 49(0 \%)$ \\
\hline $\begin{array}{l}\text { MS Lymphoblastic lymphosarcoma } \\
\text { with leukaemic manifestations }\end{array}$ & $0 / 40(0 \%)$ & $0 / 50(0 \%)$ & $1 / 46(2 \%)$ & $2 / 49(4 \%)$ \\
\hline MG Lymphoblastic lymphosarcoma & $0 / 40(0 \%)$ & $1 / 50(2 \%)$ & $0 / 46(0 \%)$ & $0 / 49(0 \%)$ \\
\hline \multicolumn{5}{|c|}{ MEDIASTINAL LYMPH NODES } \\
\hline MS Histiocytic sarcoma & $0 / 45(0 \%)$ & $1 / 49(2 \%)$ & $0 / 41(0 \%)$ & $0 / 49(0 \%)$ \\
\hline $\begin{array}{l}\text { MS Lymphoblastic lymphosarcoma } \\
\text { with leukaemic manifestations }\end{array}$ & $1 / 45(2 \%)$ & $2 / 49(4 \%)$ & $1 / 41(2 \%)$ & $2 / 49(4 \%)$ \\
\hline $\begin{array}{l}\text { MG Lymphoblastic lymphosarcoma } \\
\text { with leukaemic manifestations }\end{array}$ & $0 / 45(0 \%)$ & $0 / 49(0 \%)$ & $2 / 41(5 \%)$ & $0 / 49(0 \%)$ \\
\hline
\end{tabular}


Table A6. Incidence of neoplastic findings in male mice with glyphosate administered by diet. Part II. From Knezevich \& Hogan, 1983 [18]. BN = Benign, $\mathrm{MG}=$ Malignant, MS = Metastatic.

\begin{tabular}{|c|c|c|c|c|}
\hline Glyphosate (ppm) & 0 & Low (1000) & Mid (5000) & High $(30000)$ \\
\hline \multicolumn{5}{|c|}{ SPLEEN } \\
\hline MG Hemangio-endothelioma & $0 / 48(0 \%)$ & $0 / 49(0 \%)$ & $1 / 50(2 \%)$ & $0 / 49(0 \%)$ \\
\hline MS Histiocytic sarcoma & $0 / 48(0 \%)$ & $1 / 49(2 \%)$ & $0 / 50(0 \%)$ & $0 / 49(0 \%)$ \\
\hline MS Lymphoblastic lymphosarcoma & $1 / 48(2 \%)$ & $2 / 49(4 \%)$ & $2 / 50(4 \%)$ & $0 / 49(0 \%)$ \\
\hline $\begin{array}{l}\text { MG Lymphoblastic lymphosarcoma } \\
\text { with leukaemic manifestations }\end{array}$ & $0 / 48(0 \%)$ & $2 / 49(4 \%)$ & $0 / 50(0 \%)$ & $1 / 49(2 \%)$ \\
\hline \multicolumn{5}{|c|}{ PANCREAS } \\
\hline MS Histiocytic Sarcoma & $0 / 48(0 \%)$ & $1 / 48(2 \%)$ & $0 / 50(0 \%)$ & $0 / 49(0 \%)$ \\
\hline $\begin{array}{l}\text { MS Lymphoblastic lymphosarcoma } \\
\text { with leukaemic manifestations }\end{array}$ & $0 / 48(0 \%)$ & $0 / 48(0 \%)$ & $1 / 49(2 \%)$ & $0 / 50(0 \%)$ \\
\hline \multicolumn{5}{|c|}{ KIDNEYS } \\
\hline BN Renal tubule adenoma & $0 / 49(0 \%)$ & $0 / 49(0 \%)$ & $1 / 50(2 \%)$ & $3 / 50(6 \%)$ \\
\hline MS Histiocytic sarcoma & $0 / 49(0 \%)$ & $1 / 49(2 \%)$ & $0 / 50(0 \%)$ & $0 / 50(0 \%)$ \\
\hline MS Composite lymphosarcoma & $1 / 49(2 \%)$ & $0 / 49(0 \%)$ & $0 / 50(0 \%)$ & $0 / 50(0 \%)$ \\
\hline $\begin{array}{l}\text { MS Lymphoblastic lymphosarcoma } \\
\text { with leukaemic manifestations }\end{array}$ & $1 / 49(2 \%)$ & $3 / 49(6 \%)$ & $2 / 50(4 \%)$ & $2 / 50(4 \%)$ \\
\hline \multicolumn{5}{|c|}{ ADRENAL GLANDS } \\
\hline BN Cortical adenoma & $1 / 48(2 \%)$ & $2 / 49(4 \%)$ & $0 / 50(0 \%)$ & $1 / 48(2 \%)$ \\
\hline $\begin{array}{l}\text { MS Lymphoblastic lymphosarcoma } \\
\text { with leukaemic manifestations }\end{array}$ & $0 / 48(0 \%)$ & $1 / 49(2 \%)$ & $0 / 50(0 \%)$ & $0 / 48(0 \%)$ \\
\hline BN Lymphoblastic lymphosarcoma & $0 / 48(0 \%)$ & $0 / 49(0 \%)$ & $1 / 49(2 \%)$ & $0 / 48(0 \%)$ \\
\hline \multicolumn{5}{|c|}{ HARDERGIAN GLAND } \\
\hline BN Adenoma & $1 / 47(2 \%)$ & $0 / 48(0 \%)$ & $0 / 45(0 \%)$ & $0 / 48(0 \%)$ \\
\hline MG Liposarcoma & $0 / 47(0 \%)$ & $0 / 48(0 \%)$ & $1 / 45(2 \%)$ & $0 / 48(0 \%)$ \\
\hline \multicolumn{5}{|c|}{ BONE MARROW } \\
\hline MS Lymphoblastic lymphosarcoma & $1 / 40(2 \%)$ & $2 / 45(4 \%)$ & $1 / 47(2 \%)$ & $1 / 49(2 \%)$ \\
\hline \multicolumn{5}{|c|}{ LYMPH NODE } \\
\hline MS Histiocytic sarcoma & $0 / 0(0 \%)$ & $1 / 3(33 \%)$ & $0 / 2(0 \%)$ & $0 / 2(0 \%)$ \\
\hline MS Composite lymphosarcoma & $0 / 0(0 \%)$ & $0 / 3(0 \%)$ & $1 / 2(50 \%)$ & $0 / 2(0 \%)$ \\
\hline $\begin{array}{l}\text { MS Lymphoblastic lymphosarcoma } \\
\text { with leukaemic manifestations }\end{array}$ & $0 / 0(0 \%)$ & $1 / 3(33 \%)$ & $1 / 2(50 \%)$ & $0 / 2(0 \%)$ \\
\hline $\begin{array}{l}\text { MG Lymphoblastic lymphosarcoma } \\
\text { with leukaemic manifestations }\end{array}$ & $0 / 0(0 \%)$ & $0 / 3(0 \%)$ & $0 / 2(0 \%)$ & $1 / 2(50 \%)$ \\
\hline \multicolumn{5}{|c|}{ TESTES } \\
\hline BN Interstitial cell tumor & $1 / 49(2 \%)$ & $0 / 48(0 \%)$ & $2 / 50(4 \%)$ & $0 / 50(0 \%)$ \\
\hline $\begin{array}{l}\text { MS Lymphoblastic lymphosarcoma } \\
\text { with leukaemic manifestations }\end{array}$ & $0 / 49(0 \%)$ & $1 / 48(2 \%)$ & $0 / 50(0 \%)$ & $0 / 50(0 \%)$ \\
\hline $\begin{array}{l}\text { BN Lymphoblastic lymphosarcoma } \\
\text { with leukaemic manifestations }\end{array}$ & $0 / 49(0 \%)$ & $0 / 48(0 \%)$ & $1 / 50(2 \%)$ & $0 / 50(0 \%)$ \\
\hline
\end{tabular}


Table A7. Incidence of neoplastic findings in female mice with glyphosate administered by diet. Part I. From Knezevich \& Hogan, 1983 [18]. $\mathrm{BN}=$ Benign, $\mathrm{MG}=$ Malignant, $\mathrm{MS}=$ Metastatic.

\begin{tabular}{|c|c|c|c|c|}
\hline Glyphosate (ppm) & $\begin{array}{c}\text { Controls } \\
0\end{array}$ & $\begin{array}{c}\text { Low } \\
\text { Low (1000) }\end{array}$ & $\begin{array}{c}\text { Mid } \\
\text { Mid (5000) }\end{array}$ & $\begin{array}{c}\text { High } \\
\text { High }(30000)\end{array}$ \\
\hline \multicolumn{5}{|c|}{ BRAIN } \\
\hline $\begin{array}{l}\text { MS Lymphoblastic lymphosarcoma } \\
\text { with leukaemic manifestations }\end{array}$ & $0 / 50(0 \%)$ & $0 / 49(0 \%)$ & $1 / 50(2 \%)$ & $0 / 50(0 \%)$ \\
\hline $\begin{array}{l}\text { MS Lymphoblastic lymphosarcoma } \\
\text { with leukaemic manifestations }\end{array}$ & $\begin{array}{r}\mathrm{HE} \\
0 / 50(0 \%)\end{array}$ & $0 / 50(0 \%)$ & $2 / 50(4 \%)$ & $0 / 49(0 \%)$ \\
\hline \multicolumn{5}{|l|}{ 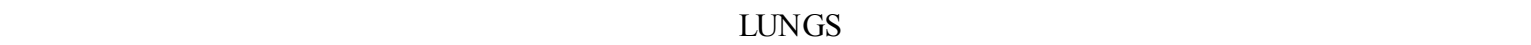 } \\
\hline BN Bronchiolar-alveolar adenoma & $10 / 49(20 \%)$ & $9 / 50(18 \%)$ & $10 / 49(20 \%)$ & $1 / 50(2 \%)$ \\
\hline MG Bronchiolar-alveolar adenocarcinoma & $1 / 49(2 \%)$ & $3 / 50(6 \%)$ & $4 / 49(8 \%)$ & $4 / 50(8 \%)$ \\
\hline BN Granulosa cell tumour & $0 / 49(0 \%)$ & $1 / 50(2 \%)$ & $0 / 49(0 \%)$ & $0 / 50(0 \%)$ \\
\hline MS Lymphoblastic lymphosarcoma & $1 / 49(2 \%)$ & $2 / 50(4 \%)$ & $5 / 49(10 \%)$ & $1 / 50(2 \%)$ \\
\hline $\begin{array}{l}\text { with leukaemic manifestations } \\
\text { MS Lymphoblastic lymphosarcoma }\end{array}$ & $\begin{array}{r}0 / 50(0 \%) \\
\text { LI }\end{array}$ & $0 / 50(0 \%)$ & $0 / 49(0 \%)$ & $1 / 50(2 \%)$ \\
\hline MG Hepatocellular adenocarcinoma & $1 / 49(2 \%)$ & $2 / 50(4 \%)$ & $1 / 49(2 \%)$ & $0 / 49(0 \%)$ \\
\hline BN Hepatocellular adenoma & $0 / 49(0 \%)$ & $1 / 50(2 \%)$ & $0 / 49(0 \%)$ & $0 / 49(0 \%)$ \\
\hline MS Leiomyosarcoma & $0 / 49(0 \%)$ & $1 / 50(2 \%)$ & $0 / 49(0 \%)$ & $0 / 49(0 \%)$ \\
\hline MS Granulocytic leukaemia & $0 / 49(0 \%)$ & $3 / 50(6 \%)$ & $0 / 49(0 \%)$ & $0 / 49(0 \%)$ \\
\hline MG Hemangioendiothelioma & $0 / 49(0 \%)$ & $0 / 50(0 \%)$ & $2 / 49(4 \%)$ & $0 / 49(0 \%)$ \\
\hline MS Composite lymphosarcoma & $2 / 49(4 \%)$ & $1 / 50(2 \%)$ & $0 / 49(0 \%)$ & $4 / 49(8 \%)$ \\
\hline $\begin{array}{l}\text { MS Lymphoblastic lymphosarcoma } \\
\text { with leukaemic manifestations }\end{array}$ & $1 / 49(2 \%)$ & $4 / 50(8 \%)$ & $4 / 49(8 \%)$ & $1 / 49(2 \%)$ \\
\hline \multicolumn{5}{|c|}{ MESENTERIC LYMPH NODES } \\
\hline MS Leimyosarcoma & $0 / 49(0 \%)$ & $1 / 49(2 \%)$ & $0 / 48(0 \%)$ & $0 / 48(0 \%)$ \\
\hline MS Granulocytic leukaemia & $0 / 49(0 \%)$ & $1 / 49(2 \%)$ & $0 / 48(0 \%)$ & $0 / 48(0 \%)$ \\
\hline MG Lymphoblastic lymphosarcoma & $0 / 49(0 \%)$ & $3 / 49(6 \%)$ & $1 / 48(2 \%)$ & $1 / 48(2 \%)$ \\
\hline $\begin{array}{l}\text { with leukaemic manifestations } \\
\text { MS Lymphoblastic lymphosarcoma } \\
\text { with leukaemic manifestations }\end{array}$ & $1 / 49(2 \%)$ & $1 / 49(2 \%)$ & $3 / 48(6 \%)$ & $0 / 48(0 \%)$ \\
\hline MS Composite lymphosarcoma & $1 / 49(2 \%)$ & $1 / 49(2 \%)$ & $1 / 48(2 \%)$ & $3 / 48(6 \%)$ \\
\hline MG Lymphoblastic lymphosarcoma & $0 / 49(0 \%)$ & $0 / 48(0 \%)$ & $0 / 48(0 \%)$ & $2 / 48(4 \%)$ \\
\hline MS Lymphoblastic lymphosarcoma & $0 / 49(0 \%)$ & $0 / 49(0 \%)$ & $0 / 49(0 \%)$ & $1 / 49(2 \%)$ \\
\hline MS Haemangioendothelioma & $0 / 49(0 \%)$ & $0 / 49(0 \%)$ & $0 / 49(0 \%)$ & $1 / 49(2 \%)$ \\
\hline
\end{tabular}


Table A8. Incidence of neoplastic findings in female mice with glyphosate administered by diet. Part II. From Knezevich \& Hogan, 1983 [18]. BN = Benign, MG = Malignant, MS = Metastatic.

\begin{tabular}{|c|c|c|c|c|}
\hline Glyphosate (ppm) & $\begin{array}{c}\text { Controls } \\
0\end{array}$ & $\begin{array}{c}\text { Low } \\
\text { Low }(1000)\end{array}$ & $\begin{array}{c}\text { Mid } \\
\operatorname{Mid}(5000)\end{array}$ & $\begin{array}{c}\text { High } \\
\text { High }(30000)\end{array}$ \\
\hline \multicolumn{5}{|c|}{ MEDIASTINAL LYMPH NODES } \\
\hline MS Leimyosarcoma & $0 / 42(0 \%)$ & $1 / 48(2 \%)$ & $0 / 39(0 \%)$ & $0 / 47(0 \%)$ \\
\hline MS Granulocytic leukaemia & $0 / 42(0 \%)$ & $1 / 48(2 \%)$ & $0 / 39(0 \%)$ & $0 / 47(0 \%)$ \\
\hline MS Liposarcoma & $1 / 42(2 \%)$ & $0 / 48(0 \%)$ & $0 / 39(0 \%)$ & $0 / 47(0 \%)$ \\
\hline MS Composite lymphosarcoma & $1 / 42(2 \%)$ & $1 / 48(2 \%)$ & $0 / 39(0 \%)$ & $2 / 47(4 \%)$ \\
\hline MS Lymphoblastic lymphosarcoma & $0 / 42(0 \%)$ & $1 / 48(2 \%)$ & $3 / 39(8 \%)$ & $0 / 47(0 \%)$ \\
\hline $\begin{array}{l}\text { with leukaemic manifestations } \\
\text { MG Lymphoblastic lymphosarcoma } \\
\text { with leukaemic manifestations }\end{array}$ & $1 / 42(2 \%)$ & $1 / 48(2 \%)$ & $2 / 39(5 \%)$ & $0 / 47(0 \%)$ \\
\hline MS Lymphoblastic lymphosarcoma & SALIVARY GLAND & $\begin{array}{l}1 / 48(2 \%) \\
\text { GLAND }\end{array}$ & $0 / 39(0 \%)$ & $1 / 47(2 \%)$ \\
\hline MS Leiomyosarcoma & $0 / 50(0 \%)$ & $0 / 50(0 \%)$ & $1 / 50(2 \%)$ & $0 / 47(0 \%)$ \\
\hline MG Hemangio-endothelioma & $1 / 50(2 \%)$ & $0 / 48(0 \%)$ & $2 / 49(4 \%)$ & $1 / 49(2 \%)$ \\
\hline MG Granulocytic leukemia & $0 / 50(0 \%)$ & $3 / 48(6 \%)$ & $0 / 49(0 \%)$ & $0 / 49(0 \%)$ \\
\hline MS Hemangio-endiothelioma & $0 / 50(0 \%)$ & $0 / 48(0 \%)$ & $0 / 49(0 \%)$ & $1 / 49(2 \%)$ \\
\hline $\begin{array}{l}\text { MS Lymphoblastic lymphosarcoma } \\
\text { with leukaemic manifestations }\end{array}$ & $1 / 50(2 \%)$ & $2 / 48(4 \%)$ & $2 / 49(4 \%)$ & $0 / 49(0 \%)$ \\
\hline MG Lymphoblastic lymphosarcoma & $0 / 50(0 \%)$ & $0 / 48(0 \%)$ & $2 / 49(4 \%)$ & $0 / 49(0 \%)$ \\
\hline $\begin{array}{l}\text { with leukaemic manifestations } \\
\text { MG Composite lymphosarcoma }\end{array}$ & $1 / 50(2 \%)$ & $1 / 48(2 \%)$ & $1 / 49(2 \%)$ & $5 / 4910 \%)$ \\
\hline MS Lymphoblastic lymphosarcoma & $0 / 50(0 \%)$ & $0 / 48(0 \%)$ & $0 / 49(0 \%)$ & $1 / 49(2 \%)$ \\
\hline \multicolumn{5}{|c|}{ STOMACH } \\
\hline MG Leiomyosarcoma & $0 / 48(0 \%)$ & $0 / 49(0 \%)$ & $1 / 50(2 \%)$ & $0 / 50(0 \%)$ \\
\hline MG Gastric adenosarcoma & $0 / 48(0 \%)$ & $0 / 49(0 \%)$ & $1 / 50(2 \%)$ & $0 / 50(0 \%)$ \\
\hline \multicolumn{5}{|c|}{ PANCREAS } \\
\hline MS Granulocytic leukaemia & $0 / 47(0 \%)$ & $1 / 47(2 \%)$ & $0 / 49(0 \%)$ & $0 / 50(0 \%)$ \\
\hline MS Composite lymphosarcoma & $2 / 47(4 \%)$ & $1 / 47(2 \%)$ & $0 / 49(0 \%)$ & $1 / 50(2 \%)$ \\
\hline $\begin{array}{l}\text { MS Lymphoblastic lymphosarcoma } \\
\text { with leukaemic manifestations }\end{array}$ & $1 / 47(2 \%)$ & $1 / 47(2 \%)$ & $1 / 49(2 \%)$ & $0 / 50(0 \%)$ \\
\hline \multicolumn{5}{|c|}{ KIDNEYS } \\
\hline MS Leiomyosarcoma & $0 / 50(0 \%)$ & $1 / 50(2 \%)$ & $0 / 50(0 \%)$ & $0 / 50(0 \%)$ \\
\hline MS Granulocytic leukaemia & $0 / 50(0 \%)$ & $1 / 50(2 \%)$ & $0 / 50(0 \%)$ & $0 / 50(0 \%)$ \\
\hline MS Composite lymphosarcoma & $2 / 50(4 \%)$ & $1 / 50(2 \%)$ & $1 / 50(2 \%)$ & $2 / 50(4 \%)$ \\
\hline $\begin{array}{l}\text { MS Lymphoblastic lymphosarcoma } \\
\text { with leukaemic manifestations }\end{array}$ & $1 / 50(2 \%)$ & $2 / 50(4 \%)$ & $3 / 50(6 \%)$ & $1 / 50(2 \%)$ \\
\hline MS Lymphoblastic lymphosarcoma & $0 / 50(0 \%)$ & $0 / 50(0 \%)$ & $0 / 50(0 \%)$ & $1 / 50(2 \%)$ \\
\hline
\end{tabular}


Table A9. Incidence of neoplastic findings in female mice with glyphosate administered by diet. Part III. From Knezevich \& Hogan, 1983 [18]. BN = Benign, $\mathrm{MG}=$ Malignant, MS = Metastatic.

\begin{tabular}{|c|c|c|c|c|}
\hline Glyphosate (ppm) & $\begin{array}{c}\text { Controls } \\
0 \\
\end{array}$ & $\begin{array}{c}\text { Low } \\
\text { Low }(1000)\end{array}$ & $\begin{array}{c}\text { Mid } \\
\operatorname{Mid}(5000)\end{array}$ & $\begin{array}{c}\text { High } \\
\text { High }(30000)\end{array}$ \\
\hline \multicolumn{5}{|c|}{ URINARY BLADDER } \\
\hline MS Granulocytic leukaemia & $0 / 47(0 \%)$ & $1 / 43(2 \%)$ & $0 / 49(0 \%)$ & $0 / 48(0 \%)$ \\
\hline MS Composite lymphosarcoma & $1 / 47(2 \%)$ & $1 / 43(2 \%)$ & $0 / 49(0 \%)$ & $0 / 48(0 \%)$ \\
\hline MS Lymphoblastic lymphosarcoma & $1 / 47(2 \%)$ & $2 / 43(4 \%)$ & $2 / 49(4 \%)$ & $0 / 48(0 \%)$ \\
\hline \multicolumn{5}{|c|}{ OVARIES } \\
\hline MG Teratoma & $0 / 47(0 \%)$ & $1 / 47(2 \%)$ & $0 / 50(0 \%)$ & $0 / 47(0 \%)$ \\
\hline MG Granulosa cell tumour & $0 / 47(0 \%)$ & $1 / 47(2 \%)$ & $0 / 50(0 \%)$ & $0 / 47(0 \%)$ \\
\hline MS Leiomyosarcoma & $0 / 47(0 \%)$ & $1 / 47(2 \%)$ & $0 / 50(0 \%)$ & $0 / 47(0 \%)$ \\
\hline $\begin{array}{l}\text { MS Lymphoblastic lymphosarcoma } \\
\text { with leukaemic manifestations }\end{array}$ & $0 / 47(0 \%)$ & $1 / 47(2 \%)$ & $0 / 50(0 \%)$ & $0 / 47(0 \%)$ \\
\hline MS/BN Lymphoblastic lymphosar- & $1 / 47(2 \%)$ & $0 / 47(0 \%)$ & $2 / 50(4 \%)$ & $0 / 47(0 \%)$ \\
\hline \multicolumn{5}{|c|}{ UTERUS } \\
\hline MS Leiomyoma & $2 / 49(4 \%)$ & $1 / 48(2 \%)$ & $1 / 49(2 \%)$ & $1 / 50(2 \%)$ \\
\hline MG Leiomyosarcoma & $2 / 49(4 \%)$ & $3 / 48(6 \%)$ & $2 / 49(4 \%)$ & $3 / 50(6 \%)$ \\
\hline MG Endometrial stromal cell carcinoma & $0 / 49(0 \%)$ & $1 / 48(2 \%)$ & $0 / 49(0 \%)$ & $0 / 50(0 \%)$ \\
\hline MS Haemangioma & $0 / 49(0 \%)$ & $1 / 48(2 \%)$ & $0 / 49(0 \%)$ & $0 / 50(0 \%)$ \\
\hline MG Haemangio-endiothelioma & $0 / 49(0 \%)$ & $0 / 48(0 \%)$ & $0 / 49(0 \%)$ & $1 / 50(0 \%)$ \\
\hline MS Lymphoblastic lymphosarcoma & $0 / 49(0 \%)$ & $3 / 48(6 \%)$ & $1 / 49(2 \%)$ & $0 / 50(0 \%)$ \\
\hline \multicolumn{2}{|c|}{ CERVIX } & & & \\
\hline MG Leiomyosarcoma & $0 / 0(0 \%)$ & $2 / 2(100 \%)$ & $0 / 0(0 \%)$ & $0 / 1(0 \%)$ \\
\hline \multicolumn{5}{|c|}{ THYROID } \\
\hline MS Follicular adenoma & $0 / 43(0 \%)$ & $0 / 37(0 \%)$ & $1 / 49(2 \%)$ & $0 / 48(0 \%)$ \\
\hline \multicolumn{5}{|c|}{ SKIN } \\
\hline MG Fibrosarcoma & $0 / 45(0 \%)$ & $1 / 45(2 \%)$ & $1 / 49(2 \%)$ & $0 / 48(0 \%)$ \\
\hline \multicolumn{5}{|c|}{ MAMMARY } \\
\hline MG Ductal adenocarcinoma & $2 / 38(5 \%)$ & $4 / 36(11 \%)$ & $2 / 40(5 \%)$ & $1 / 38(3 \%)$ \\
\hline MS Lymphoblastic lymphosarcoma & $0 / 38(0 \%)$ & $0 / 36(0 \%)$ & $1 / 40(3 \%)$ & $0 / 38(0 \%)$ \\
\hline \multicolumn{5}{|c|}{ BONE MARROW } \\
\hline MS Lymphoblastic lymphosarcoma & $0 / 46(0 \%)$ & $1 / 49(2 \%)$ & $3 / 47(6 \%)$ & $1 / 49(2 \%)$ \\
\hline with leukaemic manifestations & & & & \\
\hline MS Lymphoblastic lymphosarcoma & $0 / 46(0 \%)$ & $0 / 49(0 \%)$ & $0 / 47(0 \%)$ & $2 / 49(4 \%)$ \\
\hline MS Composite lymphosarcoma & $0 / 46(0 \%)$ & $0 / 49(0 \%)$ & $0 / 47(0 \%)$ & $1 / 49(2 \%)$ \\
\hline
\end{tabular}




\section{ACKNOWLEDGMENTS}

This work benefited from discussions with Yi-Wan Chen, Nancy Swanson, Bob Davidson, James Beecham and Gerry Koenig. This work was funded in part by Quanta Computers, Taipei, Taiwan, under the auspices of the Qmulus Project.

\section{REFERENCES}

1. Swanson, N.L., Leu, A., Abrahamson, J. \& Wallet, B. Genetically engineered crops, glyphosate and the deterioration of health in the United States of America. $J$. Organic Systems 9 (2014) 6-37.

2. World Health Organization. IARC Monographs Volume 112: Evaluation of Five Organophosphate Insecticides and Herbicides. (20 March 2015).

3. Guyton, K.Z., Loomis, D., Grosse, Y., El Ghissassi F., Benbrahim-Tallaa, L., Guha, N., Scoccianti, C., Mattock, H. \& Straif, K., on behalf of the International Agency for Research on Cancer Monograph Working Group, IARC, Lyon, France. Carcinogenicity of tetrachlorvinphos, parathion, malathion, diazinon, and glyphosate. The Lancet 16 (2015) 490-491.

4. Jayasumana, C., Gunatilake, S. \& Senanayake, P. Glyphosate, hard water and nephrotoxic metals: Are they the culprits behind the epidemic of chronic kidney disease of unknown etiology in Sri Lanka? Int. J. Environ. Res. Public Health 11 (2014) 2125-2147.

5. Jayasumana, C., Paranagama, P., Agampodi, S., Wijewardane, C., Gunatilake, S. \& Siribaddana, S. Drinking well water and occupational exposure to Herbicides is associated with chronic kidney disease, in Padavi-Sripura, Sri Lanka. Environ. Health 14(2015) 6.

6. Stengel, B. Chronic kidney disease and cancer: a troubling connection. J. Nephrol. 23 (2010) 253-262.

7. Séralini, G.E., Clair, E., Mesnage, R., Defarge, N., Malatesta, M., Hennequin, D. \& Spiroux de Vendômois, J. Republished study: Long-term toxicity of a Roundup herbicide and a Roundup-tolerant genetically modified maize. Environ. Sci. Eur. 26 (2014) 14.

8. Miller, K. Estrogen and DNA damage: The silent source of breast cancer? Natl Cancer Inst. 95 (2003) 100-102.

9. Thongprakaisang, S., Thiantanawat, A., Rangkadilok, N., Suriyo, T. \& Satayavivad, J. Glyphosate induces human breast cancer cells growth via estrogen receptors. Food Chem. Toxicol. 39 (2013) 129-136.

10. Vandenberg, L.N., Colborn, T., Hayes, T.B., Heindel, J.J., Jacobs, D.R. Jr., Lee, D.- H., Shioda, T., Soto, A.M., vom Saal, F.S., Welshons, W.V., Zoeller, T.Z. \& Myers, J.P. Hormones and endocrine-disrupting chemicals: Low-dose effects and nonmonotonic dose responses. Endocr. Rev. 33 (2012) 378-455.

11. Samsel, A. \& Seneff, S. Glyphosate's suppression of cytochrome P450 enzymes and amino acid biosynthesis by the gut microbiome: pathways to modern diseases. Entropy 15(2013) 1416-1463.

12. Balkwill, F., Charles, K.A. \& Mantovani, A. Smoldering and polarized inammation in the initiation and promotion of malignant disease. Cancer Cell 7 (2005) 211-217.

13. Monsanto. A three-generation reproduction study in rats with glyphosate. Final Report. Bio/dynamics Project No.
77-2063. Submitted to EPA for evaluation. (31 March 1981).

14. Monsanto. Addendum to pathology report for a threegeneration reproduction study in rats with glyphosate. R.D. \#374; Special Report MSL-1724. EPA Registration No 524-308, Action Code 401. Accession No 247793. CASWELL\#661A. (6 July 1982).

15. Stout, L.D. \& Ruecker, F.A. Chronic study of glyphosate administered in feed to albino rats. Unpublished Study, Project No. MSL-10495. Monsanto Agricultural Company (2,175 pp.) EPAMRID 416438-01 (26 September 1990).

16. Hogan, G.K. \& Knezevich, A.L. A chronic feeding study of glyphosate (Roundup technical) in mice. Unpublished Study No. BDN-77420, Project No 77-2061. Bio/dynamics Inc for Monsanto (3,419 pp.) Accession \#251007-251014 MRID 130406(1983).

17. Lankas, G.R. and Hogan, G.K. A lifetime feeding study of glyphosate (Roundup technical) in rats Project \#77-2062. (Unpublished study received 20 January 1982 under 524308; Bio/dynamics Inc., submitted by Monsanto to the EPA. Includes the studys 4-volume Quality Control evaluation of the Bio/dynamics assessment performed by Experimental Pathology Laboratories, Inc. (2,914 pp.) CDL:246617-A; 246618; 246619; 246620; 246621). MRID 00093879 .

18. Knezevich, A.L. \& Hogan, G.K. A chronic feeding study of glyphosate (Roundup technical) in mice. Project \# 772061. (Unpublished study received 29 January 1982 under 524-308; prepared by Bio/dynamics, Inc., submitted by Monsanto to EPA Washington, DC., CDL:246617-A; 246618; 246619; 246620; 246621). MRID \#00093879(1983).

19. Nakatsuji, S., Yamate, J. \& Sakuma, S. Macrophages, myofibroblasts, and extracellular matrix accumulation in interstitial fibrosis of chronic progressive nephropathy in aged rats. Vet. Pathol. 35 (1998) 352-360.

20. Shimizu, A., Masuda, Y., Ishizaki, M., Sugisaki, Y. \& Yamanaka, N. Tubular dilatation in the repair process of ischaemic tubular necrosis. Virchows Arch. 425 (1994) 281-290.

21. Meyer, T.W. Tubular injury in glomerular disease. Kidney Intl 63 (2003) 774-787.

22. Niendorf, E.R., Parker, J.A., Yechoor, V., Garber, J.R. \& Boiselle, P.M. Thymic hyperplasia in thyroid cancer patients. J. Thoracic Imaging. 20 (2005) 1-4.

23. Lee, D.K., Hakim, F.T. \& Gress, R.E. The thymus and the immune system: Layered levels of control. J. Thoracic Oncol. 5 (10, Suppl 4) (2010) S273-S276.

24. European Commission. Guidance document for GLP inspectors and GLP test facilities. Version 2, 2004-11-26/ MPA-RH.

25. Ridley, W.P. \& Mirly, K. The metabolism of glyphosate in Sprague Dawley rats. Part I. Excretion and tissue distribution of glyphosate and its metabolites following intravenous and oral administration. (Unpublished study MSL-7215 conducted by Monsanto's Environmental Health Laboratory and submitted to the EPA July 1988) MRID\#407671-01.(1988).

26. Howe, R.K., Chott, R.C. \& McClanahan, R.H. The metabolism of glyphosate in Sprague Dawley rats. Part II. Identification, characterization and quantification of glyphosate and its metabolites after intravenous and oral administration. (Unpublished study MSL-7206 conducted by Monsanto and submitted to the EPA July 1988) MRID\#407671-02.(1988). 
27. Colvin, L.B., Moran, S.J. \& MIller, J.A. Final report on CP 67573 residue and metabolism. Part 11 . The metabolism of aminomethylphosphonic acid-14C(CP 50435- 14C) in laboratory rat. Monsanto Commercial Products Co. Agricultural Research Report No. 303 (1973); EPA Accession No. 93849.

28. Sutherland, M.L. Metabolism of N-nitrosophosphonomethylglycine in the laboratory rat. Monsanto Final Report No. MSL-0242 (1978); EPAAccession No. 233913.

29. Mesnage, R., Defarge, N., Rocque, L.-M., Spiroux de Vendômois, J. \& Séralini, G.- E. Laboratory rodent diets contain toxic levels of environmental contaminants: Implications for regulatory tests. PLOS ONE $\mathbf{1 0}$ (2015) e0128429.

30. Dixon, D., Heider, K. \& Elwell, M.R. Incidence of nonneoplastic lesions in historical control male and female Fischer-344 rats from 90-day toxicity studies. Toxicol. Pathol. 23 (1995) 338-348.

31. Korc, M. (1983) Manganese action on pancreatic protein synthesis in normal and diabetic rats. Am. J. Physiol. 245 Part 1 (1983) G628-34.

32. Dosselaere, F. \& Vanderleyden, J. A metabolic node in action: Chorismate-utilizing enzymes in microorganisms. Crit. Rev. Microbiol. 27 (2001) 75-131.

33. Yi, K. Folate and DNA methylation: A mechanistic link between folate deficiency and colorectal cancer? Cancer Epidemiol. Biomarkers Prevention 13 (2004) 511-519.

34. Duthie, S.J. Folic acid deficiency and cancer: Mechanisms of DNA instability. Br. Med. Bull. 55 (1999) 578-592.

35. Sclapari, T.S., Bramati, V. \& Erba, A. New uses of choline chloride in agrochemical formulations. European Patent Application Number 11305356.5 (10 March 2012).

36. Richman, E.L., Kenfield, S.A., Stampfer, M.J., Giovannucci, E.L., Zeisel, S.H., Willett, W.C. \& Chan, J.M. Choline intake and risk of lethal prostate cancer: incidence and survival. Am. J. Clin. Nutr. 96 (2012) 855-863.

37. Marc, J., Mulner-Lorillon, O. \& Bellé, R. Glyphosatebased pesticides affect cell cycle regulation. Biol. Cell 96 (2004) 245-249.

38. How, V., Hashim, Z., Ismail, P., Md Said, S., Omar, D. \& Bahri Mohd Tamrin, S. Exploring cancer development in adulthood: cholinesterase depression and genotoxic effect from chronic exposure to organophosphate pesticides among rural farm children. J. Agromed. 19 (2014) 35-43.

39. Modesto, K.A. \& Martinez, C.B.R. Roundup causes oxidative stress in liver and inhibits acetylcholinesterase in muscle and brain of the fish Prochilodus lineatus. Chemosphere 78 (2010) 294-299.

40. Bolognesi, C., Bonatti, S., Degan, P., Gallerani, E., Peluso, M., Rabboni, R., Roggieri, P. \& Abbondandolo, A. Genotoxic activity of glyphosate and its technical formulation Roundup. J. Agric. Food Chem. 45 (1997) 1957-1962.

41. Braz-Mota, S., Sadauskas-Henrique, H., Duarte, R.M., Val, A.L. \& Almeida-Val, V.M. Roundup exposure promotes gills and liver impairments, DNA damage and inhibition of brain cholinergic activity in the Amazon teleost fish Colossoma macropomum. Chemosphere 135 (2015) 53-60.

42. Cavas, T. \& Köen, S. Detection of cytogenetic and DNA damage in peripheral erythrocytes of goldfish (Carassius auratus) exposed to a glyphosate formulation using the micronucleus test and the comet assay. Mutagenesis 22 (2007) 263-268.

43. Guilherme, S., Santos, M.A., Barroso, C., Gaivão, I. \& Pacheco, M. Differential genotoxicity of Roundup formulation and its constituents in blood cells of fish (Anguilla anguilla): considerations on chemical interactions and DNA damaging mechanisms. Ecotoxicology 21 (2012) 1381-1390.

44. Guilherme, S., Gaiväo, I., Santos, M.A.\& Pacheco, M. European eel (Anguilla anguilla) genotoxic and prooxidant responses following short-term exposure to Roundup glyphosate-based herbicide. Mutagenesis 25 (2010) 523-530.

45. Ames, B.N. DNA damage from micronutrient deficiencies is likely to be a major cause of cancer. Mutation Res.475 (2001) 7-20.

46. Rossi, M., Amaretti, A. \& Raimondi, S. Folate production by probiotic bacteria. Nutrients 3 (2011) 118-134.

47. Shehata, A.A., Schrödl, W., Aldin, A.A., Hafez, H.M. \& Krüger, M. The effect of glyphosate on potential pathogens and beneficial members of poultry microbiota in vitro. Curr. Microbiol. 66 (2013) 350-358.

48. Lu, W., Li, L., Chen, M., Zhou, Z., Zhang, W., Ping, S., Yan, Y., Wang, J. \& Lin, M. Genome-wide transcriptional responses of Escherichia coli to glyphosate, a potent inhibitor of the shikimate pathway enzyme 5-enolpyruvylshikimate-3phosphate synthase. Mol. Biosys. 9 (2013) 522-530.

49. Benachour, N. \& Séralini G.-E. Glyphosate formulations induce apoptosis and necrosis in human umbilical, embryonic, and placental cells. Chem. Res. Toxicol. 22 (2009) 97-105

50. Richard, S., Moslemi, S., Sipahutar, H., Benachour, N. \& Séralini, G.E. Differential effects of glyphosate and Roundup on human placental cells and aromatase. Environ. Health Perspect. 113 (2005) 716-720.

51. Benachour, N., Sipahutar, H., Moslemi, S., Gasnier, C., Travert, C., and Séralini, G.E. Time and dose-dependent effects of Roundup on human embryonic and placental cells and aromatase inhibition. Arch. Environ. Contam. Toxicol. 53 (2007) 126-133.

52. Ugarte, R. Interaction between glyphosate and mitochondrial succinate dehydrogenase. Computational Theor. Chem. 1043 (2014) 54-63.

53. Peixoto, F. Comparative effects of the Roundup and glyphosate on mitochondrial oxidative phosphorylation. Chemosphere 61 (2005) 1115-1122.

54. King, A., Selak, M.A. \& Gottlieb, E. Succinate dehydrogenase and fumarate hydratase: Linking mitochondrial dysfunction and cancer. Oncogene 25 (2006) 4675-4682.

55. Woods, W.G., Gao, R.N., Shuster, J.J., Robison, L.L., Bernstein, M., Weitzman, S., Bunin, G., Levy, I., Brossard, J., Dougherty, G., Tuchman, M. \& Lemieux, B. Screening of infants and mortality due to neuroblastoma. N. Engl. J. Med. 346 (2002) 1041-1046.

56. Rapizzi, E., Ercolino, T., Fucci, R., Zampetti, B., Felici, R., Guasti, D., Morandi, A., Giannoni, E., Giaché, V., Bani, D., Chiarugi, A. \& Mannelli, M. Succinate dehydrogenase subunit B mutations modify human neuroblastoma cell metabolism and proliferation. Hormones Cancer 5 (2014) 174-184.

57. Warburg, O. On the origin of cancer cells. Science $\mathbf{1 2 3}$ (1956) 309-314. 
58. Kim, J.W. \& Dang, C.V. Cancer's molecular sweet tooth and the Warburg effect. Cancer Res. 66 (2006) 8927-8930.

59. Rippert, P., Scimemi, C., Dubald, M. \& Matringe, M. Engineering plant shikimate pathway for production of tocotrienol and improving herbicide resistance. Plant Physiol. 134 (2004) 92-100.

60. Cleary C.M., Moreno, J.A., Fernández, B., Ortiz,A., Parra, E.G., Gracia, C., Blanco- Colio, L.M., Barat, A. \& Egido, J. Glomerular haematuria, renal interstitial haemorrhage and acute kidney injury. Nephrol. Dialysis Transplantation $\mathbf{2 5}$ (2010) 4103-4106.

61. Nagababu, E., Chrest, F.J. \& Rifkind, J.M. Hydrogenperoxide-induced heme degradation in red blood cells: The protective roles of catalase and glutathione peroxidase. Biochim Biophys Acta. 1620 (2003) 211-217.

62. Ayala, A.,Muñoz, M.F. \& Argüelles, S. Lipid peroxidation: Production, metabolism, and signaling mechanisms of malondialdehyde and 4-hydroxy-2-nonenal. Oxidative Med. Cellular Longevity 2014 (2014) 360438.

63. Nielsen, F., Mikkelsen, B.B., Nielsen, J.B., Andersen, H.R. \& Grandjean, P. Plasma malondialdehyde as biomarker for oxidative stress: reference interval and effects of lifestyle factors. Clin. Chem. 43 (1997) 1209-1214.

64. Beuret, C.J., Zirulnik, F. \& Giménez, M.S. Effect of the herbicide glyphosate on liver lipoperoxidation in pregnant rats and their fetuses. Reprod. Toxicol. 19 (2005) 501-504.

65. Desai, K.M., Chang, T., Wang, H., Banigesh, A., Dhar, A., Liu, J., Untereiner, A. \& Wu, L. Oxidative stress and aging: Is methylglyoxal the hidden enemy? Can. J. Physiol. Pharmacol. 88(2010) 273-284.

66. Wang, Y. \& Ho. C.T. Flavour chemistry of methylglyoxal and glyoxal. Chem. Soc. Rev. 41 (2012) 4140-4149.

67. Stopper, H., Schinzel, R., Sebekova, K. \& Heidland, A. Genotoxicity of advanced glycation end products in mammalian cells. Cancer Lett. 190 (2003) 151-156.

68. Tan, D., Wang, Y., Lo, C.Y. \& Ho, C.T. Methylglyoxal: Its presence and potential scavengers. Asia Pacific J. Clin. Nutr. 17 (Suppl 1) (2008) 261-264.

69. Alibhai, M.F. \& Stallings, W.C. Closing down on glyphosate inhibition with a new structure for drug discovery. Proc. Natl Acad. Sci. USA 98 (2001) 2944-2946.

70. Grüning, N.M., Du, D., Keller, M.A., Luisi, B.F. \& Ralser, M. Inhibition of triosephosphate isomerase by phosphoenolpyruvate in the feedback-regulation of glycolysis. Open Biol. 4 (2014) 130232.

71. Fraenkel, D.G. The phosphoenolpyruvate-initiated pathway of fructose metabolism in Escherichia coli. J. Biol. Chem. 243(24) (1968) 6458-6463.

72. Richard, J.P. Mechanism for the formation of methylglyoxal from triosephosphates. Biochem. Soc. Trans. 21 (1993) 549-553.

73. Ahmed, N., Battah, S., Karachalias, N., Babaei-Jadidi, R., Horányi, M., Baróti, K., Hollan, S. \& Thornalley, P.J. Increased formation of methylglyoxal and protein glycation, oxidation and nitrosation in triosephosphate isomerase deficiency. Biochim. Biophys. Acta 1639 (2003) 121-132.

74. Rabbani, N. \& Thornalley, P.J. The critical role of methylglyoxal and glyoxalase 1 in diabetic nephropathy. Diabetes 63 (2014) 50-52.
75. Rendeiro, C., Masnik, A.M., Mun, J.G., Du, K., Clark, D., Dilger, R.N., Dilger, A.C. \& Rhodes, J.S. Fructose decreases physical activity and increases body fat without affecting hippocampal neurogenesis and learning relative to an isocaloric glucose diet. Sci. Rep. 5 (2015) 9589.

76. Dhar, I., Dhar, A., Wu, L. \& Desai, K.M. Increased methylglyoxal formation with upregulation of renin angiotensin system in fructose fed Sprague Dawley rats. PLoS One 8(2013) e 74212.

77. Papsoulis, A., Al-Abed, Y. \& Bucala, R. Identification of $\mathrm{N}^{2}$-(1-carboxyethyl)guanine (CEG) as a guanine advanced glycosylation end product. Biochemistry 34 (1995) 648-655.

78. Xu, X.C., Brinker, R.J., Reynolds, T.L., Abraham, W. \& Graham, J.A. Pesticide compositions containing oxalic acid. US patent number 6, 992, 045 (2006).

79. Buc, H.A., Demaugre, F., Moncion, A. \& Leroux, J.P. Metabolic consequences of pyruvate kinase inhibition by oxalate in intact rat hepatocytes. Biochimie 63 (1981) 595-602.

80. Okombo, J. \& Liebman, M. Probiotic-induced reduction of gastrointestinal oxalate absorption in healthy subjects. Urol. Res. 38 (2010) 169-178.

81. Svedruzica, D., Jónsson, S., Toyota, C.G., Reinhardt, L.A., Ricagno, S., Lindqvist, Y. \& Richards, N.G.J. The enzymes of oxalate metabolism: unexpected structures and mechanisms. Arch. Biochem. Biophys. 433 (2005) 176-192.

82. Samsel, A. \& Seneff, S. Glyphosate, pathways to modern diseases III: Manganese, neurological diseases, and associated pathologies. Surg. Neurol. Int. 6 (2015) 45.

83. Krüger, M., Schrödl, W., Neuhaus, J. \& Shehata, A.A. Field investigations of glyphosate in urine of Danish dairy cows. J. Environ. Anal. Toxicol. 3 (2013) 17.

84. Nikiforova, V.J., Giesbertz, P., Wiemer, J., Bethan, B., Looser, R., Liebenberg, V., Noppinger, P.R., Daniel, H. \& Rein D. Glyoxylate, a new marker metabolite of type 2 diabetes. $J$. Diabetes Res. 2014 (2014) 685204.

85. Duncan, R.J. \& Tipton, K.F. The oxidation and reduction of glyoxylate by lactic dehydrogenase. Eur. J. Biochem. 11 (1969) 58-61.

86. Novoa, W.B., Winer, A.D., Glaid, A.J. \& Schwert, G.W. Lactic dehydrogenase: V. Inhibition by oxamate and by oxalate. J. Biol. Chem. 234 (1959) 1143-1148.

87. Moser, H. Process for producing N-phosphonomethylglycine. US patent number 4,534,904. (1984).

88. Rogers, TE \& Smith, LR. Process for the preparation of glyphosate and glyphosate derivatives. European Patent Application \#85870195.6. (1985).

89. Pollegioni, L., Schonbrunn, E. \& Siehl, D. Molecular basis of glyphosate resistance-different approaches through protein engineering. FEBS J. 278 (2011) 2753-2766.

90. Shangari, N., Chan, T.S., Popovic, M. \& O’Brien, P.J. Glyoxal markedly compromises hepatocytes resistance to hydrogen peroxide. Biochem. Pharmacol. 71 (2006) 1610-1618.

91. Shangari, N. \& O'Brien, P.J. The cytotoxic mechanism of glyoxal involves oxidative stress. Biochem. Pharmacol. 68(2004) 1433-1442.

92. Johnson, D.E. 21-day dermal toxicity study in rabbits. (Unpublished study 401-168, March 10, 1982 By IRDC, Mattawan, MI) submitted by Monsanto to EPA Washington, DC., MRID\#00098460. 
93. Kalapos, M.P. Methylglyoxal in living organisms: Chemistry, biochemistry, toxicology and biological implications. Toxicol. Lett. 110 (1999) 145-175.

94. de Liz Oliveira Cavalli, V.L., Cattani, D., Heinz Rieg, C.E., Pierozan, P., Zanatta, L., Benedetti Parisotto, E., Wilhelm Filho, D., Mena Barreto Silva, F.R., Pessoa-Pureur, R. \& Zamoner, A. Roundup disrupts male reproductive functions by triggering calciummediated cell death in rat testis and Sertoli cells. Free Radical Biol. Med. 65 (2013) 335-346.

95. Murata-Kamiya, N. \& Kamiya, H. Methylglyoxal, an endogenous aldehyde, crosslinks DNA polymerase and the substrate DNA. Nucl. Acids Res. 29 (2001) 3433-3438.

96. Nagao, M., Fujita, Y., Sugimura, T. \& Kosuge, T. Methylglyoxal in beverages and foods: Its mutagenicity and carcinogenicity. IARC Scientific Publications $\mathbf{7 0}$ (1986) 283-291.

97. Nafziger, E.D., Widholm, J.M., Steinrcken, H.C. \& Killmer, J.L. Selection and characterization of a carrot cell line tolerant to glyphosate. Plant Physiol. 76 (1984) 571-574.

98. Ferla, M.P. \& Patrick, W.M. Bacterial methionine biosynthesis. Microbiology 160 (2014) 1571-1584.

99. Brouwers, O., Niessen, P.M., Ferreira, I., Miyata, T., Scheffer, P.G., Teerlink, T., Schrauwen, P., Brownlee, M., Stehouwer, C.D. \& Schalkwijk, C.G. Overexpression of glyoxalase-I reduces hyperglycemia-induced levels of advanced glycation end products and oxidative stress in diabetic rats. J. Biol. Chem. 286 (2011) 1374-1380.

100. Jain, M., Choudhary, D., Kale, R.K. \& Bhalla-Sarin, N. Saltand glyphosate-induced increase in glyoxalase I activity in cell lines of groundnut (Arachis hypogaea). Physiologia Plantarum 114 (2002) 499-505.

101. Cheng, W.-L., Tsai, M.-M., Tsai, C.-Y., Huang, Y.-H., Chen, C.-Y., Chi, H.-C., Tseng, Y.-H., Chao, I.-W., Lin, W.-C., Wu, S.-M., Liang, Y., Liao, C.-J., Lin, Y.- H., Chung, I.-H., Chen, W.-J., Lin, P.Y., Wang, C.-S. \& Lin, K.-H. Glyoxalase-I is a novel prognosis factor associated with gastric cancer progression. PLoS ONE 7 (2012) e34352.

102. Baunacke, M., Horn, L.C., Trettner, S., Engel, K.M., Hemdan, N.Y., Wiechmann, V., Stolzenburg, J.U., Bigl, M. \& Birkenmeier, G. Exploring glyoxalase 1 expression in prostate cancer tissues: targeting the enzyme by ethyl pyruvate defangs some malignancyassociated properties. Prostate 74 (2014) 48-60.

103. Jemal, A., Siegel, R., Ward, E., Hao, Y., Xu, J., Murray, T. \& Thun, M.J. Cancer statistics. CA Cancer J. Clin. 58 (2008) 71-96.

104. Wu, G.S. Role of mitogen-activated protein kinase phosphatases (MKPs) in cancer. Cancer Metastasis Rev. 26(2007) 579-85.

105. Pickering Laboratories, Inc. Analysis of N-Nitroso Glyphosate in Glyphosate Samples. LCGC (Feb 1, 2010). http://www.chromatographyonline.com/analysis-nnitrosoglyphosate- glyphosate-samples. (Last accessed 12 June 2015).

106.Loh, Y.H., Jakszyn, P., Luben, R.N., Mulligan, A.A., Mitrou, P.N. \& Khaw, K.-T. N-nitroso compounds and cancer incidence: the European Prospective Investigation into Cancer and Nutrition (EPIC) Norfolk Study. Am. J. Clin. Nutr. 93 (2011) 1053-1061.

107. Bogovski, P. \& Bogovski, S. Animal species in which Nnitroso compounds induce cancer. Int. J. Cancer 27 (1981) 471-474.
108. Schmähl, D. \& Habs, M. Carcinogenicity of N-nitroso compounds. Oncology 37 (1980) 237-242.

109. Montesano, R. \& Magee, P.N. Metabolism of dimethylnitrosamine by human liver slices in vitro. Nature (Lond.) 228 (1970) 173-174.

110. Wogan, G.N. \& Tannenbaum, S.R. Environmental Nnitroso compounds: Implications for public health. Toxicol. Appl. Pharmacol. 31 (1975) 375-383.

111. Lijinsky, W. Intestinal cancer induced by N-nitroso compounds. Toxicol. Pathol. 16 (1988) 198-204.

112. Zhu, Y., Wang, P.P., Zhao, J., Green, R., Sun, Z., Roebothan, B., Squires, J., Buehler, S., Dicks, E., Zhao, J., Cotterchio, M., Campbell, P.T., Jain, M., Parfrey, P.S., Mclaughlin, J.R. Dietary N-nitroso compounds and risk of colorectal cancer: a case-control study in Newfoundland and Labrador and Ontario. Br. J. Nutr. 111 (2014) 1109-1117.

113. FAO Specifications and Evaluations for Plant Protection Products: Glyphosate, N-(phosphonomethyl)glycine, (evaluation report 284) (2001).

114. Monsanto Agricultural Products Company, Standard Analytical Method No. AQC-684-86 (1986).

115. Kim, M. Stripeikis, J., Inón, F. \& Tudino, M. A simplified approach to the determination of N-nitroso glyphosate in technical glyphosate using HPLC with post-derivatization and colorimetric detection. Talanta 72 (2007) 1054-1058.

116. Liu, C.-M., McLean, P.A., Sookdeo, C.C. \& Cannon, F.C. Degradation of the herbicide glyphosate by members of the family Rhizobiaceae. Appl. Environ. Microbiol. 57 (1991) 1799-1804.

117. Wogan, GN., Paglialunga, S., Archer, M.C.\& Tannenbaum, S.R. Carcinogenicity of nitrosation products of ephedrine, sarcosine, folic acid, and creatinine. Cancer Res. 35 (1975) 1981-1984.

118. Sreekumar, A., Poisson, L.M., Rajendiran, T.M., Khan, A.P., Cao, Q., Yu, J., Laxman, B., Mehra, R., Lonigro, R.J., Li, Y., et al. Metabolomic profiles delineate potential role for sarcosine in prostate cancer progression. Nature 457 (2009) 910-914.

119. Khan, A.P., Rajendiran, T.M., Ateeq, B., Asangani, I.A., Athanikar, J.N., Yocum, A.K., Mehra, R., Siddiqui, J., Palapattu, G., Wei, J.T., Michailidis, G., Sreekumar, A. \& Chinnaiyan, A.M. The role of sarcosine metabolism in prostate cancer progression. Neoplasia 15 (2013) 491-501.

120. Jemal, A., Bray, F., Center, M.M., Ferlay, J., Ward, E. \& Forman, D. Global cancer statistics. CA Cancer J. Clin. 61 (2011) 69-90.

121. Li, Q., Lambrechts, M.J., Zhang, Q., Liu, S., Ge, D., Yin, R., Xi, M. \& You, Z. Glyphosate and AMPA inhibit cancer cell growth through inhibiting intracellular glycine synthesis. Drug Design Development Therapy 7 (2013) 635-43.

122. Rose, M.L., Cattley, R.C., Dunn, C., Wong, V., Li, X. \& Thurman, R.G. Dietary glycine prevents the development of liver tumors caused by the peroxisome proliferator WY14,643. Carcinogenesis 20 (1999) 2075-81.

123. Yamashina, S., Ikejima, K., Rusyn, I., Sato, N. Glycine as a potent anti-angiogenic nutrient for tumor growth. $J$. Gastroenterol. Hepatol. 22 (Suppl. 1) (2007) S62-64.

124. Lees, H.J., Swann, J.R., Wilson, I.D., Nicholson, J.K. \& Holmes, E. Hippurate: the natural history of a mammalianmicrobial cometabolite. J. Proteome Res. 12 (2013) 1527-1546. 
125. Gregus, Z., Fekete, T., Varga, F. \& Klaassen, C.D. Dependence of glycine conjugation on availability of glycine: role of the glycine cleavage system. Xenobiotica 23 (1993) 141-153.

126. Waldram, A., Holmes, E., Wang, Y., Rantalainen, M., Wilson, I.D., Tuohy, K.M., McCartney, A.L., Gibson, G.R. \& Nicholson, J.K. Top-down systems biology modeling of host metabotype-microbiome associations in obese rodents. J. Proteome Res. 8 (2009) 2361-2375.

127. Calvani, R., Miccheli, A., Capuani, G., Tomassini Miccheli, A., Puccetti, C., Delfini, M., Iaconelli, A., Nanni, G. \& Mingrone, G. Gut microbiome-derived metabolites characterize a peculiar obese urinary metabotype. Int. J. Obesty 34 (2010) 1095-1098.

128. Williams, H.R.T., Cox, I.J., Walker, D.G., North, B.V., Patel, V.M., Marshall, S.E., Jewell, D.P., Ghosh, S., Thomas, H.J.W., Teare, J.P., Jakobovits, S., Zeki, S., Welsh, K.I., Taylor-Robinson, S.D. \& Orchard, T.R. Characterization of inammatory bowel disease with urinary metabolic profiling. Am. J. Gastroenterol. 104 (2009) 1435-1444.

129. Hemminki, K., Li, X., Sundquist J. \& Sundquist, K. Cancer risks in Crohn disease patients. Ann. Oncol. 20(3) (2009) 574-580.

130. Lim, J.S., Mietus-Snyder, M., Valente, A., Schwarz, J.-M. \& Lustig, R.H. The role of fructose in the pathogenesis of NAFLD and the metabolic syndrome. Nature Rev. Gastroentero. Hepatol. 7 (2010) 251-264.

131. Michelotti, G.A., Machado, M.V. \& Diehl, A.M. NAFLD, NASH and liver cancer. Nature Rev. Gastroenterol. Hepatol. 10 (2013) 656-665.

132. Ascha, M.S., Hanouneh, I.A., Lopez, R., Tamimi, T.A., Feldstein, A.F. \& Zein, N.N. The incidence and risk factors of hepatocellular carcinoma in patients with nonalcoholic steatohepatitis. Hepatology 51 (2010) 1972-1978.

133. Fernández-Zamorano, A., Arnalich, F., Codoceo, R., Vigara, M.R., Valverde, F., Jara, P. \& Vázquez, J.J. Hemolytic anemia and susceptibility to hydrogen-peroxide hemolysis in children with vitamin E-deficiency and chronic liver disease. J. Med. 19 (1988) 317-334.

134. Masuda, Y., Ichii, H., Vaziri, N.D. At pharmacologically relevant concentrations intravenous iron preparations cause pancreatic beta cell death. Am. J. Transl. Res. 6 (2014) 64-70.

135. Villeneuve, J.P. \& Pichette, V. Cytochrome P450 and liver diseases. Curr. Drug Metab. 5 (2004) 273-282.

136. Hotamisligil, G.S. Inammation and metabolic disorders. Nature 444 (2006) 860-867.

137. Tsuei, J., Chau, T., Mills, D. \& Wan, Y-J.Y. Bile acid dysregulation, gut dysbiosis, and gastrointestinal cancer. Exp. Biol. Med.239(2014) 1489-1504.

138. Shanab, A.A., Scully, P., Crosbie, O., Buckley, M., O’Mahony, L., Shanahan, F., Gazareen, S., Murphy, E. \& Quigley, E.M. Small intestinal bacterial overgrowth in nonalcoholic steatohepatitis: association with toll-like receptor 4 expression and plasma levels of interleukin 8 . Digestive Dis. Sci. 56 (2011) 1524-1534.

139. Ilan, Y. Leaky gut and the liver: a role for bacterial translocation in nonalcoholic steatohepatitis. World $J$. Gastroenterol. 18 (2012) 2609-2618.

140. Kappas, A., Sassa, S., Galbraith, R.A. \& Nordmann, Y. The porphyrias. In: Scriver, C.R., Beaudet, A.L., Sly, W.S. \&
Valle, D., eds. The Metabolic and Molecular Bases of Inherited Disease. 7th ed. Vol. 2. New York: McGraw-Hill, 2103-59. (1995).

141. Kauppinen, R. \& Mustajoki, P. Acute hepatic porphyria and hepatocellular carcinoma. Br. J. Cancer 57 (1988) 117-20.

142. Andersson, C., Bjersing, L. \& Lithner, F. The epidemiology of hepatocellular carcinoma in patients with acute intermittent porphyria. J. Intern. Med. 240 (1996) 195-201.

143. Hardell, L., Bengtsson, N.O., Jonsson, U., Eriksson, S. \& Larsson, L.G. Aetiological aspects on primary liver cancer with special regard to alcohol, organic solvents and acute intermittent porphyria $\{$ an epidemiological investigation. Br. J. Cancer 50 (1984) 389-397.

144. Kitchen, L.M., Witt, W.W. \& Rieck, C.E. Inhibition of -aminolevulinic acid synthesis by glyphosate. Weed Sci. 29(1981) 571-577.

145. Kitchen, L.M., Witt, W.W. \& Rieck, C.E. Inhibition of chlorophyll accumulation by glyphosate. Weed Science 29(4) (1981) 513-516.

146. Lee, D.H., Blomhoff, R. \& Jacobs, D.R. Jr. Is serum gamma glutamyltransferase a marker of oxidative stress? Free Radical Res. 38 (2004) 535-539.

147. Fentiman, I.S. Gamma-glutamyl transferase: risk and prognosis of cancer. Br. J. Cancer 106 (2012) 1467-1468.

148. Whitfield, J.B. Serum -glutamyltransferase and risk of disease. Clin. Chem. 53 (2007) 1-2.

149. Kazemi-Shirazi, L., Endler, G., Winkler, S., Schickbauer, T., Wagner, O. \& Marsik, C. Gamma glutamyltransferase and long-term survival: Is it just the liver? Clin. Chem. $\mathbf{5 3}$ (2007) 940-946.

150. Mok, Y., Son, D.K., Yun Y.D., Jee, S.H. \& Samet, J.M. Glutamyltransferase and cancer risk: the Korean Cancer Prevention Study. Int. J. Cancer (2015) [Epub ahead of print].

151. Paolicchi, A., Tongiani, R., Tonarelli, P., Comporti, M. \& Pompella, A. gamma-Glutamyl transpeptidase-dependent lipid peroxidation in isolated hepatocytes and HepG2 hepatoma cells. Free Radical Biol. Med. 22 (1997) 853860.

152. Drozdz, R., Parmentier, C., Hachad, H., Leroy, P., Siest, G. \& Wellman, M. gamma-Glutamyltransferase dependent generation of reactive oxygen species from a glutathione/ transferrin system. Free Radical Biol. Med. 25 (1998) 786792.

153. Mastellone, V., Tudisco, R., Monastra, G., Pero, M.E., Calabro, S., Lombardi, P., Grossi, M., Cutrignelli, M.I., Avallone, L. \& Infascelli, F. Gamma-glutamyl transferase activity in kids born from goats fed genetically modified soybean. Food Nutr. Sci. 4 (2013) 50-54.

154. Bohn, T., Cuhra, M., Traavik, T., Sanden, M., Fagan, J. \& Primicerio, R. Compositional differences in soybeans on the market: Glyphosate accumulates in Roundup Ready GM soybeans. Food Chem. 153 (2014) 207-215.

155. Benedetti, A.L., Vituri Cde, L., Trentin, A.G., Domingues, M.A. \& Alvarez-Silva, M. The effects of sub-chronic exposure of Wistar rats to the herbicide GlyphosateBiocarb. Toxicol. Lett. 153 (2004) 227-232.

156. Ala-Kokko, L., Pihlajaniemi, T., Myers, J.C., Kivirikko, K.I. \& Savolainen, E.R. Gene expression of type I, III and IV collagens in hepatic fibrosis induced by dimethylnitrosamine in the rat. Biochem. J. 244 (1987) 75-79. 
157. Hietanen, E., Linnainmaa, K. \& Vainio, H. Effects of phenoxyherbicides and glyphosate on the hepatic and intestinal biotransformation activities in the rat. Acta Pharmacol. Toxicol. 53 (1983) 103-112.

158. Samsel, A. \& Seneff, S. Glyphosate, pathways to modern diseases II: celiac sprue and gluten intolerance. Interdiscip. Toxicol. 6 (2013) 159-184.

159. Qian, L., Zolfaghari, R. \& Ross, A.C. Liver-specific cytochrome P450 CYP2C22 is a direct target of retinoic acid and a retinoic acid-metabolizing enzyme in rat liver. J. Lipid Res. 51(2010) 1781-1792.

160. Helms, J., Thaller, C. \& Eichele, G. Relationship between retinoic acid and sonic hedgehog, two polarizing signals in the chick wing bud. Development 120 (1994) 3267-3274.

161. Philips, G.M., Chan, I.S., Swiderska, M., Schroder, V.T., Guy, C., Karaca, G.F., Moylan, C., Venkatraman, T., Feuerlein, S., Syn, W.-K., Jung, Y., Witek, R.P., Choi, S., Michelotti, G.A., Rangwala, F., Merkle, E., Lascola, C. \& Diehl, A.M. Hedgehog signaling antagonist promotes regression of both liver fibrosis and hepatocellular carcinoma in a murine model of primary liver cancer. PLOS ONE 6 (2011) e23943.

162. Paganelli, A., Gnazzo, V., Acosta, H., López, S.L. \& Carrasco, A.E. Glyphosate-based herbicides produce teratogenic effects on vertebrates by impairing retinoic acid signaling. Chem. Res. Toxicol. 23 (2010) 1586-1595.

163. Jemal, A., Thomas, A., Murray, T. \& Thun, M. Cancer statistics, 2002. CA Cancer J. Clin. 52 (2002) 23-47.

164. Dhar, A., Dhar, I., Jiang, B., Desai, K.M. \& Wu, L. Chronic methylglyoxal injection by minipump causes pancreatic beta-cell dysfunction and induces type 2 diabetes in Sprague Dawley rats. Diabetes 60 (2011) 899-908.

165. Baly, D.L., Curry, D.L., Keen, C.L. \& Hurley, L.S. Effect of manganese deficiency on insulin secretion and carbohydrate homeostasis in rats. J. Nutr. 114 (1984) 1438-1446.

166. Klimstra, D.S., Heffess, C.S., Oertel, J.E. \& Rosai, J. Acinar cell carcinoma of the pancreas: A clinicopathologic study of 28 cases. Am. J. Surg. Pathol. 16 (1992) 815-837.

167. Malatesta, M., Caporaloni, C., Rossi, L., Battistelli, S., Rocchi, M.B.L., Tonucci, F. \& Gazzanelli, G. Ultrastructural analysis of pancreatic acinar cells from mice fed on genetically modified soybean. J. Anat. 201 (2002) 409-415.

168. Brooks, S.E. \& Golden, M.H. The exocrine pancreas in kwashiorkor and marasmus. Light and electron microscopy. West Indian Med. J. 41 (1992) 56-60.

169. Kau, A.L., Planer, J.D., Liu, J., Rao,S., Yatsunenko, T., Trehan, I., Manary, M.J., Liu, T.-C., Stappenbeck, T.S., Maleta, K.M., Ashorn, P., Dewey, K.G., Houpt, E.R., Hsieh, C.-S. \& Gordon, J.I. Functional characterization of IgAtargeted bacterial taxa from undernourished Malawian children that produce diet-dependent enteropathy. Sci. Transl. Med. 7 (276) (2015) 276ra24.

170. United States Environmental Protection Agency. Glyphosate-EPA Registration No. 524-308 - 2-Year Chronic Feeding/Oncogenicity Study in Rats with Technical Glyphosate. (13 December 1991). sustainablepulse.com/ 2015/03/26/who-glyphosate-report-ends-thirtyyear-cancercover-up/\#.VSVPZ2Z3bJk (Last accessed 10 June 2015).

171. US Renal Data Systems. USRDS 2006 Annual Data Report: Atlas of End-Stage Renal Disease in the United States. Bethesda, Maryland: National Institutes of Health,
National Institute of Diabetes and Digestive and Kidney Diseases (2007).

172. Coresh, J., Selvin, E., Stevens, L.A., Manzi, J., Kusek, J.W., Eggers, P., Van Lente F. \& Levey, A.S. Prevalence of chronic kidney disease in the United States. JAMA 298 (2007) 2038-2047.

173. Tian, N., Arany, I., Waxman, D.J. \& Baliga, R. Cytochrome P450 2B1 gene silencing attenuates puromycin aminonucleoside-induced cytotoxicity to glomerular epithelial cells. Kidney Int. 78 (2010) 182-190.

174. Chen, X., Mori, T., Guo, Q., Hu, C., Ohsaki, Y., Yoneki, Y., Zhu, W., Jiang, Y., Endo, S., Nakayama, K., Ogawa, S., Nakayama, M., Miyata, T. \& Ito, S. Carbonyl stress induces hypertension and cardio-renal vascular injury in Dahl salt-sensitive rats. Hypertens. Res. 36 (2013) 361-367.

175. Sule, N., Yakupoglu, U., Shen, S.S., Krishnan, B., Yang, G., Lerner, S., Sheikh-Hamad, D. \& Truong, L.D. Calcium oxalate deposition in renal cell carcinoma associated with acquired cystic kidney disease: A comprehensive study. Am. J. Surg. Pathol. 29 (2005) 443-451.

176. Rioux-Leclercq, N.C. \& Epstein, J.I. Renal cell carcinoma with intratumoral calcium oxalate crystal deposition in patients with acquired cystic disease of the kidney. Arch. Pathol. Lab. Med. 127 (2003) E89-E92.

177. Torres, V.E., Bengal, R.J., Litwiller, R.D. \& Wilson, D.M. Aggravation of polycystic kidney disease in Han:SPRD rats by buthionine sulfoximine. J. Am. Soc. Nephrol. 8 (1997) 1283-1291.

178. Chiang, C.C., Lin, C.L., Peng, C.L., Sung, F.C. \& Tsai, Y.Y. Increased risk of cancer in patients with early-onset cataracts: a nationwide population-based study. Cancer Sci. 105 (2014) 431-436.

179. Palsamy, P., Bidasee, K.R., Ayaki, M., Augusteyn, R.C., Chan, J.Y. \& Shinohara, T. Methylglyoxal induces endoplasmic reticulum stress and DNA demethylation in the Keap1 promoter of human lens epithelial cells and agerelated cataracts. Free Radical Biol. Med. 72 (2014) 134-148.

180. Shamsi, F.A., Lin, K., Sady, C. \& Nagaraj, R.H. Methylglyoxal-derived modifications in lens aging and cataract formation. Invest. Ophthalmol. Vis. Sci. 39 (1998) 2355-2364.

181. Okonkwo, F.O., Ejike, C.E.C.C., Anoka, A.N. \& Onwurah, I.N.E. Toxicological studies on the short term exposure of Clarias albopunctatus (Lamonte and Nichole 1927) to sublethal concentrations of Roundup. Pakistan J. Biol. Sci. 16(2013) 939-944.

182. Floreani, A., Baragiotta, A., Martines, D., Naccarato, R. \& D'odorico, A. Plasma antioxidant levels in chronic cholestatic liver diseases. Aliment. Pharmacol. Ther. 14 (2000) 353-358.

183. Ribaya-Mercado, J.D. \& Blumberg J.B. Lutein and zeaxanthin and their potential roles in disease prevention. $J$. Am. Coll. Nutr. 23 (6, Suppl) (2004) 567S-587S.

184. Gao, S., Qin, T., Liu, Z., Caceres, M.A., Ronchi, C.F., Chen, C.Y., Yeum, K.J., Taylor, A., Blumberg, J.B., Liu, Y. \& Shang, F. Lutein and zeaxanthin supplementation reduces $\mathrm{H} 2 \mathrm{O} 2-$ induced oxidative damage in human lens epithelial cells. Mol. Vision 17 (2011) 3180-3190.

185. Ohrloff, C., Stoffel, C., Koch, H.R., Wefers, U., Bours, J. \& Hockwin, O. Experimental cataracts in rats due to tryptophan-free diet. Arch. Klin. Exp. Ophthalmol. 205 (1978) 73-79. 
186. Zarnowski, T., Rejdak, R., Zielinska-Rzecka, E., Zrenner, E., Grieb, P., Zagórski, Z., Junemann, A. \& Turski, W.A. Elevated concentrations of kynurenic acid, a tryptophan derivative, in dense nuclear cataracts. Curr. Eye Res. 32 (2007) 27-32.

187. De Roos, A.J., Blair, A., Rusiecki, J.A., Hoppin, J.A., Svec, M., Dosemeci, M., Sandler, D.P. \& Alavanja, M.C. Cancer incidence among glyphosate-exposed pesticide applicators in the agricultural health study. Environ. Health Perspectives 113 (2005) 49-54.

188. George, J. \& Shukla, Y. Emptying of intracellular calcium pool and oxidative stress imbalance are associated with the glyphosate-induced proliferation in human skin keratinocytes HaCaT cells. ISRN Dermatol. 2013 (2013) Article ID:825180.

189. Brenner, M. \& Hearing, V.J. The protective role of melanin against UV damage in human skin. Photochem. Photobiol. 84 (2008) 539-549.

190. Raposo, G. \& Marks, M.S. Melanosomes - dark organelles enlighten endosomal membrane transport. Nature Rev. Mol. Cell. Biol. 8(2007) 786-797.

191. Slominski, A., Moellmann, G., Kuklinska, E., Bomirski, A. \& Pawelek, J. Positive regulation of melanin pigmentation by two key substrates of the melanogenic pathway, Ltyrosine and L-dopa. J. Cell Sci. 89 (1988) 287-296.

192. Becerra, T.A., von Ehrenstein, O.S., Heck, J.E., Olsen, J., Arah, O.A., Jeste, S.S., Rodriguez, M. \& Ritz, B. Autism spectrum disorders and race, ethnicity, and nativity: a population-based study. Pediatrics 134 (2014) e63-e71.

193. Magnusson, C., Rai, D., Goodman, A., Lundberg, M., Idring, S., Svensson, A., Koupil, I., Serlachius, E. \& Dalman, C. Migration and autism spectrum disorder: population-based study. Br. J. Psychiatry 201 (2012) 109-115.

194. Keen, D.V., Reid, F.D. \& Arnone, D. Autism, ethnicity and maternal immigration. Br. J. Psychiatry 196(4) (2010) 274-281.

195. Hamilton, P.J., Campbell, N.G., Sharma. S., Erreger. K., Herborg Hansen, F., Saunders, C., Belovich, A.N., NIH ARRA Autism Sequencing Consortium, Sahai, M.A., Cook, E.H., Gether, U., McHaourab, H.S., Matthies, H.J., Sutcliffe, J.S. \& Galli, A. De novo mutation in the dopamine transporter gene associates dopamine dysfunction with autism spectrum disorder. Mol. Psychiatry 18 (2013) 1315-1323.

196. Emanuele, E. Does reverse transport of dopamine play a role in autism? EBioMedicine 2 (2015) 98-99.

197. Nakamura, K., Anitha, A., Yamada, K., Tsujii, M., Iwayama, Y., Hattori, E., Toyota, T., Suda, S., Takei, N., Iwata, Y., Suzuki, K., Matsuzaki, H., Kawai, M., Sekine, Y., Tsuchiya, K.J., Sugihara, G., Ouchi, Y., Sugiyama, T., Yoshikawa, T. \& Mori, N. Genetic and expression analyses reveal elevated expression of syntaxin 1A (STX1A) in high functioning autism. Int. J. Neuropsychopharmacol. 11 (2008) 1073-1084.

198. Qian, Y., Chen, M., Forssberg, H., Diaz \& Heijtz R. Genetic variation in dopaminerelated gene expression inuences motor skill learning in mice. Genes Brain Behav. 12 (2013) 604-614.

199. Munn, D.H., Shafizadeh, E., Attwood, J.T., Bondarev, I., Pashine, A., Mellor, A.L. Inhibition of T cell proliferation by macrophage tryptophan catabolism. J. Exp. Med. 189 (1999) 1363-1372.
200. Hwu, P., Du, M.X., Lapointe, R., Do, M., Taylor, M.W. \& Young, H.A. Indoleamine 2,3-dioxygenase production by human dendritic cells results in the inhibition of $\mathrm{T}$ cell proliferation. J. Immunol. 164 (2000) 3596-3599.

201. Astigiano, S., Morandi, B., Costa, R., Mastracci, L., DAgostino, A., Ratto, G.B., Melioli, G. \& Frumento, G. Eosinophil granulocytes account for indoleamine 2,3dioxygenasemediated immune escape in human non-small cell lung cancer. Neoplasia 7 (2005) 390-396.

202. Amberger, A. Prognostic value of indoleamine 2,3dioxygenase expression in colorectal cancer: effect on tumor-infiltrating T cells. Clin. Cancer Res. 12 (2006) 1144-1151.

203. Ishio, T., Goto, S., Tahara, K., Tone, S., Kawano, K. \& Kitano, S. Immunoactivative role of indoleamine 2,3dioxygenase in human hepatocellular carcinoma. $J$. Gastroenterol. Hepatol. 19 (2004) 319-326.

204. Basu, G.D., Tinder, T.L., Bradley, J.M., Tu, T., Hattrup, C.L., Pockaj, B.A. \& Mukherjee, P. Cyclooxygenase-2 inhibitor enhances the efficacy of a breast cancer vaccine: role of IDO. J. Immunol. 177 (2006) 2391-2402.

205. Chen, P.W., Mellon, J.K., Mayhew, E., Wang, S., He, Y.G., Hogan, N. \& Niederkorn, J.Y. Uveal melanoma expression of indoleamine 2,3-deoxygenase: Establishment of an immune privileged environment by tryptophan depletion. Exp. Eye Res. 85 (2007) 617-625.

206. Weinlich, G., Murr, C., Richardsen, L., Winkler, C. \& Fuchs, D. Decreased serum tryptophan concentration predicts poor prognosis in malignant melanoma patients. Der matology 214 (2007) 8-14.

207. Serbecic, N. \& Beutelspacher, S.C. Indoleamine 2,3dioxygenase protects corneal endothelial cells from UV mediated damage. Exp. Eye Res. 82 (2006) 416-426.

208. Takikawa, O., Littlejohn, T., Jamie, J.F., Walker, M.J. \& Truscott, R.J. Regulation of indoleamine 2,3-dioxygenase, the first enzyme in UV filter biosynthesis in the human lens. Relevance for senile nuclear cataract. Adv. Exp. Med. Biol. 467 (1999) 241-245.

209. Bald, T., Quast, T., Landsberg, J., Rogava, M., Glodde, N., Lopez-Ramos, D., Kohlmeyer, J., Riesenberg, S., van den Boorn-Konijnenberg, D., Hömig-Hölzel, C., Reuten. R., Schadow. B., Weighardt, H., Wenzel, D., Helfrich, I., Schadendorf, D., Bloch, W., Bianchi, M.E., Lugassy, C., Barnhill, R.L., Koch, M., Fleischmann, B.K., Förster, I., Kastenmüller, W., Kolanus, W., Hölzel, M., Gaffal, E. \& Tüting, T. Ultravioletradiation-induced inflammation promotes angiotropism and metastasis in melano Nature 507 (2014) 109-113.

210. Duntas, L.H. The role of selenium in thyroid autoimmunity and cancer. Thyroid 16 (2006) 455-60.

211. Whitehead, K., Versalovic, J., Roos, S. \& Britton, R.A. Genomic and genetic characterization of the bile stress response of probiotic Lactobacillus reuteri ATCC 55730. Appl. Environ. Microbiol. 74 (2008) 1812-1819.

212. Lin, Y.P., Thibodeaux, C.H., Pena, J.A., Ferry, G.D. \& Versalovic, J. Probiotic Lactobacillus reuteri suppress proinammatory cytokines via c-Jun. Inamm. Bowel Dis. 14 (2008) 1068-1083.

213. Galano, E., Mangiapane, E., Bianga, J., Palmese, A., Pessione, E., Szpunar, J., Lobinski, R. \& Amoresano, A. Privileged incorporation of selenium as selenocysteine in Lactobacillus reuteri proteins demonstrated by selenium- 
specific imaging and proteomics. Mol. Cell Proteomics 12 (2013) 2196-2204.

214. Archibald, F.S. \& Duong, M.N. Manganese acquisition by Lactobacillus plantarum. J. Bacteriol. 158 (1984) 1-8.

215. Archibald, F.S. \& Fridovich, I. Manganese, superoxide dismutase, and oxygen tolerance in some lactic acid bacteria. J. Bacteriol. 146 (1981) 928-936.

216. Chlebowski, R.T., Hendrix, S.L., Langer, R.D., Stefanick, M.L., Gass, M., Lane, D., Rodabough, R.J., Gilligan, M.A., Cyr, M.G., Thomson, C.A., Khandekar, J., Petrovitch, H., McTiernan, A. \& WHI Investigators. Inuence of estrogen plus progestin on breast cancer and mammography in healthy postmenopausal women: the Women's Health Initiative Randomized Trial. JAMA 289 (2003) 3243-3253.

217. Hou, N., Hong, S., Wang, W., Olopade, O.I, Dignam, J.J. \& Huo, D. Hormone replacement therapy and breast cancer: Heterogeneous risks by race, weight, and breast density. J. Natl Cancer Inst. 105 (2013) 1365-1372.

218. Kochukov, Y., Jeng, J. \& Watson, S. Alkylphenol xenoestrogens with varying carbon chain lengths differentially and potently activate signaling and functional responses in GH3/B6/F10 somatomammotropes. Environ. Health Perspectives 117 (2009) 723-730.

219. Laden, F., Ishibe, N., Hankinson, S.E., Wolff, M.S., Gertig, D.M., Hunter, D.J. \& Kelsey, K.T. Polychlorinated biphenyls, cytochrome P450 1A1, and breast cancer risk in the Nurses Health Study. Cancer Epidemiol. Biomarkers Prevention 11 (2002) 1560-1565.

220. Meldahl, A.C., Nithipatikom, K. \& Lech, J.J. Metabolism of several 14C-nonylphenol isomers by rainbow trout (Oncorhynchus mykiss): In vivo and in vitro microsomal metabolites. Xenobiotica 26 (1996) 1167-1180.

221. Niwa, T., Fujimoto, M., Kishimoto, K., Yabusaki, Y., Ishibashi, F. \& Katagiri, M. Metabolism and interaction of bisphenol A in human hepatic cytochrome P450 and steroidogenic CYP17. Biol. Pharm. Bull. 24(9) (2001) 1064-1067.

222. Liehr, J.G. \& Jones, J. Role of iron in estrogen-induced cancer. Current Med. Chem. 8 (2001) 839-849.

223. Kwiatkowska, M., Huras, B. \& Bukowska, B. The effect of metabolites and impurities of glyphosate on human erythrocytes (in vitro). Pestic. Biochem. Physiol. 109 (2014) 34-43.

224. Nagababu, E. \& Rifkind, J.M. Heme degradation by reactive oxygen species. Antioxidants Redox Signaling 6 (2004) 967-978.

225.Aberkane, H., Stoltz, J.-F.; Galteau, M.-M. \& Wellman, M. Erythrocytes as targets for gamma-glutamyltranspeptidase initiated pro-oxidant reaction. Eur. J. Haematol. 68 (2002) 262-271.

226. Adamson, P., Bray, F., Costantini, A.S., Tao, M.H., Weiderpass, E. \& Roman, E. Time trends in the registration of Hodgkin and non-Hodgkin lymphomas in Europe. Eur. J. Cancer 43 (2007) 391-401.

227. Eltom, M.A., Jemal, A., Mbulaiteye, S.M., Devesa, S.S. \& Biggar, R.J. Trends in Kaposis sarcoma and non-Hodgkins lymphoma incidence in the United States from 1973 through 1998. J. Natl. Cancer Inst. 94 (2002) 1204-1210.

228. Schinasi, L. \& Leon, M.E. Non-Hodgkin lymphoma and occupational exposure to agricultural pesticide chemical groups and active ingredients: a systematic review and meta-analysis. Int. J. Environ. Res. Public Health 11 (2014) 4449-4527.

229. Hardell, L., Eriksson, M. \& Nordstrom, M. Exposure to pesticides as risk factor for non-Hodgkins Lymphoma and hairy cell leukemia: pooled analysis of two Swedish casecontrol studies. Leuk. Lymphoma 43 (2002) 1043-1049.

230. Eriksson, M., Hardell, L., Carlberg, M. \& Akerman, M. Pesticide exposure as risk factor for non-Hodgkin lymphoma including histopathological subgroup analysis. Int. J. Cancer 123 (2008) 1657-1663.

231. McDuffie, H.H., Pahwa, P., McLaughlin, J.R., Spinelli, J.J., Fincham, S., Dosman, J.A., Robson, D., Skinnider, L.F. \& Choi, N.W. Non-Hodgkins lymphoma and specific pesticide exposures in men: Cross-Canada study of pesticides and health. Cancer Epidemiol. Biomarkers Prevention 10 (2001) 1155-1163.

232. Pervaiz, S. \& Clement, M.V. Superoxide anion: Oncogenic reactive oxygen species? Int. J. Biochem. Cell Biol. 39 (2007) 1297-1304.

233. Candas, D. \& Li, J.J. MnSOD in oxidative stress responsepotential regulation via mitochondrial protein inux. Antioxid. Redox. Signal. 20 (2014) 1599-1617.

234. Van Remmen, H., Ikeno, Y., Hamilton, M., Pahlavani, M., Wolf, N., Thorpe, S.R., Alderson, N.L., Baynes, J.W., Epstein, C.J., Huang, T.-T., Nelson, J., Strong, R. \& Richardson, A. Life-long reduction in MnSOD activity results in increased DNA damage and higher incidence of cancer but does not accelerate aging. Physiol. Genomics 16(2003) 29-37.

235. Jaramillo, M.C., Briehl, M.M., Crapo, J.D., Batinic-Haberle, I. \& Tome, M.E. Manganese porphyrin, MnTE-2-PyP5+, acts as a pro-oxidant to potentiate glucocorticoidinduced apoptosis in lymphoma cells. Free Radical Biol. Med. 52 (2012) 1272-1284.

236. Wang, Y.H., Yang, X.L., Han, X., Zhang, L.F. \& Li, H.L. Mimic of manganese superoxide dismutase to induce apoptosis of human non-Hodgkin lymphoma Raji cells through mitochondrial pathways. Int. Immunopharmacol. $14(2012) 620-628$.

237. Jaramillo, M.C., Frye, J.B., Crapo, J.D., Briehl, M.M. \& Tome, M.E. Increased manganese superoxide dismutase expression or treatment with manganese porphyrin potentiates dexamethasone-induced apoptosis in lymphoma cells. Cancer Res. 69 (2009) 5450-5457.

238. Crapo, J., Day, B. \& Fridovich, I. Development of manganic porphyrin mimetics of superoxide dismutase activity. Madame Curie Bioscience Database. Landes Bioscience. Retrieved 10 June 2015.

239. Cuzzocrea, S., Zingarelli, B., Costantino, G. \& Caputi, A. Beneficial effects of Mn(III)tetrakis (4-benzoic acid) porphyrin (MnTBAP), a superoxide dismutase mimetic, in carrageenan-induced pleurisy. Free Radical Biol. Med. 26(1999) 25-33.

240. Conlan, M.G., Bast, M., Armitage, J.O. \& Weisenburger, D.D. Bone marrow involvement by non-Hodgkin's lymphoma: the clinical significance of morphologic discordance between the lymph node and bone marrow. Nebraska Lymphoma Study Group. J. Clin. Oncol. 8(1990) 1163-1172.

241. Ridley, W.P. A study of the plasma and bone marrow levels of glyphosate following intraperitoneal administration in the rat. Unpublished report, study No. 830109, project No. ML-83-218, dated 24 October 1988, from Monsanto 
Environmental Health Laboratory, St. Louis, Missouri, USA. Submitted to WHO by Monsanto Int. Services SA, Brussels, Belgium (1983).

242. Prasad, S., Srivastava, S., Singh, M. \& Shukla, Y. Clastogenic effects of glyphosate in bone marrow cells of Swiss albino mice. J. Toxicol. 2009 (2009) article ID:308985.

243.Raab, M.S., Podar, K., Breitkreutz, I., Richardson, P.G. \& Anderson, K.C. Multiple myeloma. Lancet 374 (2009) 324-339.
244. Kapur, G., Patwari, A.K., Narayan, S. \& Anand, V.K. Serum prolactin in celiac disease. J. Trop. Pediatr. 50 (2004) 37-40.

245. Goloubkova, T., Ribeiro, M.F., Rodrigues, L.P., Cecconello, A.L. \& Spritzer, P.M. Effects of xenoestrogen bisphenol A on uterine and pituitary weight, serum prolactin levels and immunoreactive prolactin cells in ovariectomized Wistar rats. Arch. Toxicol. 74 (2000) 92-98.

246. Gudelsky, G.A., Nansel, D.D. \& Porter, J.C. Role of estrogen in the dopaminergic control of prolactin secretion. Endocrinology 108 (1981) 440-444. 